Aus der Poliklinik für Zahnärztliche Prothetik

(Prof. Dr. R. Bürgers)

im Zentrum Zahn-, Mund- und Kieferheilkunde

der Medizinischen Fakultät der Universität Göttingen

\title{
Ein Vergleich der Genexpression von humanem oralem periimplantärem Gewebe zwischen Krank und Gesund auf mRNA-Ebene in vivo
}

\author{
INAUGURAL-DISSERTATION \\ zur Erlangung des Doktorgrades \\ für Zahnmedizin \\ der Medizinschen Fakultät der \\ Georg-August-Universität zu Göttingen
}

vorgelegt von

Simon Schmitt

aus

Erfurt

Göttingen 2016 
Dekan:

I. Berichterstatter:

II. Berichterstatter/in:

III. Berichterstatter/in:

Tag der mündlichen Prüfung:
Prof. Dr. rer. nat. H. K. Kroemer

Prof. Dr. med. N. Miosge

PD Dr. med. dent. S. Sennhenn-Kirchner

12.01.2017 
Inhaltsverzeichnis

Abkürzungsverzeichnis

1 Einleitung 1

1.1 Die Implantologie . . . . . . . . . . . . . . . . . . . . . . 1

1.1.1 Implantologie gestern und heute . . . . . . . . . . . . 1

1.1.2 Das dentale Implantat . . . . . . . . . . . . . . . 2

1.1.3 Der strukturelle Aufbau des periimplantären Gewebes . . . . . 3

1.1.4 Risiken für die Implantatintegrität . . . . . . . . . . . . . 5

1.1 .5 Die Entzündung . . . . . . . . . . . . 6

1.1 .6 Die Immunantwort . . . . . . . . . . . . . . . 7

1.1.7 Ablauf der Immunabwehr bei der Parodontitis . . . . . . . . . . 9

1.2 Die Periimplantitis . . . . . . . . . . . . . . . . . 10

1.2.1 Definition . . . . . . . . . . . . . . 10

1.2.2 Die Ätiologie, Inzidenz und Biologie der Periimplantitis . . . . 10

1.2.3 Die Therapie der Periimplantitis . . . . . . . . . . . . . . . 12

1.2.4 Periimplantitis - Stand der Forschung . . . . . . . . . . . . . 13

1.2.5 Vorstellung der untersuchten Gene/ Gengruppen . . . . . . . . 14

1.2.6 Aufbau und Ziel der Arbeit . . . . . . . . . . . . . . . . . . 16

2 Material und Methoden $\quad 18$

2.1 Versuchsaufbau . . . . . . . . . . . . . . . . . . . 18 
2.2 Isolation der RNA aus periimplantärem Gewebe . . . . . . . . . . . . . 19

2.3 Bestimmung der Qualität und Konzentration der Gesamt-RNA . . . . . 20

2.4 Microarray . . . . . . . . . . . . . . . . . 21

2.4.1 Allgemeines zur Methode . . . . . . . . . . . . 21

2.4.2 Durchführung und Auswertung . . . . . . . . . . . 21

2.5 Reverse-Transkriptase quantitative Real-Time PCR (RT-qPCR) . . . . . 25

2.5.1 Allgemeines zur Methode . . . . . . . . . . . 25

2.5.2 RT-qPCR Protokoll . . . . . . . . . . . . . . . . . . 27

2.5.3 Statistische Auswertung . . . . . . . . . . . . . . 28

2.5.4 Primerdesign . . . . . . . . . . . . . . . . . . . 29

2.5.5 Primersynthese und -überprüfung . . . . . . . . . . . 32

2.5.6 Gradienten-PCR . . . . . . . . . . . . . . 32

3 Ergebnisse $\quad 34$

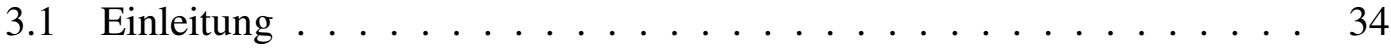

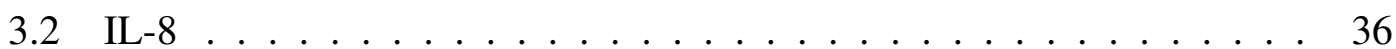

3.3 Weitere Interleukine . . . . . . . . . . . . . . . . . 37

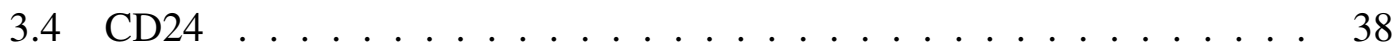

3.5 Weitere CD-Moleküle . . . . . . . . . . . . . . . . . 39

$3.6 \mathrm{MMP1} \ldots \ldots \ldots \ldots \ldots$. . . . . . . . . . . . . . 40

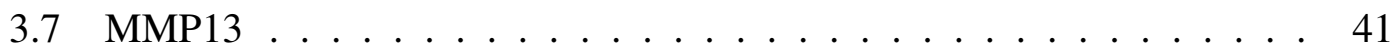

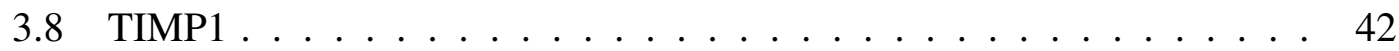

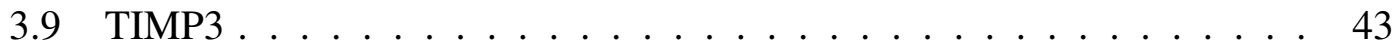

3.10 COL9A $1 \ldots \ldots \ldots \ldots 4 \ldots \ldots \ldots$

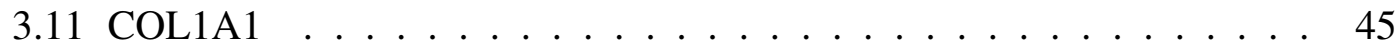

3.12 Weitere Kollagene . . . . . . . . . . . . . . . . 46

3.13 BGLAP . . . . . . . . . . . . . . . . . . . 47

3.14 OPG $($ TNFRSF11B $) \ldots \ldots \ldots \ldots . \ldots \ldots$

3.15 RUNX2 . . . . . . . . . . . . . . . . . . . . . . 49

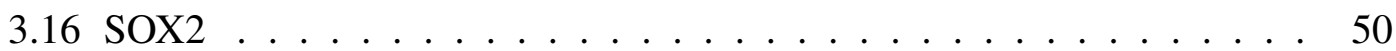

3.17 Weitere Transkriptionsfaktoren . . . . . . . . . . . . . 51

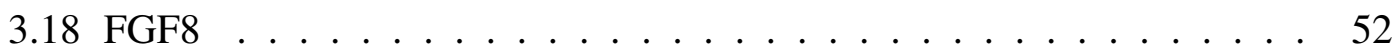

3.19 FGF18 . . . . . . . . . . . . . . . . 53

4 Diskussion $\quad 54$

4.1 Einleitung . . . . . . . . . . . . . . . . . . 54 
4.2 Diskussion der Methoden . . . . . . . . . . . . . . . . . . 55

4.2.1 Diskussion der Probengewinnung und des Studienaufbaus . . . 55

4.2.2 Diskussion der Microarray-Technik . . . . . . . . . . . 56

4.2.3 Diskussion der PCR-Technik . . . . . . . . . . . . . . . . 57

4.3 Diskussion der Ergebnisse $\ldots \ldots \ldots$. . . . . . . . . . . . 58

4.3.1 Diskussion der Expression der Interleukine . . . . . . . . . 58

4.3.2 Diskussion der Expression von CD24 . . . . . . . . . . 60

4.3.3 Diskussion der Expression der Matrix-Metalloproteinasen (MMPs) und der Inhibitoren der Matrix-Metalloproteinasen (TIMPs) . . 61

4.3.4 Diskussion der Expression der Kollagene . . . . . . . . . . . 63

4.3.5 Diskussion der Expression von Osteocalcin (BGLAP) und Osteoprotegerin $($ TNFRSF11B) . . . . . . . . . . . 65

4.3.6 Diskussion der Expression von RUNX2, SOX2 und weiterer Transkriptionsfaktoren . . . . . . . . . . . . 66

4.3.7 Diskussion der Expression von FGF8 und FGF18 . . . . . . . . 67

$\begin{array}{llr}5 & \text { Zusammenfassung } & 69\end{array}$

6 Anhang $\quad \mathbf{7 1}$

Abbildungsverzeichnis . . . . . . . . . . . . . . . 72

Tabellenverzeichnis . . . . . . . . . . . . . . . . 74

$\begin{array}{lll}7 & \text { Literaturverzeichnis } & 75\end{array}$ 


\section{Abkürzungsverzeichnis}

$\begin{array}{ll}\boldsymbol{A} \boldsymbol{b} \boldsymbol{b} . & \text { Abbildung } \\ \boldsymbol{A} \boldsymbol{G} & \text { Arbeitsgruppe } \\ \boldsymbol{B} \boldsymbol{G L A P} & \text { Bone Gamma-Carboxyglutamate (gla) Protein } \\ \boldsymbol{B M P} & \text { Bone Morphogenetic Protein } \\ \boldsymbol{B O P} & \text { bleeding on probing } \\ \boldsymbol{b z w} . & \text { beziehungsweise } \\ \boldsymbol{c a} . & \text { circa } \\ \boldsymbol{C D} & \text { Cluster of Differentiation } \\ \boldsymbol{c D N A} & \text { komplementäre Desoxyribonukleinsäure } \\ \boldsymbol{C O L} & \text { Kollagen } \\ \boldsymbol{C y} 3 / 5-d \boldsymbol{C} \boldsymbol{T P} & \text { Cyanin 3/5 Deoxyuridin Triphosphate } \\ \boldsymbol{D E P C} & \text { Diethyldicarbonat } \\ \boldsymbol{d A T P} & \text { Desoxyadenosintriphosphat }\end{array}$




\begin{tabular}{|c|c|}
\hline$d C T P$ & Desoxycytidintriphosphat \\
\hline$d G T P$ & Desoxyguanosintriphosphat \\
\hline$d U T P$ & Desoxyuridintriphosphat \\
\hline DNA & Desoxyribonukleinsäure \\
\hline$d N T P$ & Desoxyribonukleosidtriphosphate \\
\hline$d t$. & deutsch \\
\hline E-Cup & Eppendorf-Cup \\
\hline eng. & englisch \\
\hline$E Z M$ & Extrazelluläre Matrix \\
\hline$F G F$ & Fibroblasten-Wachstumsfaktor, engl. Fibroblast Growth Factor \\
\hline$g$ & Gramm \\
\hline$I L$ & Interleukin \\
\hline$l$ & Liter \\
\hline $\log F C$ & logarithmic Fold Change (relative logaritmische Ratio) \\
\hline$M$ & Molarität \\
\hline MHC & Major Histocompatibility Complex \\
\hline$M M P$ & Matrix-Metalloproteinasen \\
\hline mol & SI-Basiseinheit der Stoffmenge \\
\hline$m R N A$ & messenger-Ribonukleinsäure \\
\hline$O P G$ & Osteoprotegerin \\
\hline Pat. & Patient \\
\hline PCR & Polymerase-Kettenreaktion \\
\hline$q P C R$ & Real-Time PCR \\
\hline
\end{tabular}


RNA

RT-qPCR

RUNX2

$\operatorname{sog}$.

SOX

Taq

TGF-beta

TIMP

TNF-alpha

USA

z. B.

zum Beispiel

sogenannt
Ribonukleinsäure

Reverse-Transkriptase quantitative Real-Time PCR

Runt-related Transcription Factor 2

SRY (Sex Determining Region Y)-box

Thermus aquaticus

Transforming Growth Factor beta

Tissue Inhibitor of Metalloproteinase

Tumornekrosefaktor-Alpha

United States of America 
KAPITEL 1

\section{Einleitung}

\subsection{Die Implantologie}

\subsubsection{Implantologie gestern und heute}

Vor über 40 Jahren wurde das erste Titanimplantat bei einem Menschen eingesetzt, nachdem der Schwede Per-Ingvar Brånemark feststellte, dass sich Titan in den Knochen integriert. Er nannte diesen Vorgang „Osseointegration“ (Brånemark 1983). Erste Erwähnungen von Implantaten als Ersatz von Zähnen gehen auf das Jahr 880 n. Chr. zurück. Ernsthafte Implantationsversuche wurden ab dem 19. Jahrhundert dokumentiert. Zwischen 1800 und 1900 wurden verschiedenste Materialien wie Elfenbein, Knochen, Gold, Platin, Porzellan und auch Holz zur Herstellung von Implantaten vorgeschlagen, jedoch mit mäßigem Erfolg (Rudy et al. 2008; Ring 1995a; Ring 1995b).

Die Entwicklung der dentalen Implantation hat in den letzten dreißig Jahren sehr große Fortschritte gemacht. Heute existiert ein großer und fast unüberschaubarer Markt an Anbietern für Implantate und die dazugehörigen Systeme. Das verbreitetste Material ist Titan. Jedoch kommen immer mehr Implantatsysteme auf den Markt, die zu einem Teil oder komplett aus keramischen Werkstoffen bestehen (Sykaras et al. 2000). In immer 
mehr Zahnarztpraxen wird heutzutage dentale Implantologie praktiziert. Pro Jahr werden in Deutschland über 500.000 Implantate gesetzt, Tendenz steigend. Allein durch den Anstieg der Anzahl an gesetzten Implantaten steigt auch die totale Zahl an Fällen von Implantatverlust. Der häufigste Grund für den Verlust von Implantaten ist die Periimplantitis. Aus einer Studie von 2010 geht hervor, dass 80\% der untersuchten Patienten mit Implantaten Fälle von periimplantärer Mukositis aufwiesen. Bei 28 bis 56\% davon konnte eine Periimplantits festgestellt werden (Winkelhoff 2010). Eine Metaanalyse von Mombelli et al. von 29 relevanten Studien lässt darauf schließen, dass über einen Zeitraum von 10 Jahren von 20 gesetzten Implantaten 1 Implantat verloren geht (Mombelli et al. 2012).

Aufgrund dieser Tatsachen ergibt sich die Dringlichkeit, speziell zum Thema der Periimplantitis zu forschen, um eine bessere Überlebenszeit von Implantaten zu erreichen.

\subsubsection{Das dentale Implantat}

Als Implantat versteht man in der Zahnheilkunde eine im Ober- oder Unterkiefer verankerte Zahnwurzel aus alloplastischem Material. Ein Implantat wird operativ in einen zahnlosen Kieferabschnitt eingebracht. In der modernen Zahnmedizin werden sie zunehmend als "State of the Art" bei der Behandlung von Zahnverlust angewandt. Das Implantat besteht im Wesentlichen aus drei Teilen:

Der Implantatkörper: Er stellt eine künstliche Zahnwurzel dar und wird direkt in den Knochen eingebracht. Die heutzutage gängigste Form ist zylinderförmig und in verschiedenen Längen mit unterschiedlichen Gewindeformen und Gewindesteigungen erhältlich. Durch ihn gewinnt der Zahnersatz seine nötige Stabilität.

Der Implantatpfosten: Er stellt das verbindende Element zwischen dem Implantatkörper und dem Zahnersatz, der sogenannten Suprakonstruktion, dar. Im Englischen wird er Abutment genannt. Das am häufigsten verwendete Material für diesen Teil ist Titan. Mittlerweile sind Abutments auch in keramischen Materialien erhältlich.

Die Suprakonstruktion: Die Suprakonstruktion ist der Teil, welcher nach erfolgreicher Behandlung im Mund des Patienten zu sehen ist und ständig dem oralen Milieu ausge- 
setzt ist. Die Suprakonstruktion kann sowohl festsitzend sein, z.B. für Einzelkronen oder Brücken, als auch herausnehmbar gefertigt werden, z.B. als Halteelemente von Totalprothesen. Der bisherige Standard in der Ausführung der Suprakonstruktion ist keramisch verblendetes Metall. Mittlerweile sind aber auch Anfertigungen aus vollkeramischem Material möglich. Die Fixierung auf dem Abutment kann entweder durch Zementieren oder durch eine Fixierschraube erfolgen.
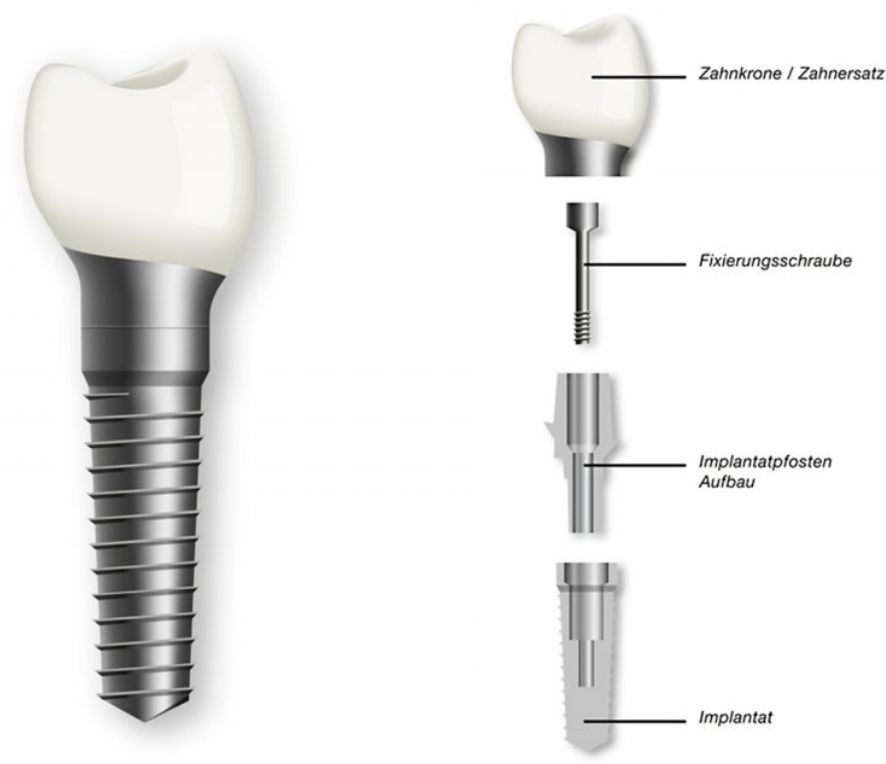

Abbildung 1.1: Aufbau eines dentalen Implantats in Einzelteilen (http://www.ztwietzel.de/leistungen/implantate, Zugriff am 15.12.2014).

\subsubsection{Der strukturelle Aufbau des periimplantären Gewebes}

Die periimplantäre Mukosa weist viele Gemeinsamkeiten mit der den natürlichen Zahn umgebenden Gingiva auf. Es konnte gezeigt werden, dass zur Mundhöhle hin ein mehrschichtiges verhorntes orales Plattenepithel vorhanden ist (Berglundh et al. 1991). Zur Implantatoberfläche hin konnte ein verbindendes Epithel nachgewiesen werden, welches auf der Implantatoberfläche haftet. Es ist dem Saumepithel des natürlichen Zahnes damit sehr ähnlich (Berglundh und Lindhe 1996; Schupbach und Glauser 2007).

Im Unterschied zur Gingiva der Zähne besteht bei der periimplantären Mukosa der bindegewebige Abschnitt zwischen dem verbindenden Epithel und dem krestalen Knochen aus narbenähnlichem Gewebe, das kaum Blutgefäße, viel Kollagen und wenige Fibroblasten enthält (Berglundh et al. 1994). 
Die an das Implantat angrenzende Basalmembran des verbindenden Epithels ist fibroblastenreich und hat einen großen Zellumsatz, was vermuten lässt, dass Fibroblasten eine wichtige Rolle beim Aufbau und Erhalt der mukosalen Barriere spielen (Schupbach und Glauser 2007).

Zum Verständnis, wie das Implantat im Knochen verankert ist, gibt es unterschiedliche Meinungen bzw. Theorien. Es gibt die verschieden bis sehr ähnlich definierten Termini der Fibro-Osseointegration (Weiss 1986), Osseointegration (Brånemark 1983) und mittlerweile auch die Biointegration (Kent et al. 1990) und Osseoinkorporation. Weiss geht bei der Fibro-Osseointegration davon aus, dass wenn man das Implantat nach dem Setzen für eine Zeit von zwei Monaten außer Funktion belässt, sich ein Pseudo-periimplantäres Ligament zwischen Knochen und Implantat bildet. Von diesem Ligament sollen positive Impulse auf die Knochenneubildung und Formation ausgehen. Brånemark schlägt vor, das gesetzte Implantat bis zu 12 Monate ohne Belastung einheilen zu lassen. Seine Theorie der Osseointegration sieht vor, dass ein Knochen-zu-Implantat-Kontakt vorliegt, ohne das Vorhandensein einer bindegewebigen Verankerung. 

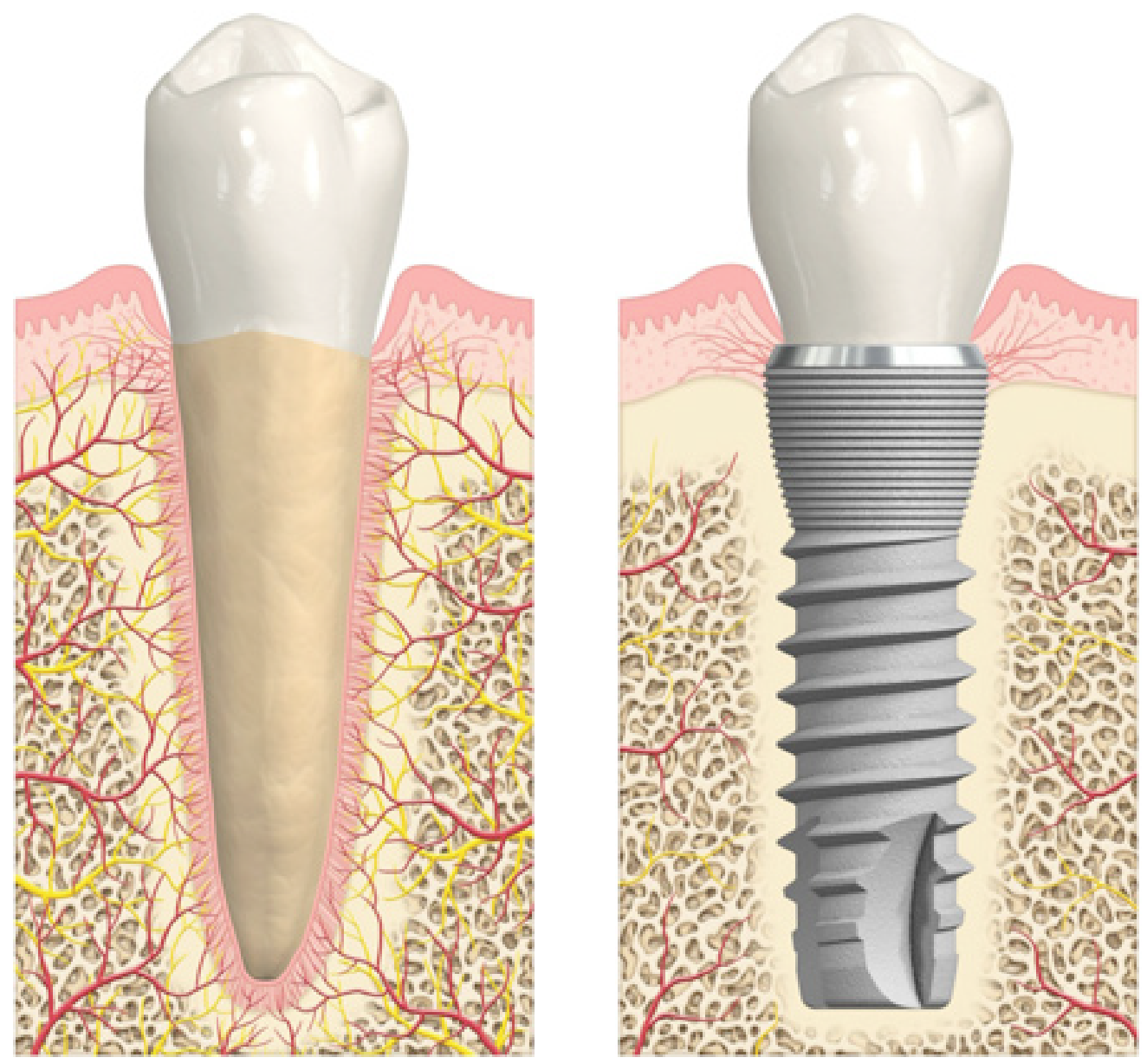

Abbildung 1.2: Darstellung der unterschiedlichen Verankerung von Zahn (links) und Implantat (rechts) im Kieferknochen (Albrektsson et al. 2014, S.6).

Der Abdruck/ die Verwendung erfolgt mit freundlicher Genehmigung von Prof. Tomas Albreksson und des John Wiley and Sons-Verlags.

\subsubsection{Risiken für die Implantatintegrität}

In der Mundhöhle wurden bisher über 600 Bakterienspezies gefunden und regelmäßig werden weitere entdeckt. Die absolute Anzahl von Bakterien in der Mundhöhle kann bis zu sechs Milliarden betragen. Das entspricht dem Vielfachen der Anzahl von Menschen auf der Erde (Cromie 2002). Längst nicht alle Bakterien im Mund sind gefährlich für den menschlichen Organismus. Bei körperlicher Gesundheit, guter Mundhygiene und mäßigem Verzehr niedermolekularer Kohlenhydrate ist unser Immunsystem problemlos in der Lage, auch mit potenziell pathogenen Erregern zurechtzukommen (He et al. 2015). Verlagert sich jedoch das Gleichgewicht zwischen Abwehr und Angreifer zugunsten 
der Angreifer, so kann es zu Gewebezerstörung durch Bakterientoxine und/ oder als Folge einer Immunreaktionen kommen. Eine Verlagerung dieses Gleichgewichtes kann unterschiedliche Gründe haben. Eine übermäßige Ansammlung von Bakterien in einer organisierten Matrix (Plaque) oder eine Schwächung der Wirtsabwehr aus verschiedenen Gründen kommen dafür in Frage. Außerdem können eine Fehlbelastung bzw. Überbelastung in Zusammenhang mit einer Entzündung zu einer stärkeren Schädigung des Implantatbetts führen (Klinge und Meyle 2012). Auch gibt es Autoren, die einen völlig anderen Ansatz verfolgen. Sie sehen die Periimplantitis als eine Abstoßungsreaktion oder eine Art allergische Reaktion des Körpers gegenüber dem Titanimplantat bzw. den -partikeln als Fremdkörper (Quabius et al. 2012; du Preez et al. 2007).

\subsubsection{Die Entzündung}

Wie der Name vermuten lässt, ist die Periimplantitis eine Krankheit entzündlicher Genese. Entzündungen kennzeichnen sich üblicherweise durch die typischen Symptome nach Galen: durch Rötung (rubor), Schwellung (tumor), Schmerz (dolor), Überwärmung (calor) und eingeschränkte Funktion (functio laesa). Obwohl die Periimplantitis definitiv eine entzündliche Erkrankung ist, lassen sich die genannten Symptome nur bedingt klinisch feststellen (Khammissa et al. 2012). Entzündungen können unterschiedlichen Ursprungs sein. Viele Entzündungen werden durch eine Infektion mit Mikroorganismen verursacht. Es gibt aber auch sterile Entzündungen (Shen et al. 2013). Diese können z.B. durch die mechanische Überbelastung von Gewebe verursacht werden. Eine Entzündung stellt eine Beeinträchtigung des physiologischen Zustandes des Körpers dar. Der Körper reagiert auf diesen äußeren oder inneren Reiz mit einer lokalen oder systemischen Reaktion oder beidem. Die Stärke der Reaktion ist von Individuum zu Individuum und je nach Art und Ausmaß der Noxe unterschiedlich. Als Noxe werden alle den Körper schädigenden Einflüsse bezeichnet. Noxen können chemischen, physikalischen oder autoimmunen Ursprungs sein oder von lebenden sowie vermehrungsfähigen Erregern ausgehen (Ohshima et al. 2003; Rigante et al. 2014; Goldbach-Mansky 2012; Chiu et al. 2013).

Am Vorgang der Entzündung sind viele Entzündungsfaktoren beteiligt wie Histamin, Serotonin, Bradykinin, Prostaglandine, Komplementfaktoren und viele Zytokine (Cavaillon 1994).

Entzündliche Geschehen können nach ihrem Verlauf in akut und chronisch unterteilt werden, wobei es dabei noch weitere Unterteilungen gibt. Die chronische Entzündung kann primär oder sekundär verlaufen. Die primär chronische Entzündung entwickelt 
sich von Beginn an her schleichend und meist unbemerkt. Sie kann unentdeckt und unbehandelt lange anhalten. Die sekundär chronische Entzündung geht aus einer akuten Entzündung hervor, deren Ursache nicht beseitigt werden konnte oder deren Schädigung weiter besteht (Costa et al. 2007; Gardemann et al. 2013). Eine entzündliche Reaktion hat eine erhöhte Durchblutung und Permeabilität der Blutgefäße zur Folge. Dieser Mechanismus dient dazu, Stoffwechselprodukte und abgebaute Zellbestandteile abzutransportieren und Abwehrzellen den Weg zum Entzündungsort zu ermöglichen. Signalstoffen wird die Ausbreitung in umliegendes Gewebe erleichtert (Costa et al. 2007).

\subsubsection{Die Immunantwort}

Das menschliche Immunsystem lässt sich in ein spezifisches und ein unspezifisches unterteilen. Beide Systeme bestehen aus zellulären und aus humoralen (in den Körperflüssigkeiten gelösten) Faktoren. Auf eingedrungene Erreger reagiert zunächst das unspezifische Immunsystem. Es ist angeboren und kann sofort auf jegliche Noxen reagieren ohne zuvor mit ihnen in Kontakt gekommen zu sein. In seiner Reaktion unterscheidet es kaum zwischen den einzelnen Erregern. $\mathrm{Zu}$ den zellulären Bestandteilen gehören eosinophile, neutrophile und basophile Granulzyten, Makrophagen/Monozyten und Mastzellen. Nach dem Eindringen der Erreger erkennen diese Zellen, dass es sich um nicht-körpereigene Zellen bzw. Stoffe handelt. Sie sezernieren Signalstoffe, die andere Abwehrzellen zum Infektionsort locken (Medzhitov und Janeway 1997). Makrophagen, also große Fresszellen, phagozytieren körperfremde Zellen und verdauen diese in ihrem Inneren durch spezielle Enzyme. Nach der Lyse präsentieren diese Zellen wieder Teile der verdauten Erreger auf ihrer Oberfläche und ermöglichen der spezifischen Immunabwehr die Produktion spezifischer Antikörper (Hume 2006).

Granulozyten enthalten ihrem Namen nach Granula, welche mit lytischen Enzymen gefüllt sind. Bei Kontakt mit als körperfremd erkannten Zellen werden diese Bläschen nach außen entleert und es findet eine extrazelluläre Lyse der Bakterien statt. Diese Enzyme sind außerdem in der Lage, Kollagen abzubauen, um den Entzündungszellen die Bewegung im Gewebe zu erleichtern (Lazarus et al. 1972). Die im Blut gelöste humorale Komponente der unspezifischen Immunabwehr ist das Komplementsystem. Es besteht aus einer Gruppe von Proteinen, die kaskadenartig aktiviert werden. Dieses System mündet schließlich in einer Perforation der Zellwand des Erregers und macht diesen damit lebensunfähig (Ricklin et al. 2010).

Das spezifische Immunsystem greift erst mit einer gewissen Verzögerung in die Wirtsab- 
wehr ein. Im Gegensatz zum unspezifischen, dem angeborenen Immunsystem, entwickelt sich das spezifische Immunsystem erst im Laufe des Lebens, wobei die ersten Lebensjahre besonders wichtig sind (M'Rabet et al. 2008). Durch den Kontakt mit Fremdstoffen aller Art setzt sich das Immunsystem mit diesen auseinander und erwirbt auf diese Weise spezifische Abwehrmechanismen gegen diese Stoffe. Daher bezeichnet man diesen Teil des Immunsystems auch als erworbene Immunabwehr. Die Zellen der spezifischen Immunabwehr sind die Lymphozyten und kommen zum größten Teil in den primären lymphatischen Organen vor. Diese primären lymphatischen Organe sind das Knochenmark und der Thymus. Die Lymphozyten lassen sich grob in zwei Gruppen unterteilen. Es gibt die B- und die T-Lymphozyten. Sie haben ihren Namen von ihren Differenzierungs- und Reifungsorten. B- von "bone marrow” und T- von "thymus". Sie sind die kleinsten unter den weißen Blutkörperchen und stellen ca. ein Viertel von ihnen (Osmond 1985). Durch Zytokine, die von den Zellen der unspezifischen Immunabwehr sezerniert werden, werden die Zellen der spezifischen Immunantwort zum Ort der Entzündung gelockt (Schall et al. 1990). Die spezifische Immunantwort kann dann auf drei Wegen eingeleitet werden. Zum einen können Makrophagen Fremdstoffe und Krankheitserreger phagozytieren und Teile davon auf ihrer Oberfläche durch MHC-II-Moleküle präsentieren. Diese können von ruhenden T4-Zellen erkannt werden, die dann zu aktiven T-Helferzellen werden und durch die Produktion von Signalstoffen und weitere Zellteilung die Immunantwort anregen. Zum anderen können infizierte Zellen von ruhenden T8-Zellen erkannt werden. Diese transformieren darauf zu aktiven T-Killerzellen und können die infizierte Zelle durch Lyse zerstören. Als dritte Möglichkeit können ruhende B-Zellen nach dem Kontakt mit einem Antigen zu Plasmazellen transformieren und spezifische Antikörper bilden. Nach dem gleichen Prinzip verläuft auch die Aktivierung von B-Gedächtniszellen, mit dem Unterschied, dass diese sofort in der Lage sind, die spezifischen Antikörper zu bilden (Janeway et al. 2001). Zellen der Immunabwehr wie Granulozyten werden im Laufe der Entzündung durch Zytokine wie Interleukin-1 und -8 zum Ort der Entzündung gelockt und können selbst wieder Interleukin- 8 und Chemokine produzieren, welche wiederum T-Lymphozyten und Monozyten anlocken können. Interleukin-8 spielt unter anderem eine wichtige Rolle, indem es die Gefäßwand für einwandernde Leukozyten durchlässig macht (Taub et al. 1996; Garlanda et al. 2013). Durch die Anwesenheit dieser Zellen und ihrer Zytokine und Chemokine im entzündeten Gewebe werden die ortständigen Zellen zur Produktion von gewebezerstörenden Proteasen angeregt. Unter diesen Proteasen sind die Matrix Metalloproteinasen und Catepsine wichtige Vertreter. Sie können je nach Ausmaß und Dauer der Entzündung zu einem unterschiedlich großen Verlust von Bindegewebe führen (Sorsa et al. 2004; Birkedal-Hansen et al. 1993). 


\subsubsection{Ablauf der Immunabwehr bei der Parodontitis}

Unter physiologischen Bedingungen können die Gingiva und das Saumepithel mikrobielle Noxen durch verschiedene Abwehrmechanismen abfangen. Ist das Gleichgewicht von Abwehr und bakterieller Belastung zugunsten der Bakterien verschoben, z. B. durch schlechte Mundhygiene oder eine immunologische Abwehrschwäche, kommt es zu einer Veränderung der den Zahn umgebenden Strukturen (Schroeder und Listgarten 1997). Durch die übermäßige Besiedelung mit Bakterien kommt es durch die von Bakterien produzierten Zellgifte und Proteasen zur Zerstörung von Zellen und zur Zerstörung von Bindegewebe. Zusätzlich kann der Körper mit einer überschießenden Immunreaktion auf die Fremdstoffe und die mikrobielle Belastung reagieren. Die Folge ist eine weitere Zerstörung von Zellen und Bindegewebe. Durch die Gewebedestruktion wandert das schützende Saumepithel in Richtung Wurzel, um an nicht-kontaminierten Oberflächen neuen Halt zu finden. Dadurch entstehen Taschen, welche eine größere Oberfläche bilden und das weitere Eindringen von Bakterien in den Sulkus ermöglichen (Nanci und Bosshardt 2006). Die Veränderung der Gegebenheiten führt zu einer Veränderung der Bakterienflora hin zu vermehrt gram-negativen und anaeroben Spezies, welche durch ihre höhere Agressivität die Gewebedestruktion zusätzlich beschleunigen können (Abusleme et al. 2013). Das Sulkusepithel reagiert auf diese Belastung unter anderem mit einer erhöhten Produktion von Sulkusflüssigkeit. Der Zweck dessen ist wahrscheinlich das Ausschwemmen von Bakterien und Toxinen aus dem Sulkus und eine bessere Migration von Abwehrzellen an den Ort der Entzündung.

Durch das Fortschreiten der Entzündung Richtung Apex wird das Parodont, das zu einem großen Teil aus kollagenen Fasern besteht, Stück für Stück zerstört. Durch die hohe Umsatzrate und Plastizität des Parodonts und die Verschiebung der Gewebshomöostase Richtung Gewebeabbau, ausgelöst durch Antigene und vermittelt durch die körpereigene Immunreaktion, kommt es zu einem Verlust von Knochengewebe (Nanci und Bosshardt 2006). Unbehandelt führt eine Parodontitis über einen kürzeren oder längeren Zeitraum zum Verlust des betroffenen Zahnes.

Die Parodontitis kann unterschiedliche Verlaufsformen annehmen. Am häufigsten ist die chronische Verlaufsform, welche meist vom Patienten unbemerkt verläuft und über Jahre hin bestehen kann, ohne dass Symptome bemerkt werden. Weitere Verlaufsformen sind die juvenile Parodontitis, welche schon in jungen Jahren auftritt und für die ein rasches Krankheitsgeschehen typisch ist. Außerdem gibt es die aggressive Parodontitis, welche in jedem Lebensalter auftreten kann und durch ihren aggressiven und schnellen Verlauf mit häufigen Rückfällen nach Behandlung gekennzeichnet ist (Albandar 2014). 


\subsection{Die Periimplantitis}

\subsubsection{Definition}

Die Periimplantitis ist eine Erkrankung entzündlicher Genese (Lindhe und Meyle 2008). Bei einer entzündlichen Veränderung, die ausschließlich das umgebende Weichgewebe osseointegrierter Implantate betrifft, spricht man von einer Mukositis. Die Mukositis ist reversibel. Schreitet die Entzündung jedoch fort und erreicht den krestalen periimplantären Knochen, so spricht man von einer Periimplantitis. Einer Periimplantitis geht in den meisten Fällen eine periimplantäre Mukositis voraus (Lindhe und Meyle 2008). Die Periimplantitis ist irreversibel. Dabei wird durch die Entzündung das marginale knöcherne Implantatbett abgebaut (Algraffee et al. 2012; Lindhe und Meyle 2008). Eine nicht behandelte Periimplantitis führt letztlich zum Verlust des Implantats.

Frühe periimplantäre Knochenresorption kann durch sog. bone remodeling verursacht werden und muss nicht durch eine Infektion verursacht sein. In diesem Fall liegt keine Form der Periimplantitis vor (Klinge und Meyle 2012; Mombelli et al. 2012). Als ein weiterer Grund für den Verlust von stützendem Knochengewebe an Implantaten wird der Knochenabbau durch eine Überbelastung des Implantats diskutiert. Das Problem der bisherigen Arbeiten zu diesem Thema ist, dass die genaue Kraft der Überbelastung nicht gemessen wurde und dass bei Versuchen an Tier und Mensch unterschiedliche Ergebnisse festgestellt wurden. Außerdem geben die bisherigen Forschungsergebnisse keinen Anhalt, dass die Überbelastung von Implantaten allein zu einem Verlust an Knochenmasse führt. Stattdessen wurde eine Zunahme festgestellt. Dagegen konnte jedoch in Zusammenhang mit einem entzündlichem Geschehen und einer Überbelastung ein verstärkter Abbau von Knochengewebe festgestellt werden (Klinge und Meyle 2012; Naert et al. 2012).

\subsubsection{Die Ätiologie, Inzidenz und Biologie der Periimplantitis}

Als Risikofaktoren für eine hohe Prävalenz, an einer Periimplantitis zu erkranken, stehen vor allem eine schlechte Mundhygiene, Nikotinabusus und eine parodontale Vorerkrankung. Die Metaanalyse von fünf Publikationen ergab, dass die Überlebensraten von Implantaten bei Patienten, die keine parodontalen Vorerkrankungen aufwiesen, signifikant höher war als die von Patienten mit einer parodontalen Vorerkrankung (Gatti 
et al. 2008; Hardt et al. 2002; Karoussis et al. 2003; Mengel et al. 2007; Mengel und Flores-de-Jacoby 2005).

Auch ein schlecht eingestellter Diabetes mellitus und übermäßiger Alkoholkonsum können zu einem Krankheitsgeschehen beitragen (Heitz-Mayfield und Lang 2010). Diskutiert wird außerdem, welchen Einfluss die Gestaltung der Implantatoberfläche auf die Prävalenz und den Verlauf der Erkrankung hat. Bisherige Studien kommen zu der Erkenntnis, dass glatte Oberflächen rauen vorzuziehen sind. Zudem gibt es Hinweise darauf, dass eine genetische Prädisposition eine Rolle bei der Entwicklung einer Periimplantitis spielen kann (Klinge und Meyle 2012; Lindhe und Meyle 2008). Auch ein zu dichtes Setzen von Implantaten zueinander kann zu einem Verlust an Knochengewebe führen (Porter und von Fraunhofer 2004).

Es herrscht allgemeiner Konsens darüber, dass die Periimplantitis in erster Linie von Bakterien verursacht ist (Khammissa et al. 2012). Die Entzündung wird dabei durch verschiedene Mechanismen ausgelöst. Zum einen produzieren Bakterien Toxine und Enzyme, welche zur Gewebsdegradierung führen. Zum anderen lösen Oberflächenproteine und Bakterienzellreste in Abwehrzellen die Ausschüttung von gewebedestruierenden Stoffen aus. In den infizierten Taschen findet man grundsätzlich eine gemischte anaerobe Bakterienflora, die von gram-negativen Bakterien dominiert wird. Man konnte außerdem Mischinfektionen mit Staphylococcus aureus feststellen (Mombelli und Decaillet 2011; Persson und Renvert 2014).

Studien zeigten, dass Patienten mit Implantaten ein höheres Risiko aufweisen, eine Periimplantitis zu entwickeln als Patienten mit natürlichen Zähnen eine Parodontitis. Ein wahrscheinlicher Grund - neben anderen - ist das im Vergleich zum normalen Zahnhalteapparat andersartige Weich- und Hartgewebe um die Implantate herum (Wilson 2013). Nach der Implantation heilt das Implantat ein und um den transmukosalen Teil lagert sich ein dem natürlichen Zahn ähnliches Saumepithel an. Dieses Gewebe weist allerdings, wie bereits erwähnt, Charakteristiken von Narbengewebe auf, wie z. B. eine geringere Durchblutung und einen hohen Anteil an kollagenen Fasern. Im Vergleich zum am natürlichen Zahn haftenden Saumepithel ist es weniger resistent gegenüber äußeren Noxen wie z. B. bakterieller Plaque. 


\subsubsection{Die Therapie der Periimplantitis}

Wie bereits erwähnt, geht dem Krankheitsbild der Periimplantitis in fast allen Fällen eine periimplantäre Mukositis voraus. Entsprechend ist bekannt, dass einer Parodontitis meist eine Gingivitis vorausgeht.

Die Ursachen der Periimplantitis sind denen der Parodontitis sehr ähnlich. Trotz der vielen Gemeinsamkeiten beider Erkrankungen werden nach aktuellen Forschungsergebnissen in einigen Punkten unterschiedliche Behandlungsmethoden vorgeschlagen (Renvert et al. 2012). Wenn es zur Therapie kommt, muss man zwischen der periimplantären Mukositis und der Periimplantitis unterscheiden. Diagnostiziert man eine periimplantäre Mukositis bevor es zu einer Periimplantitis gekommen ist, sind die Chancen auf Heilung ohne bleibende Schäden sehr gut. Die Therapie besteht in jedem Fall darin, den Ursprung der Entzündung und mögliche Kofaktoren zu beseitigen. Der Ursprung der Entzündung geht in den meisten Fällen von mikrobieller Plaque aus. In dieser Situation besteht der erste Schritt der Therapie darin, die Plaque zu beseitigen. Die Therapie der Wahl ist eine nicht-chirurgische, mechanische Therapie. Zur Anwendung kommen dabei geeignete Instrumente aus Titan, Kohlefaser oder Kunststoff, um die Implantatoberfläche möglichst wenig zu manipulieren (Schwarz et al. 2006). Ob adjuvante Maßnahmen wie die lokale antimikrobielle Therapie der Implantatoberfläche mit Laserbestrahlung, das Auftragen von Säuren oder die Bestrahlung mit Mikropartikeln einen zusätzlichen Vorteil bei der Therapie erbringen, wurde in vielen Studien untersucht. Die Ergebnisse lassen jedoch keinen signifikanten Vorteil erkennen (Armas et al. 2013; Renvert et al. 2012). Als nächster Schritt sollte versucht werden, die Ursache für die Plaqueansammlung auszuschalten. Schuld daran können u. a. eine schlechte Mundhygiene des Patienten, eine Überdimensionierung der Suprakonstruktion oder eine ungünstige Platzierung des Implantats sein.

Sollte die Mukositis bereits zu einer Periimplantitis mit Knochenabbau fortgeschritten sein, muss eine andere Behandlungsstrategie angewendet werden.

Im Gegensatz zur Therapie der Parodontitis, bei welcher in fast allen Fällen, unabhängig von der Schwere der Erkrankung, eine konservative Therapie zum Erfolg führt, belegen bisherige Studien, dass bei der Behandlung der Periimplantitis eine chirurgische Therapie notwendig ist (Renvert et al. 2012). 


\subsubsection{Periimplantitis - Stand der Forschung}

Zum Thema Periimplantitis wurde im klinischen Bereich bisher zu den Risikofaktoren und der Diagnose, der Ätiologie und Epidemiologie sowie zu den Behandlungsmethoden geforscht (Heitz-Mayfield 2008; Javed et al. 2013b; Javed et al. 2013a; Mombelli et al. 2012). Im mikrobiologischen Fokus stand bislang die Art der Keimbesiedelung der periimplantären Tasche. Festgestellt wurde, dass das Keimspektrum der Periimplantitis ein sehr ähnliches Profil wie das bei der Parodontitis aufweist (Hultin et al. 2002; Mombelli und Decaillet 2011). Auf dem Gebiet der Molekularmedizin wurde bisher das Auftreten von Zytokinen und Gewebefaktoren in der periimplantären Sulkusflüssigkeit untersucht (Javed et al. 2011; Severino et al. 2011). Dabei wurde besonders eine erhöhte Expression der Interleukine-1, -6 und -8 festgestellt. Außerdem zeigte sich eine erhöhte Konzentration der Matrix-Metalloproteinase-1 und des Tumornekrosefaktor-alpha (TNF$\alpha)$.

Bisher gibt es nur wenige Arbeiten, die auf der Ebene der mRNA-Genexpression das von Periimplantitis betroffene periimplantäre Gewebe untersuchen bzw. mit der Genexpression bei der Parodontitis vergleichen (Becker et al. 2014; Roediger et al. 2009; Duarte et al. 2009). Bei diesen Untersuchungen wurden zwar auch Gemeinsamkeiten zwischen der Periimplantitis und der Parodontitis festgestellt, jedoch auch große Unterschiede in der Expression einzelner Gene und Gengruppen. Das Resümee dieser Publikationen ist durchweg, dass die Parodontitis und die Periimplantitis Krankheiten mit Gemeinsamkeiten aber auch Unterschieden sind. Die Hauptunterschiede werden vor allem in der Reaktion des Gewebes bzw. der ortsständigen Zellen an Zahn und Implantat gesehen.

Bisher gilt der allgemeine Konsens, dass die Hauptursache der Periimplantitis in der bakteriellen Besiedlung der Implantatoberfläche zu suchen ist. Als weitere Risikofaktoren gelten, wie bei der Parodontitis, eine schlechte Mundhygiene, Rauchen, eine genetische Prädisposition und parodontale Vorerkrankungen (Winkelhoff 2010). Seit geraumer Zeit wird an der optimalen Oberfläche von Implantaten geforscht. Zum einen möchte man eine Oberfläche schaffen, an welcher der Knochen bestmöglich anwachsen kann. Zum anderen wird eine Oberfläche angestrebt, an welcher Bakterien so wenig wie möglich haften können. Diese beiden Ziele sind bisher nur schwer zu vereinen. Seit vielen Jahren wird in der Forschung über die optimale Oberflächenstruktur diskutiert. Bisher ist eine raue Oberfläche von Implantaten am verbreitetsten. Mittlerweile gibt es viele Techniken der Oberflächenvergütung. Eine der neueren Methoden ist die Nanotechnologie. Auch 
die Beschichtung von Implantaten mit Hydroxylapatit oder Knochenwachstumsfaktoren wird mittlerweile praktiziert (Gaviria et al. 2014).

Die bisherigen Forschungsergebnisse wirken sich aber letztlich nur bedingt auf die Therapie aus. Lediglich die klinischen Studien ergaben, dass ein chirurgisches Vorgehen bei der Behandlung der Periimplantitis im Vergleich zum konservativen Vorgehen einen größeren Erfolg zeigt (Klinge und Meyle 2012; Winkelhoff 2010). In der Praxis kommen bisher noch keine Methoden zum Einsatz, die entzündungsfördernde oder gewebedestruierende Zytokine bzw. Faktoren blockieren oder deren Produktion einschränken. Wie weiter oben bereits erwähnt, gibt es mittlerweile Autoren, welche die Periimplantitis als eine Fremdkörperreaktion bzw. allergische Reaktion der Immunabwehr betrachten. Bisher ist die Studienlage in diesem Bereich jedoch eher dürftig. Es häufen sich jedoch die klinischen Verdachtsfälle auf Unverträglichkeiten gegen Titandioxid-Partikel (du Preez et al. 2007; Olmedo et al. 2003; Olmedo et al. 2009).

\subsubsection{Vorstellung der untersuchten Gene/ Gengruppen}

\section{Die Interleukine}

Die Interleukine sind eine Gruppe von Zytokinen, welche in unterschiedlichste zelluläre Prozesse involviert sind. Ein wichtiger Teil ihrer Funktion ist die Aktivierung von Entzündungsprozessen und deren Aufrechterhaltung. Zum anderen können gewisse Interleukine wie Interleukin-10 einen gegenteiligen Effekt haben, indem sie entzündungshemmend wirken. Auch für die Immunantwort sind Interleukine von Bedeutung, da sie verschiedene Abwehrzellen durch einen Konzentrationsgradienten zum Einsatzort locken können. Außerdem sind Interleukine indirekt für den Abbau extrazellulärer Matrix mitverantwortlich, da sie Zellen zur Produktion von Matrix-Metalloproteinasen anregen. Von Interesse in dieser Arbeit sind neben anderen vor allem die Interleukine-1, -8 und -10 .

\section{CD24 und weitere Oberflächenproteine}

CD24 kann auf hämatopoetischen und nicht-hämatopoetischen Zellen nachgewiesen werden. Dazu zählen B-Zellen (Allman et al. 1993; Kay et al. 1991; Pirruccello und LeBien 1986), T-Zellen (Li et al. 2004; Williams et al. 1996), neutrophile und eosinophile Granulozyten (Elghetany und Patel 2002; Williams et al. 1996) sowie dendritische Zellen (Martinez del Hoyo et al. 2002) und Makrophagen (De Bruijn et al. 1996). Das Ober- 
flächenprotein CD24 kann somit zur Identifizierung von Zelltypen dienen, die sich im entzündeten periimplantären Gewebe aufhalten.

Die Matrix-Metalloproteinasen (MMPs) und ihre Inhibitoren, die TIMPs

Eine wichtige Proteingruppe für den Abbau von Bindegewebe sind die MMPs und ihre Gegenspieler, die TIMPs. MMPs sind Polypeptide mit einem Metall-Komplex in ihrer Struktur. Es gibt eine große Anzahl von MMPs, welche jeweils unterschiedliche extrazelluläre Strukturen abbauen können. Da Kollagene in den hier untersuchten Strukturen eine wesentliche Rolle spielen, liegt das Augenmerk in dieser Arbeit besonders auf den MMPs 1, 8 und 13. Sie sind fähig extrazelluläres Kollagen abzubauen. Die TIMPs 1, 2 und 3 sind die haupsächlichen Gegenspieler dieser genannten MMPs und sollen daher auch in ihrer Expression untersucht werden (Sorsa et al. 2004; Degidi et al. 2013; Visse und Nagase 2003; Uchida et al. 2000).

\section{Kollagene}

Von Interesse in dieser Arbeit sind vor allem die Kollagene 1, 3 und 9. Kollagen 1 ist das Kollagen des Knochens. Es stellt den größten Anteil an organischer Masse im Knochen. Kollagen 1 ist maßgeblich für die Stabilität und Elastizität des Knochens verantwortlich. Außerdem spielt Kollagen 1 eine wichtige Rolle bei der Neubildung von Knochengewebe, da sich die Osteoblasten bei der Bildung von mineralischer Knochenmatrix an den Kollagenfibrillen orientieren (Matsugaki et al. 2015; Kerschnitzki et al. 2011; Jones et al. 1975). Kollagen 3 kommt in den Bindegeweben aber vor allem in der Wand von Blutgefäßen vor (Chen et al. 2012; Shalhub et al. 2014). Die Gefäßneubildung ist ein Zeichen für chronische Entzündungen.

\section{Osteocalcin (BGLAP) und OPG (TNFRSF11B)}

Osteocalcin ist auch als bone gamma-carboxyglutamate (gla) protein (BGLAP) bekannt. Es soll in dieser Arbeit in seiner Expression untersucht werden. Es wird von Osteoblasten synthetisiert und ist für den Knochenauf- und abbau wichtig. BGLAP ist ein Peptidhormon und kommt im Körper der meisten Wirbeltiere vor. Es stellt ein bis zwei Prozent der extrazellulären organischen nicht-kollagenen Knochenmatrix dar. Sezerniert wird es im Zahn von Odontoblasten und im Knochen von Osteoblasten. Es hat eine hohe Affinität zu Hydroxylapatit und Calcium (Raymond et al. 1999). OPG wird ebenfalls von Osteoblasten sezerniert und hat eine hemmende Wirkung auf Osteoklasten.

\section{RUNX2 und SOX2}

RUNX2 und SOX2 sind Transkriptionsfaktor. Sie sind hier von besonderem Interesse, da RUNX2 besonders für die Knochenentwicklung wichtig ist. Er ist für die Entwicklung 
und Differenzierung von Osteoblasten verantwortlich und dient außerdem einigen $\mathrm{Nu}-$ kleinsäuren und regulierenden Faktoren der skelettalen Genexpression als Gerüstprotein (Dalle Carbonare et al. 2012). SOX2 ist für die Aufrechterhaltung der Pluripotenz von Stammzellen wichtig und wurde in seiner Expression bereits im Zusammenhang mit der Parodontitis untersucht.

Die Fibroblasten Wachstumsfaktoren (FGFs)

Die fibroblast growth factors sind eine Gruppe von 22 Genen, die unter den Wirbeltieren in ihrer Struktur und Aminosäuresequenz stark konserviert sind. In der Embryonalentwicklung sind sie unter anderem für die Entwicklung, Differenzierung und Bewegung von Zellen zuständig. Sie sind sind in dieser Arbeit vor allem deshalb von Interesse, da sie im erwachsenen Körper für die Gewebehomöostase und die Reparatur von Verletzungen zuständig sind (Ornitz und Itoh 2001). Explizit sollen die Genexpression von FGF8 und FGF18 untersucht werden, da sie dafür bekannt sind, unter anderem für das Knochenwachstum und die -reparatur wichtig zu sein (Haque et al. 2007b; Haque et al. 2007a).

\subsubsection{Aufbau und Ziel der Arbeit}

In dieser Arbeit wurde zum ersten Mal erkranktes Implantatgewebe (Periimplantitis) mit gesundem Implantatgewebe auf mRNA-Ebene verglichen. Durch diese Versuchsgestaltung sind die Ergebnisse in ihrer Aussagekraft möglichst wenig verzerrt, da man nicht wie in bisherigen Studien die Periimplantitis mit der Parodontitis vergleicht. Dazu wurden von sechs Patienten aufgrund von Periimplantitis nicht erhaltungswürdige Implantate entnommen. Von zwei Patienten wurden Implantate entnommen, die ohne eine Erkrankung waren, aber aufgrund einer falschen Platzierung explantiert werden mussten. Aus dem Gewebe, das an der Implantatschraube nach der Extraktion verblieb, wurde die mRNA isoliert, in cDNA umgeschrieben und für jede Probe ein Microarray angefertigt, in welchem die Gene des kompletten Genoms hybridisiert wurden. Die Expressionsraten wurden daraufhin verglichen, um unterschiedliche Herauf- oder Herabregulierungen zwischen Gesund und Erkrankt festzustellen. Für eine Gruppe ausgewählter Gene wurden diese Ergebnisse mit der qPCR-Technik überprüft und mit den Ergebnissen des Microarrays verglichen. 
Gesucht wurde in dieser Arbeit vor allem nach Entzündungsmarkern, Transkriptionsfaktoren, Stammzellmarkern und Markern, die für den Auf- und Abbau von extrazellulärer Matrix stehen. Ziel dieser Arbeit soll es sein, einen Überblick über die molekularbiologischen Vorgänge bei der Periimplantitis im Vergleich zu gesunden periimplantären Verhältnissen zu gewinnen. Aus den gewonnenen Ergebnissen können Schlussfolgerungen auf Signalwege und Eigenschaften des Gewebes gezogen werden, die für den Verlauf und die Therapie der Krankheit entscheidend sein können. Auf die Ergebnisse dieser Arbeit können weitere Arbeiten aufbauen, die den Effekt der Regulierung einzelner Gene untersuchen oder etwa die Veränderung von Expressionsmustern im Zusammenhang mit unterschiedlichen Implantatmaterialien. 
KAPITEL 2

Material und Methoden

\subsection{Versuchsaufbau}

Für diese wissenschaftliche Arbeit wurden insgesamt acht Implantate von acht Patienten entnommen. Sechs Implantate wurden aufgrund von periimplantärer Entzündung und Desintegration entnommen. Als Zeichen für den absoluten Misserfolg und die damit verbundene Indikation zur Explantation gilt die Beweglichkeit des Implantats in seinem knöchernen Implantatbett (Heitz-Mayfield 2008). Zwei Implantate wurden aufgrund falscher Positionierung im Kiefer explantiert und wiesen keine Zeichen einer periimplantären Entzündung auf. Die definierten Befunde für die Diagnose einer Periimplantitis, - bleeding on probing, Suppuration, erhöhte Sondierungstiefe und röntgenologischer Knochenabbau -, waren alle negativ. Die Patienten wurden nicht nach bestimmten Kriterien wie Alter, speziellen Krankheiten oder ähnlichen ausgewählt; die explantierten Implantate wurden unabhängig von Material, Hersteller oder Verweildauer im Kieferknochen ausgewählt. Direkt nach der Explantation wurden die Implantate inklusive der anhaftenden Gewebereste in flüssigem Stickstoff schockgefroren und bis zur weiteren Untersuchung bei $-80^{\circ} \mathrm{C}$ gelagert. Das an den Implantaten haftende Gewebe wurde später vom Implantatkörper getrennt. Anschließend wurde die mRNA aus dem gewonnenen 
Material direkt isoliert. Die mRNA wurde genutzt, um pro Implantat und Patient ein Microarray anzufertigen, welches 19742 Gene in ihrer Expression untersuchte. Dasselbe Probenmaterial wurde für die Verifizierung einzelner ausgesuchter Gene mit der qPCRMethode verwendet. Alle Arbeitsschritte im Labor wurden mit sterilen und RNAse-freien Geräten und Gefäßen durchgeführt. Es wurden permanent ein sauberer Laborkittel und Latexhandschuhe getragen.

\subsection{Isolation der RNA aus periimplantärem Gewebe}

Um verwertbares Genmaterial zu gewinnen, wurde das an den Implantaten haftende Gewebe mit einem Skalpell entfernt und in 2-ml-E-Cups (Eppendorf Cup) gegeben. Eine Menge von $100 \mathrm{mg}$ pro E-Cup wurde nicht überschritten. Die E-Cups enthielten jeweils $1 \mathrm{ml}$ peqGOLD TriFast ${ }^{1}$. Dieses Gemisch zur Isolierung von RNA, DNA und Proteinen enthält Phenol und Guanidinisothiocyanat in einer einphasigen Lösung. Bei dieser Methode wird das zu untersuchende Material, welches humanen, tierischen, pflanzlichen, bakteriellen oder viralen Ursprungs sein kann, mit einer Einschritt-Flüssigphasen-Separation in eine wässrige, eine organische und eine Interphase aufgetrennt. Um das gelöste Gewebe zu dispergieren, wurde ein Ultra Turrax $\mathrm{T} 8^{2}$ verwendet. Danach wurden die Proben 5 Minuten bei Raumtemperatur inkubiert, um eine Dissoziation der Nukleotidkomplexe zu erreichen. Pro $1 \mathrm{ml}$ TriFast-Lösung wurden dann 0,2 ml Chloroform zugegeben und die Lösung kurz mit einem Vortex-Mixer gemischt. Die Proben wurden bei Raumtemperatur bis zu 10 Minuten inkubiert. Im nächsten Schritt wurden die Cups bei 12.000 x g zentrifugiert. Es ergeben sich die drei Phasen. In der oberen, wässrigen Phase befindet sich die RNA. Die untere rote organische Phenol-ChloroformPhase und die Interphase enthalten die DNA und Proteine. Die wässrige RNA-haltige Phase wurde daraufhin abpipettiert und in neue E-Cups überführt. Da in der wässrigen Phase nach der Auftrennung immer noch Verunreinigungen wie Polysaccharide und Proteoglykane in unterschiedlichen Konzentrationen vorhanden sein können, ist eine weitere Aufreinigung der RNA nötig. Die Aufreinigung der RNA erfolgte mit dem Qiagen RNeasy Mini Kit nach Protokoll des Herstellers ${ }^{3}$. Die Konzentration der mRNA wurde mit einem NanoDrop 1000 Photospektrometer ${ }^{4}$ gemessen. Für die Versuche mit der

\footnotetext{
${ }^{1}$ PEQLAB Biotechnologie GMBH - Carl-Thiersch-Str. 2b 91052 Erlangen, Deutchland

${ }^{2}$ IKA ${ }^{\circledR}$-Werke GmbH \& Co. KG - Janke \& Kunkel-Str. 10, 79219 Staufen, Deutschland

${ }^{3}$ RNeasy Mini Kit, Qiagen Handbook 2010, QIAGEN GmbH - Qiagen Str. 1, 40724 Hilden, Deutschland

${ }^{4}$ NanoDrop products - 3411 Silverside Rd Bancroft Building Wilmington, DE 19810 USA
} 
Microarray- und qPCR-Methode wurde die mRNA in cDNA umgeschrieben. Dazu wurde das QuantiTect ${ }^{\circledR}$ Reverse Transcriptase $\mathrm{Kit}^{5}$ verwendet und nach dem entsprechenden Protokoll von Quiagen verfahren.

\subsection{Bestimmung der Qualität und Konzentration der Gesamt-RNA}

Es wurden nur Proben verwendet, die eine vergleichbare RNA-Güte aufwiesen. Dazu wurde mit Hilfe eines Agilent Bioanalyzer ${ }^{\circledR}$ Chips $^{6}$ die gewonnene RNA vor der Weiterverwendung mittels Microarrays oder RT-qPCR auf ihre Güte untersucht. Dazu wurde das RNA 6000 Nano LabChip ${ }^{\circledR}$ Kit $^{7}$ verwendet. Für dieses Verfahren reichen lediglich 5 ng RNA aus. Über den Fluoreszenzfarbstoff PicoGreen, welcher mit der RNA interkaliert, kann diese mit dem Nano LabChip ${ }^{\circledR}$ Kit detektiert werden. Das Kit wird mit der fluoreszenzfarbstoffmarkierten RNA und einem Größenstandard (Leiter) beladen. Die Auftrennung der Proben erfolgt in einem Separationskanal nach Anlegen eines elektrischen Feldes. Die so entstandenen Echtzeit-Daten können mit der Agilent 2100 Bioanalyzer Software ausgewertet werden. Die Software analysiert das Elektropherogramm mit einem speziellen Algorithmus. Abschließend wurde die entsprechende RNA-Konzentration, nach einer geeigneten Verdünnung der Proben mit Nuklease-freiem Wasser, durch eine photometrische Messung (Photometer Gene Quant) der Absorption bei einer Wellenlänge von $260 \mathrm{~nm}$ bestimmt. Alle Messungen der Proben sowie der des Referenz-Leerwerts (nuklease-freies Wasser) wurden in einer Ultrospec-Küvette ${ }^{8}$ durchgeführt. Das Absorptionsspektrum bei einer Wellenlänge von $260 \mathrm{~nm}$ entspricht dem Absorptionsmaximum der Pyrin- und Pyrimidin-Basen der RNA. RNA-Lösungen mit einer Ratio von 1.8 bis 2.0 wurden als ausreichend angesehen, um mit ihnen weitere Versuche durchzuführen.

\footnotetext{
${ }^{5}$ QuantiTect Reverse Transcription Kit, Quiagen Handbook 2011, QIAGEN GmbH - Qiagen Str. 1, 40724 Hilden, Deutschland

${ }^{6}$ Agilent 2100 Bioanalyzer, Fa. Agilent Technologies, Palo Alto, Ca, USA

${ }^{7}$ Agilent Technologies, Inc. Life Sciences and Chemical Analysis Group 5301 Stevens Creek Boulevard Santa Clara, CA 95051-7201 USA

${ }^{8}$ Ultrospec 4000 UV/Vis Diode Array Spectrophotometer (Typ 40008455)
} 


\subsection{Microarray}

\subsubsection{Allgemeines zur Methode}

Die Technik des Microarray ist eine der aktuelleren technischen Fortschritte im Bereich der Molekularbiologie und Genetik. 1991 veröffentlichte Stephen P. Fodor im Science Magazine seine ersten Ergebnisse zur Microarray Technologie (Fodor et al. 1991). In den folgenden Jahren wurde diese Technik immer weiter verfeinert und wird auch in der kommenden Zeit noch an Möglichkeiten dazugewinnen. Zum jetzigen Zeitpunkt ist man in der Lage, mit einem einzigen Array das komplette menschliche Genom zu erfassen, das sich nach derzeitigem Wissensstand auf ca. 20.000 bis 22.000 Gene beläuft (Evans 2010). Somit besitzt man die Möglichkeit einer Momentaufnahme der Genexpression von tausenden von Genen gleichzeitig. Die produzierten Datenmengen können dabei sehr groß werden (Alvis Brazma 2000). Die richtige Präsentation und Evaluierung dieser Daten ist mittlerweile die schwierigste Aufgabe bei der Durchführung eines Microarray.

\subsubsection{Durchführung und Auswertung}

Ein Microarray nach heutigem Stand ist eine Glasplatte, auf welcher synthetische einzelsträngige DNA-Moleküle an genau bestimmten Stellen fixiert sind, sogenannten Spots. Auf einem Array können tausende von solchen Spots sein. Jeder entspricht einem bestimmten Gen. Die Technologie des Microarrays macht sich die bevorzugte Bindung komplementärer DNA-Einzelstränge zu Nutzen. Es gibt auf diesem Grundprinzip aufbauend viele verschiedene Varianten von Microarrays, welche sich je nach Art der Probe und Forschungsziel unterscheiden. Es gibt beispielsweise Microarrays, die pro Spot mehrere Gensonden besitzen und zusätzlich mit einer Sonde mit leicht abgeänderter Nukleotidsequenz als Negativkontrolle ausgestattet sind.

Eine der meistgenutzten Varianten ist der experimentelle Vergleich von mRNA-Level in zwei oder mehreren verschiedenen Proben bzw. zwischen einer Probe und einer Kontrolle. Die RNA wird aus den jeweiligen Proben extrahiert und mit unterschiedlichen Fluoreszensfarbstoffen markiert. Die Markierung erfolgt in den meisten Fällen während des Umschreibens der zu untersuchenden mRNA in cDNA. Dazu dienen mit dem Farbstoff interkalierende Nukleotide. Die am häufigsten verwendeten Farbstoffe sind die Cyanin-Floureszensfarbstoffe (Cy3- und Cy5-dUTP) (Harrington et al. 2000). Es wird für die Testprobe und die Kontrolle ein unterschiedlicher Floureszensfarbstoff verwendet. 
Vor der Hybridisierung werden die Proben gemischt. Der Microarray wird daraufhin mit dem markierten Probenmaterial beschickt und die Gensequenzen der Proben hybridisieren mit ihren komplementären Sequenzen der jeweiligen Spots. Die relative Menge der mRNA des gesuchten Gens in den jeweiligen Proben wird durch die Messung der Strahlungsintensität der beiden Floureszensfarbstoffe bestimmt, die dann zueinander in Verhältnis gesetzt werden (Alvis Brazma 2000). Je nach vorhandener Menge an einsträngigen Oligonukleotid-Strängen pro Spot und Probe lässt sich ein entsprechend höheres oder niedrigeres Lichtsignal im Vergleich zu anderen Spots auf dem selben Array oder einem anderen Array feststellen. Die Ergebnisse eines Array sind deshalb relative und keine absoluten Werte (Alvis Brazma 2000; Harrington et al. 2000). Durch die vorherige Zuordnung von Spot-Lage und Gen kann mit Hilfe eines Computerprogramms die genaue Genexpression für jedes einzelne untersuchte Gen ermittelt werden.

In der vorliegenden Arbeit kam jedoch eine neuere Methode der Gensondenmarkierung zum Einsatz. Diese basiert auf der Biotinylierung der Proben-cDNA in Verbindung mit Anti-Biotin-Goldpartikeln. Dabei wird die zu untersuchende cDNA mit dem BiotinMolekül hybridisiert und Goldpartikel werden mit Anti-Biotin-Antikörpern versehen. Die beiden zu vergleichenden Proben werden nicht gemischt, sondern separat ausgewertet. Es werden keine zwei unterschiedlichen Floureszensfarbstoffe, wie im weiter oben genannten Verfahren, verwendet. Mit einem Laser werden die einzelnen Glasplatten ausgelesen und anhand des von den Goldpartikeln reflektierten Lichts lässt sich auf die relative Menge an cDNA-Strängen pro Spot rückschließen. Die Vorteile dieses Verfahrens sind u. a. eine erhöhte Sensitivität, der Verbrauch sehr geringer Mengen an Probenmaterial (1-2 $\mu \mathrm{g}$ RNA) und ein geringerer Zeitaufwand. Außerdem ist ein mehrfaches Auslesen der Microarray-Platten möglich.

Im Jahr 2010 führte die Arbeitsgruppe Orale Biologie und Geweberegeneration der Abteilung Poliklinik für Zahnärztliche Prothetik in Zusammenarbeit mit dem Transkriptomanalyselabor Göttingen unter Leitung von Frau Gabriela Salinas-Rister diese Microarray-Untersuchung durch. In dieser Untersuchung wurde ein Affymetrix GeneChip ${ }^{\circledR}$ Human Gene 1.0 ST Array ${ }^{9}$ verwendet. Auf diesem GeneChip ${ }^{\circledR}$ ist jedes Gen mit bis zu 26 verschiedenen Gensonden vertreten, welche 25 Basen lang sind und in ihrer Lokalisation über das komplette Gen verteilt sind. Eine zusätzliche Sonde, die in nur einer Base an einer zentralen Stelle vom richtigen Codon abweicht, dient als Negativkontrolle und zur Berechnung des Hintergrundleuchtens (Whole-transcript Expression Analysis, Affymetrix, Inc. Santa Clara, USA). Die für das Microarray gewonnene mRNA

\footnotetext{
${ }^{9}$ Affymetrix, Inc, Santa Clara, CA, USA
} 
wurde in cDNA umgeschrieben. Die cDNA wurde bei diesem Prozess aus biotinylierten Nukleotiden generiert.

Die Analyse und Auswertung der Daten erfolgte unter Verwendung der Affymetrix Microarray Suite 5.0 und dem Affymetrix Data Mining Tool 3.0. Die statistische Bearbeitung der Daten erfolgte mit dem Limma-Package und dem empirischen Bayesschen-Verfahren. Die Ermittlung der p-Werte und der FDR (False Discovery Rate) erfolgte nach der Benjamini-Hochberg-Prozedur. Der komplette Datensatz des Microarrays wurde auf die GEO-Datenbank (Gene Expression Omnibus) hochgeladen und kann dort unter der Zugangsnummer GSE57631 eingesehen werden.

(http://www.ncbi.nlm.nih.gov/geo/query/acc.cgi?acc=GSE57631) 


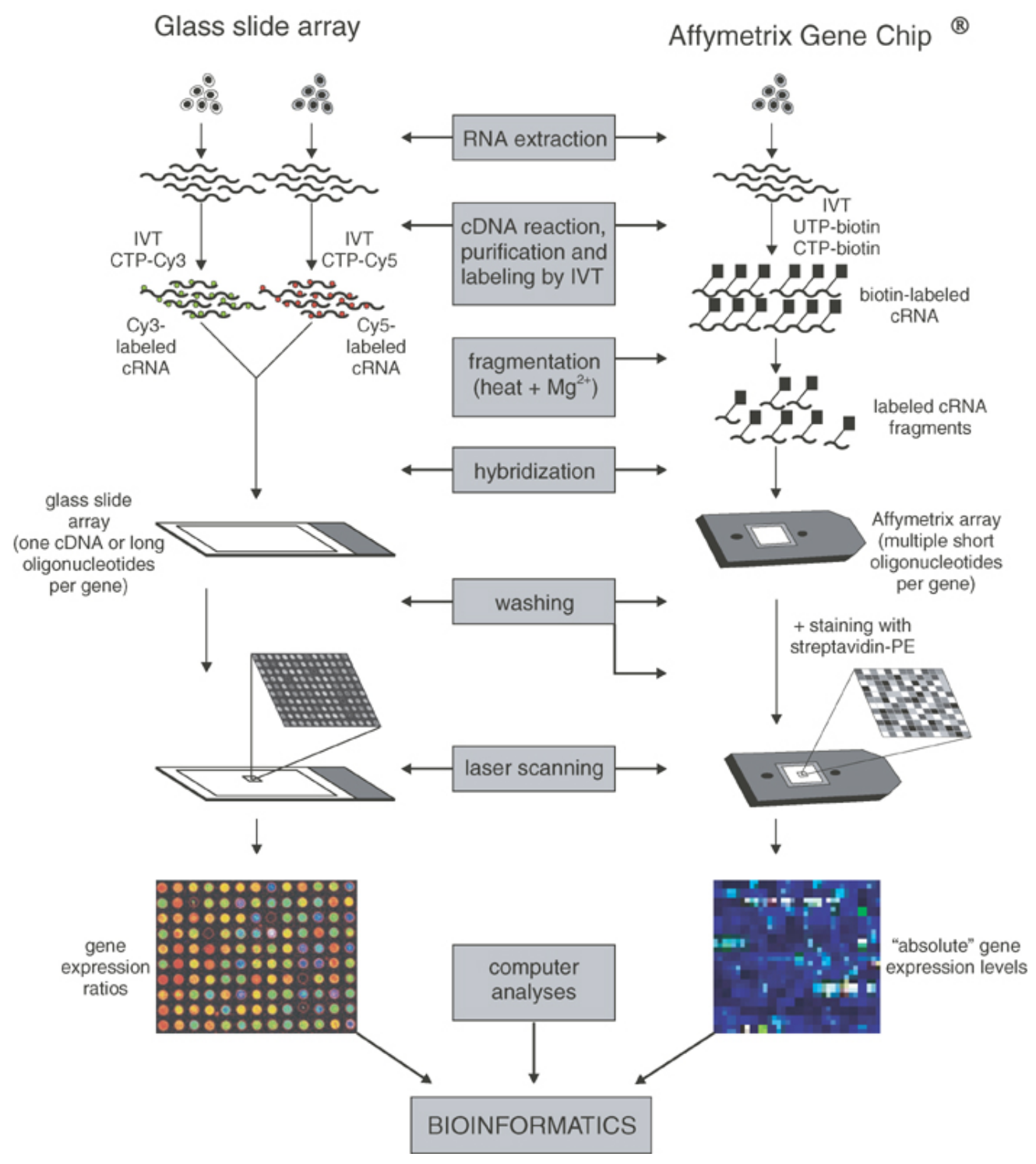

Abbildung 2.1: Darstellung der unterschiedlichen Microarray Techniken (Staal et al. 2003, S.1325). Der Abdruck/ die Verwendung erfolgt mit freundlicher Genehmigung von J.J.M. van Dongen, Dept. of Immunology, Erasmus MC und der Nature Publishing Group. 


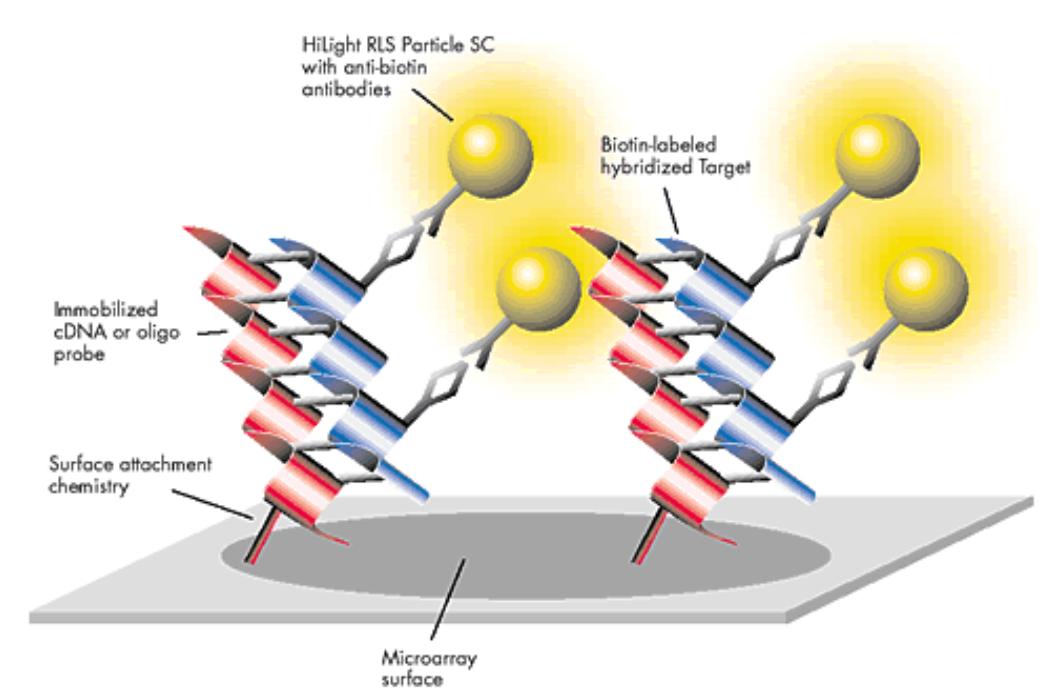

Abbildung 2.2: Schematische Darstellung des Prinzips der Biotinylierung (http://www.ebiotrade.com/, Zugriff am 17.09.14)

\subsection{Reverse-Transkriptase quantitative Real-Time PCR (RT-qPCR)}

\subsubsection{Allgemeines zur Methode}

Um die Ergebnisse der Microarray-Untersuchung zu verifizieren, wurden mit einer Auswahl an Genen RT-qPCRs durchgeführt. Erstmalig erwähnt wurde die Technik der PCR 1971 im Journal of Molecular Biology von Kleppe et al. (Kleppe et al. 1971). Damals wurde dieser Bekanntmachung jedoch keine große Aufmerksamkeit zuteil. Erst Kary Mullis, welcher in Emeryville, Kalifornien, für die Firma Cetus Corporation arbeitete, machte 1983 die Methode weltweit bekannt und erhielt dafür 1993 den Nobelpreis in Chemie (Nicholl 2008; Rabinow 1996). Der Name PCR steht im Englischen für Polymerase chain reaction (dt. Polymerase-Kettenreaktion). Die Hauptbestandteile einer PCR sind sowohl ein als Schablone dienender DNA-, cDNA- oder RNA-Strang als auch zwei Primer. Einer dieser zwei Primer ist für einen bestimmten Bereich in 3'-5'-Richtung komplementär zu einem Einzelstrang der DNA-Doppelhelix und der zweite Primer komplementär zu einem bestimmten Bereich des entgegengesetzten Strangs. Dadurch wird der zu amplifizierende Bereich definiert. Außerdem wird eine Polymerase benötigt, ein Enzym, welches an den Einzelstrang-Primer-Komplex bindet und die Replikation einleitet. Heutzutage wird zu 
diesem Zweck die Taq-Polymerase verwendet. Dieses Enzym wird aus dem Bakterium Thermus aquaticus isoliert. Dieses Bakterium ist ein wärmeliebendes Bakterium und lebt in heißen Quellen. Seine Enzyme arbeiten bei Temperaturen bis über $90^{\circ} \mathrm{C}$, was man sich für die moderne Durchführung der PCR zunutze macht und was die Durchführung dieser sehr vereinfacht und beschleunigt. Vor der Entdeckung der Taq-Polymerase im Jahr 1976 musste nach jedem PCR-Zyklus erneut Polymerase zugegeben werden.

Außerdem benötigt man für die Durchführung Desoxyribonukleotidtriphosphate, die Bausteine für den von der DNA-Polymerase neu synthetisierten DNA-Einzel- bzw. Doppelstrang. Des Weiteren sind geeignete Pufferlösungen und Magnesium-Ionen nötig. Der Vorgang der PCR besteht zum größten Teil aus drei aufeinanderfolgenden Einzelschritten in Form von Temperaturänderungen, die sich 20- bis 40-mal wiederholen. Im ersten Schritt wird die DNA denaturiert. Das bedeutet, die Probe wird auf bis zu $98^{\circ} \mathrm{C}$ erhitzt und die Doppelhelix wird dabei in komplementäre Einzelstränge aufgetrennt. Im zweiten Schritt wird die Probe auf 50 bis $65^{\circ} \mathrm{C}$ temperiert, was es den Primern erlaubt, sich an die DNA-Einzelstränge anzulagern. Im dritten Schritt wird die Probe auf die Temperatur erhöht, bei welcher die DNA-Polymerase am besten arbeiten kann. Das sind üblicherweise $72^{\circ} \mathrm{C}$.

Bisher wurde eine Vielzahl an Varianten der PCR-Technik entwickelt. Moderne Geräte erlauben mittlerweile die quantitative Bestimmung einer ausgewählten Gensequenz in Echtzeit. Verfahren mit dieser Technik bekommen den Zusatz „Real-Time“ bzw. die Abkürzung „, “ im Namen. Die heute am häufigsten verwendeten Methoden sind die quantitative Real-Time PCR (qPCR) und die Reverse-Transkriptase qPCR (RT-qPCR) (Bustin et al. 2009). Für die vorliegende Arbeit wurde das Verfahren der Reverse-TranskriptaseqPCR (RT-qPCR), sprich eine Echtzeitquantifizierung (Real-Time), angewendet. Um eine Echtzeitdetektion der Produkte zu erlauben, muss ein detektierbarer Farbstoff vorhanden sein. In diesem Versuch diente dazu das SYBR ${ }^{\circledR}$ Green ${ }^{10}$. SYBR ${ }^{\circledR}$ Green ist ein Fluoreszenzfarbstoff, der direkt an doppelsträngige DNA bindet. In der qPCR ist die Menge an neu gebildeter DNA daher proportional zur Signalstärke, die durch das SYBR $^{\circledR}$ Green verursacht wird. Die für den Einsatz fertig gemischte Lösung enthält neben SYBR ${ }^{\circledR}$ Green die benötigte Taq-Polymerase, außerdem Magnesiumchlorit, die Nukleotide dGTP, dATP, dCTP, dUTP und weitere Bestandteile, welche beim Hersteller eingesehen werden können.

\footnotetext{
${ }^{10}$ Platinum ${ }^{\circledR}$ SYBR ${ }^{\circledR}$ Green qPCR SuperMix-UDG, Invitrogen by Life Technologies
} 


\subsubsection{RT-qPCR Protokoll}

Die Gene für die PCR-Untersuchung wurden nach Relevanz für die zu diskutierende Fragestellung ausgewählt. Die ausgewählten Gene repräsentieren jeweils die Gruppe der Entzündungsmediatoren, der Entzündungsmarker, der Matrix-Metalloproteinasen, der Inhibitoren der Matrix-Metalloproteinasen, der EZM-Proteine, der Knochenmarker, der Stammzellmarker und der Wachstumsfaktoren. Genau genannt sind das: IL8, CD24, MMP1, MMP13, TIMP1, TIMP3, COL9A1, COL1A1, BGLAP, OPG (TNFRSF11B), RUNX2, SOX2, FGF8 und FGF18.

Für die RT-qPCR-Untersuchung wurde dasselbe Genmaterial verwendet wie für die Microarray-Untersuchung. Die mRNA wurde mit einem Quiagen Reverse Transcriptase $K i t^{11}$ in cDNA umgeschrieben. Die PCR wurde in einem Eppendorf PCR Cycler in 96 Well Plates à $10 \mathrm{ml}$ durchgeführt. Die cDNA-Proben lagerten während der Versuche bei $-20^{\circ} \mathrm{C}$. Als Referenz-Gen diente $\beta 2$-Mikroglobulin (B2M). B2M steht in Zusammenhang mit dem Haupthistokompatibilitätskomplex Klasse-I (eng. MHC-I), der auf der Oberfläche fast aller menschlichen Zellen mit einem Zellkern gefunden werden kann (Warrington et al. 2000).

Die RT-qPCR für die Patientenproben mit den oben genannten Genen wurden in drei mal drei Durchgängen an jeweils unterschiedlichen Tagen durchgeführt. Die Proben wurden mit Eppendorf- und ErgoOne-Pipetten pipettiert. Es kamen 96-Well-PCR-Platten der Firma Biozym $^{12}$ zur Verwendung, welche vor Beginn der Versuche mit einer Microseal $B$ Adhesive Folie ${ }^{10}$ versiegelt wurden. Kurz vor der Verwendung wurden nur diejenigen Wells mit einem Skalpell frei geschnitten, die befüllt werden sollten. Nach der Befüllung wurden die entsprechenden Wells mit Optical Flat Caps $^{10}$ verschlossen. Für die qPCR Untersuchung wurde das HotStar Taq Polymerase Kit der Firma Qiagen verwendet. Ein Master-Mix-Ansatz wurde zu Beginn in einem 1,5 ml E-Cup angesetzt. Von diesem Mix wurden dann in die jeweiligen Wells $9 \mu 1$ gegeben. Die Zusammensetzung des Master-Mix bestand aus $5 \mu$ l SYBR-Green-Ansatz, welcher die Polymerase, die dNTP (10 mM) und den 10-fach PCR-Puffer (15 mM $\left.\mathrm{MgCl}_{2}\right)$ enthält. Außerdem enthalten sind $2 \mu 1$ RNAse-freies Wasser und $2 \mu 1$ Primermix (10 pmol/ $\mu 1 /$ Primer), bestehend aus forward und reverse Primer. Als nächster Schritt folgte nun die Befüllung der Wells mit jeweils $9 \mu 1$ Master-Mix. In jedes der befüllten Wells wurden $1 \mu 1$ der zu untersuchenden cDNA ( $1 \mathrm{ng} / \mu \mathrm{l})$ gegeben, sodass sich in jedem Well eine Gesamtmenge von $10 \mu \mathrm{l}$ befand.

\footnotetext{
${ }^{11}$ QIAGEN - Qiagen Str. 1, 40724 Hilden, Deutschland

${ }^{12}$ Biozym Scientific GmbH - Steinbrinksweg 27, 31840 Hessisch Oldendorf, Deutschland
} 
Danach wurden die Well-Platten kurz abzentrifugiert, um zu gewährleisten, dass der gesamte Ansatz im unteren Teil des Wells versammelt war. Als nächster Schritt folgte das Einsetzen der Well-Platte in den Eppendorf Mastercycler und die Durchführung der qPCR.

\begin{tabular}{lc} 
Substanzen & Menge (in $\mu \mathrm{l})$ \\
\hline SYBR Green & 5 \\
DEPC Wasser & 2 \\
Primermix $(10 \mathrm{pmol} / \mu \mathrm{l})$ & 2 \\
\hline cDNA $(1 \mathrm{ng} / \mu \mathrm{l})$ & 1 \\
\hline \hline Gesamtvolumen: & $10 \mu \mathrm{l}$
\end{tabular}

Tabelle 2.1: Pipettieransatz der qPCR pro Well: Master-Mix + cDNA

\begin{tabular}{llll} 
Phase & Temperatur & Zeit & Zyklen \\
\hline Initiale Aktivierung & $95^{\circ} \mathrm{C}$ & 5 Minuten & $1 \mathrm{x}$ \\
\hline Denaturierung & $95^{\circ} \mathrm{C}$ & 15 Sekunden & \\
Annealing & 53 bis $63^{\circ} \mathrm{C}$ & 15 Sekunden & $45 \mathrm{x}$ \\
Elongation & $72^{\circ} \mathrm{C}$ & 20 Sekunden & \\
\hline Finale Extension & $72^{\circ} \mathrm{C}$ & 10 Minuten & $1 \mathrm{x}$ \\
\hline Schmelzkurve & Ann.-Temp. 40 bis $95^{\circ} \mathrm{C}$ & 15 Minuten & $1 \mathrm{x}$ \\
& in $0,2^{\circ} \mathrm{C}$ Schritten & je 3 Sekunden & \\
\hline
\end{tabular}

Tabelle 2.2: Protokoll der qPCR

\subsubsection{Statistische Auswertung}

Zur statistischen Auswertung wurde für diese Arbeit ein Verfahren nach M. W. Pfaffl angewendet. Bei dieser Methode werden vier Datensätze gegeneinander normalisiert. Es dient ein sog. Housekeeping-Gen als Referenz-Gen. Das Referenz-Gen sollte in allen Zellen des Körpers oder zumindest im zu untersuchenden Gewebe zu jedem Zeitpunkt und unter unterschiedlichen Gegebenheiten gleich stark exprimiert sein. Eine interne oder externe Regulierung sollte demnach ausgeschlossen sein. Das $\beta 2$-Mikroglobulin (B2M) diente als Referenz-Gen. Ein weiteres Detail dieser Normalisierung ist, dass neben dem zu untersuchenden Gewebe ein weiteres Gewebe oder weitere Zellen auf die relevanten Gene plus das Referenz-Gen untersucht werden. In dieser Arbeit dienten in vitro gezogene Osteozyten als Kontrolle. Es werden demnach pro untersuchtem Gen vier Werte gegeneinander normalisiert. Dies sind die Expressionwerte des untersuchten Gens für das untersuchte Gewebe plus die Expressionswerte für die Osteozyten. Dazu kommen 
jeweils die Expressionswerte des Referenz-Gens für das zu untersuchende Gewebe und die Osteozyten. Dadurch, dass diese Werte in ein Verhältnis zueinander gesetzt werden, können Fehler bzw. Ungleichheiten, welche parallel in den vier Datensätzen auftreten, gegengerechnet und so genauere Ergebnisse erzielt werden.

Für diese Berechnungen wurde zuvor eine Effizienzbestimmung der verwendeten Primer mit dem verwendeten Thermocycler durchgeführt. Die Effizienswerte lagen im Bereich von 1,85 bis 2,0. In der durchgeführten Normalisierung nach Pfaffl wurde ein Effizienzwert von 2,0 angewandt.

\subsubsection{Primerdesign}

Primer sind ein essenzieller Bestandteil jeder PCR. Sie geben den zu amplifizierenden Genabschnitt eines Gens vor. Für einen ausgewählten Genabschnitt werden grundsätzlich zwei Primer benötigt. Einen in Sinn- und einen in Gegensinnrichtung laufenden Primer. Durch die Lokalisation der Primer auf der Aminosequenz wird die Länge des Replikates festgelegt. Das Design von Primern muss je nach Verwendungszweck bestimmten Richtlinien entsprechen, um ein möglichst gutes Ergebnis zu erzielen. Ein Teil der Primer für die durchgeführten qPCRs wurde eigens für diese Arbeit designt.

Für die Primer dieser Arbeit wurde eine Replikonlänge von 100 bis maximal 250 Basenpaaren gewählt. Das hat den Zweck, mögliche falsche Hybridisierungen zu minimieren und eine kurze Replikationszeit bei dennoch ausreichender Signalstärke zu erzielen. Die Länge der Primer wurde von 18 bis maximal 22 Basen gewählt, um eine kostengünstige Herstellung zu erlauben, ohne jedoch an Spezifität einzubüßen. Der Guanin- und CytosinGehalt der Oligonukleotidprimer wurde auf $40 \%$ bis $60 \%$ veranschlagt, um auf diesem Weg die Schmelz- und Annealing-Temperatur festzulegen und um eine genügend starke Wasserstoffbrückenbindung zwischen Oligonukleotid-Strang und DNA-Strang zu gewährleisten. Die Annealing-Temperatur wurde auf den Bereich von 55 bis $63^{\circ} \mathrm{C}$ festgelegt, um einen guten Mittelweg zwischen guter Spezifität bei niedriger Temperatur und geringer Fehlhybridisierung bei hohen Temperaturen zu erzielen. Am 3'-Ende sollten im besten Falle ein bis zwei Cytosin- oder Guaninbasen sein, um eine gute Bindung und Elongation zu ermöglichen. Es sollten aber nicht mehr als drei $\mathrm{G}$ oder $\mathrm{C}$ am $3^{6}$-Ende platziert werden, da sonst das $3^{`}$ - zu ,klebrig“ wird und unspezifisch bindende Primer stabilisiert werden können. Außerdem wurde darauf geachtet, dass die Primer nicht mit sich selbst hybridisieren können, folglich also keine Haarnadelschleifen oder Primerdimere entstehen. 
Die Aminosequenzen der gesuchten Gene bzw. Proteine für das Primerdesign wurden der NCBI-Webseite ${ }^{13}$ entnommen. Zum Entwerfen der Primer wurden die Aminosequenzen der entsprechenden Gene in das Onlineprogramm Primer $3{ }^{14}$ kopiert. Die oben genannten Anforderungen an das Primerdesign wurden im Onlineprogramm Primer3 eingegeben. Die vorgeschlagenen Primer wurden dann mit dem Basic Local Alignment Search Tool $^{15}$ von der NCBI-Webseite auf ihre Spezifität von Primer- zu cDNA-Sequenz getestet. Nur Primer mit einer 100\%igen Spezifität für das gewünschte Gen und einer Spezifität für ein anderes Gen von unter $70 \%$ wurden ausgewählt.

\footnotetext{
${ }^{13}$ NCBI Nucleotide: http://www.ncbi.nlm.nih.gov/nuccore

${ }^{14} \mathrm{http}: / /$ primer3.ut.ee/

${ }^{15}$ BLAST ${ }^{\circledR}$,http://blast.st-va.ncbi.nlm.nih.gov/Blast.cgi
} 


\begin{tabular}{|c|c|c|c|c|c|}
\hline Transcript & Forward Primer 5' -3 ' & Reverse Primer 5'-3' & Länge [Bp] & Annealing $\mathrm{T}\left[{ }^{\circ} \mathrm{C}\right]$ & Accession Number (GenBank) \\
\hline BGLAP & ACA CTC CTC GCC CTA TTG & GAT GTG GTC AGC CAA CTC & 250 & 61,6 & NM_199173.4 \\
\hline CD24 & GAA ATA AAG GAT GGG ATT GTG G & TGT CGA AAC AAT ACG TTG AGG A & 166 & 60 & NM_013230.2 \\
\hline Col I & TTC CCC CAG CCA CAA AGA GTC & CGT CAT CGC ACA ACA CCT & 261 & 61 & NM_000088 \\
\hline COL IX & GTG TTG CTG GTG AAA AGG GT & GGG ATC CCA CTC CTA AT & 152 & $60 / 62,7$ & X54412 \\
\hline FGF8 & CGC TTC GAG TTC CTC AAC TAC & CCC AAC AGC AAA CAA TAT CAA C & 236 & 53 & NM_006119.4 \\
\hline FGF18 & AAC AAA CTC CСС CТА АCT ТTC C & AGT CAC GGA AGG TCG ATA GC & 243 & 63 & NM_003862.2 \\
\hline IL8 & TCT GGA CCC CAA GGA AAA C & CAT CTG GCA ACC CTA CAA CA & 183 & 63 & NM_0000584 \\
\hline MMP1 & CTG AAG GTG ATG AAG CAG CC & AGT CCA AGA GAA TGG CCG AG & 429 & 61 & NM_2421.3 \\
\hline MMP13 & CTA TGG TCC AGG AGA TGA A & AGA GTC TTG CCT GTA TCC T & 390 & 63 & NM_002427.3 \\
\hline OPG & ACA ATG AAC AAG TTG CTG TGC T & GCT GAT GAG AGG TTT CTT CGT C & 118 & 58 & U94332 \\
\hline RUNX2 & TTC CAG ACC AGC AGC ACT C & CAG CGT CAA CAC CAT CAT T & 181 & 63 & NM_004348 \\
\hline SOX2 & GCC GAG TGG AAA CTT TTG TCG & GCA GCG TGT ACT TAT CCT TCT T & 155 & 61,6 & NM_003106.3 \\
\hline TIMP1 & AAT TCC GAC CTC GTC AT & GCA GTT TTC CAG CAA TGA G & 230 & 56 & NM_003254 \\
\hline TIMP3 & TGC CCT TCT CCT CCA ATA CA & СТТ ССТ ТСС СТС ССТ САС ТC & 197 & 63 & NM_000362 \\
\hline
\end{tabular}

Tabelle 2.3: Oligonukleotidprimer für die qPCR 


\subsubsection{Primersynthese und -überprüfung}

Die designten Primer wurden bei der Firma Eurofins ${ }^{16}$ zur Synthese in Auftrag gegeben. Der Synthesemaßstab betrug $0.01 \mu$ mol. Die als Pellet gelieferten Primer wurden auf eine Konzentration von $100 \mathrm{pmol} / \mu \mathrm{l}$ aliquotiert und bei $-20^{\circ} \mathrm{C}$ gelagert. Für den Einsatz bei der qPCR wurden die Primer weiter verdünnt auf eine Konzentration von $10 \mathrm{pmol} / \mu 1$.

\subsubsection{Gradienten-PCR}

Um die optimale Annealing-Temperatur und Spezifität der Primer zu ermitteln, wurde eine Gradienten-PCR durchgeführt. Dazu wurden für jeden Primer acht Temperaturen getestet. Für jeden Primer dienten sowohl cDNA aus Osteozyten als auch aus chondrogenen Progenitorzellen zur Untersuchung. Der Temperaturgradient verlief von 45 bis $63^{\circ} \mathrm{C}$. Die PCR-Platte wurde jedoch jeweils nur von Position 5 nach 12 belegt. Das heißt, es wurde letztendlich ein Gradient von $50,7^{\circ} \mathrm{C}$ bis $63^{\circ} \mathrm{C}$ durchgeführt. Die Einzelschritte waren: $50,7^{\circ} \mathrm{C}-53,1^{\circ} \mathrm{C}-55,5^{\circ} \mathrm{C}-57,9^{\circ} \mathrm{C}-60,0^{\circ} \mathrm{C}-61,6^{\circ} \mathrm{C}-62,7^{\circ} \mathrm{C}-63^{\circ} \mathrm{C}$. Der Versuchsansatz der Proben stellte sich wie folgt dar:

\begin{tabular}{lc} 
Substanzen & Menge (in $\mu \mathrm{l})$ \\
\hline SYBR Green & 5 \\
DEPC Wasser & 2 \\
Primermix $(10 \mathrm{pmol} / \mu \mathrm{l})$ & 2 \\
\hline cDNA $(1 \mathrm{ng} / \mu \mathrm{l})$ & 1 \\
\hline \hline Gesamtvolumen: & $10 \mu \mathrm{l}$
\end{tabular}

Tabelle 2.4: Pipettieransatz der Gradienten-PCR pro Well

Die Gesamtmenge des Probenvolumens betrug $10 \mu 1$. Mit einem Mastercycler realplex $2 \mathrm{~S}^{17}$ wurde dann die qPCR durchgeführt. Im Ganzen wurden 45 Zyklen durchlaufen. Als einmalige Schritte erfolgten die initiale Denaturierung der DNA für 5 min bei $95^{\circ} \mathrm{C}$ sowie die finale Extension für $10 \mathrm{~min}$ bei $72^{\circ} \mathrm{C}$ und die Schmelzkurve.

\footnotetext{
${ }^{16}$ Eurofins MWG Synthesis GmbH, www. Eurofinsgenomics.com

${ }^{17} \mathrm{Fa}$. Eppendorf AG, Hamburg, Germany
} 


\begin{tabular}{llll} 
Phase & Temperatur & Zeit & Zyklen \\
\hline Initiale Aktivierung & $95^{\circ} \mathrm{C}$ & 5 Minuten & $1 \mathrm{x}$ \\
\hline Denaturierung & $95^{\circ} \mathrm{C}$ & 15 Sekunden & \\
Annealing & unterschiedlich & 15 Sekunden & $45 \mathrm{x}$ \\
Elongation & $72^{\circ} \mathrm{C}$ & 20 Sekunden & \\
\hline Finale Extension & $72^{\circ} \mathrm{C}$ & 10 Minuten & $1 \mathrm{x}$ \\
\hline Schmelzkurve & Ann.-Temp. 40 bis $95^{\circ} \mathrm{C}$ in & 20 Minuten & $1 \mathrm{x}$ \\
& $0,2^{\circ} \mathrm{C}$ Schritten & je 5 Sekunden & \\
\hline
\end{tabular}

Tabelle 2.5: Protokoll der Gradienten-PCR

Nach der Auswertung der Schmelzkurven für die jeweiligen Primer wurde die Temperatur mit der höchsten Extinktion, sprich jene mit dem höchsten homogenen Peak, als Annealing-Temperatur für die weiteren qPCRs ausgewählt. Um die Spezifität der Primer in vivo zu prüfen, wurden die Produkte der beiden besten Proben eines jeden Primers an die Firma Seqlab ${ }^{18}$ in Göttingen geschickt. Dort wurde eine Sequenzierung nach der Methode von Sanger durchgeführt (Sanger und Coulson 1975), um zu ermitteln, ob die gewonnenen Produkte den gewünschten entsprechen. Die erhaltenen Sequenzen wurden nochmals mithilfe des Blastprogramms der NCBI-Website ${ }^{19}$ überprüft, ob das PCRProdukt dem gesuchten Gen entspricht. Nachdem alle diese Untersuchungen mit einem positiven Ergebnis abgeschlossen werden konnten, wurden die Primer als einsatzbereit für die qPCR-Untersuchung angesehen.

\footnotetext{
${ }^{18}$ Sequence Laboratories Göttingen GmbH Hannah-Vogt-Str. 137085 Göttingen, info@ seqlab.de

${ }^{19}$ http://www.ncbi.nlm.nih.gov/
} 
KAPITEL 3

Ergebnisse

\subsection{Einleitung}

Im Folgenden sind 14 Gene mit ihren Expressionsmustern nach dem Microarray- und qPCR-Verfahren dargestellt: IL8, CD24, MMP1, MMP13, TIMP1, TIMP3, COL9A1, COL1A1, BGLAP, OPG (TNFRSF11B), RUNX2, SOX2, FGF8 und FGF18.

Die Darstellung der Ergebnisse ist nach folgendem Schema aufgebaut: Die oberen ersten beiden Graphen stellen die Ergebnisse des Microarray dar, die unteren beiden Graphen die Ergebnisse der qPCR. Insgesamt wurden sieben verschiedene Proben von sieben Patienten untersucht. Davon waren zwei von gesundem und fünf von entzündetem periimplantärem Gewebe.

Für die Verifizierung der Ergebnisse mit der qPCR war eine der beiden gesunden Proben leider nicht mehr geeignet. Daher ist in den Ergebnissen der qPCR nur eine gesunde Probe zu sehen. Für Pat. 19 standen für einige qPCR-Versuche nicht mehr genügend verwertbares Genmaterial zur Verfügung, weshalb für Pat. 19 nicht für alle untersuchten Gene Ergebnisse vorliegen.

Es sind außerdem Graphen mit Übersichten zu ausgewählten Gruppen von Interleukinen, CD-Molekülen, Kollagenen und Transkriptionsfaktoren aus den Ergebnissen der 
Microarray-Untersuchung aufgeführt.

In den folgenden Graphen sind die Ergebnisse der gesunden Proben mit healthy und die erkrankten mit diseased bezeichnet. 


\subsection{IL-8}

Das Ergebnis des Microarray zeigt, dass das Interleukin-8 Gen im entzündeten periimplantären Gewebe signifikant stärker exprimiert ist. Der Mittelwert sowie alle Einzelproben des entzündeten Gewebe weisen höhere Werte im Vergleich zum gesunden auf. Besonders Pat. 19 und 21 zeigen hohe Expressionsraten. Das Resultat der PCRVersuche zeigt im Durchschnitt keine signifikant höhere Expression von Interleukin-8 im entzündeten Gewebe. Jedoch ist definitiv eine Tendenz in diese Richtung zu erkennen. Die einzelnen Ergebnisse aus den Proben der entzündlichen Gewebe weisen zum Teil große Unterschiede in ihren Expressionsraten auf. Die Werte von Pat. 11 und Pat. 21 sind fast gleich bis geringer im Vergleich zum gesunden Gewebe. Dagegen zeigen die Expressionsraten der Patienten 18, 19 und 20 höhere Werte, die das Vielfache der Werte von Pat. 11 und 21 aufweisen als auch von der gesunden Probe von Pat. 15.
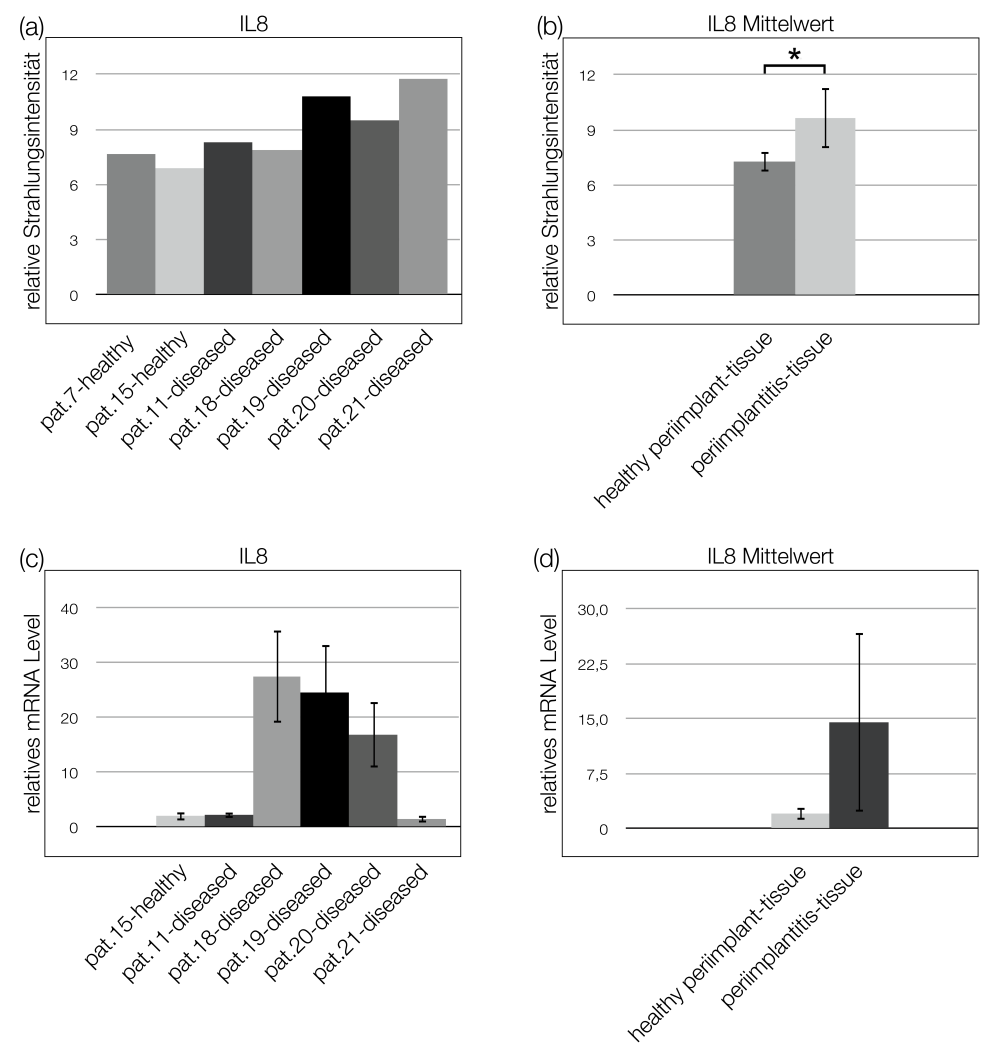

Abbildung 3.1: (a-d) Zu sehen ist die Genexpression von Interleukin-8 im Vergleich Gesund (healthy) mit Erkrankt (diseased) mit Microarray und qPCR-Technik. (a) Zu sehen sind die Ergebnisse des Microarray mit den Einzelwerten der Patienten und (b) die Darstellung der Mittelwerte. (c) Zu sehen sind die Ergebnisse der qPCR mit den Einzelwerten der Patienten und (d) die Darstellung der Mittelwerte. 


\subsection{Weitere Interleukine}

Die Ergebnisse des Microarray zeigen, dass beim Vergleich der Genexpression der Interleukine zwischen der erkrankten und gesunden Patientengruppe die Werte für Interleukin-1, -6 und -8 im erkrankten Gewebe über den Werten im gesunden liegen. Dabei sind Interleukin-1A und -1B am höchsten exprimiert und Interleukin-6 am niedrigsten. Interleukin-8 liegt in seiner Expressionsrate zwischen diesen beiden. Die Interleukine-2 bis -5 sowie Interleukin-10 und weitere sind in ihrer Expression im erkrankten Gewebe niedriger im Vergleich zum gesunden.

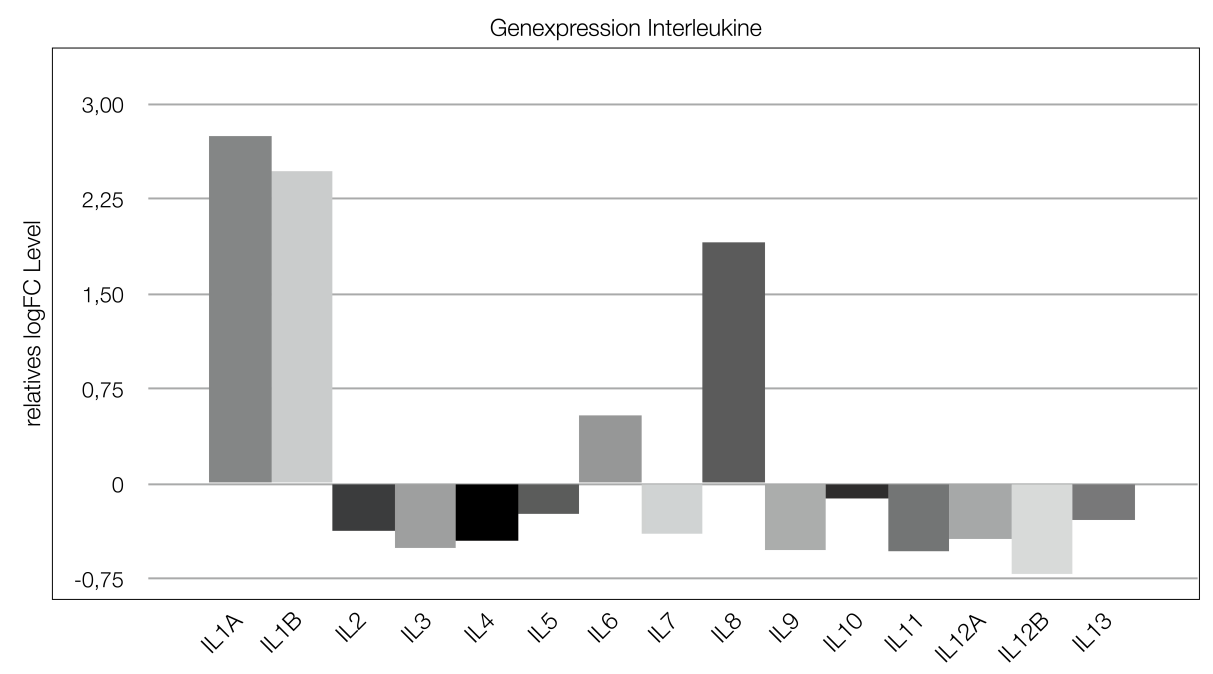

Abbildung 3.2: Zu sehen sind die Ergebnisse der Microarray-Untersuchung für die Interleukine IL1A (Interleukin-1 Alpha), IL1B (Interleukin-1 Beta), IL2 (Interleukin-2), IL3 (Interleukin-3), IL4 (Interleukin4), IL5 (Interleukin-5), IL6 (Interleukin-6), IL7 (Interleukin-7), IL8 (Interleukin-8), IL9 (Interleukin-9), IL10 (Interleukin-10), IL11 (Interleukin-11), IL12A (Interleukin-12 Alpha), IL12B (Interleukin-12 Beta) und IL13 (Interleukin-13). Relatives $\operatorname{logFc}$ Level = relative Ratio von Erkrankt gegenüber Gesund. 


\subsection{CD24}

CD24 ist ein Oberflächenprotein und wird besonders von reifen Granulozyten und BZellen exprimiert, es ist für die Vermittlung von Wachstums- und Differenzierungsstimuli an diesen Zellen verantwortlich. Nach den Ergebnissen des Microarray ist CD24 im entzündeten Gewebe signifikant höher exprimiert als im gesunden. Die Werte der erkrankten Patienten 11, 18, 19, 20 und 21 sind relativ homogen. Sowohl der Mittelwert als auch die Einzelwerte sind signifikant höher in ihrer Expression im Vergleich zum gesunden Gewebe. Die Ergebnisse für die Genexpression von CD24 nach der PCR-Methode weisen eine ähnliche Tendenz auf. Die höhere Exprimierung von CD24 im erkrankten gegenüber dem gesunden Gewebe ist gemittelt nicht signifikant. Die Ergebnisse für Pat. 19 und 20 sind im Vergleich zum gesunden Pat. signifikant höher. Die Exprimierung von CD24 für die Patienten 18 und 21 ist verglichen mit dem Gesunden signifikant niedriger. Pat. 11 zeigt keine Signifikanz.
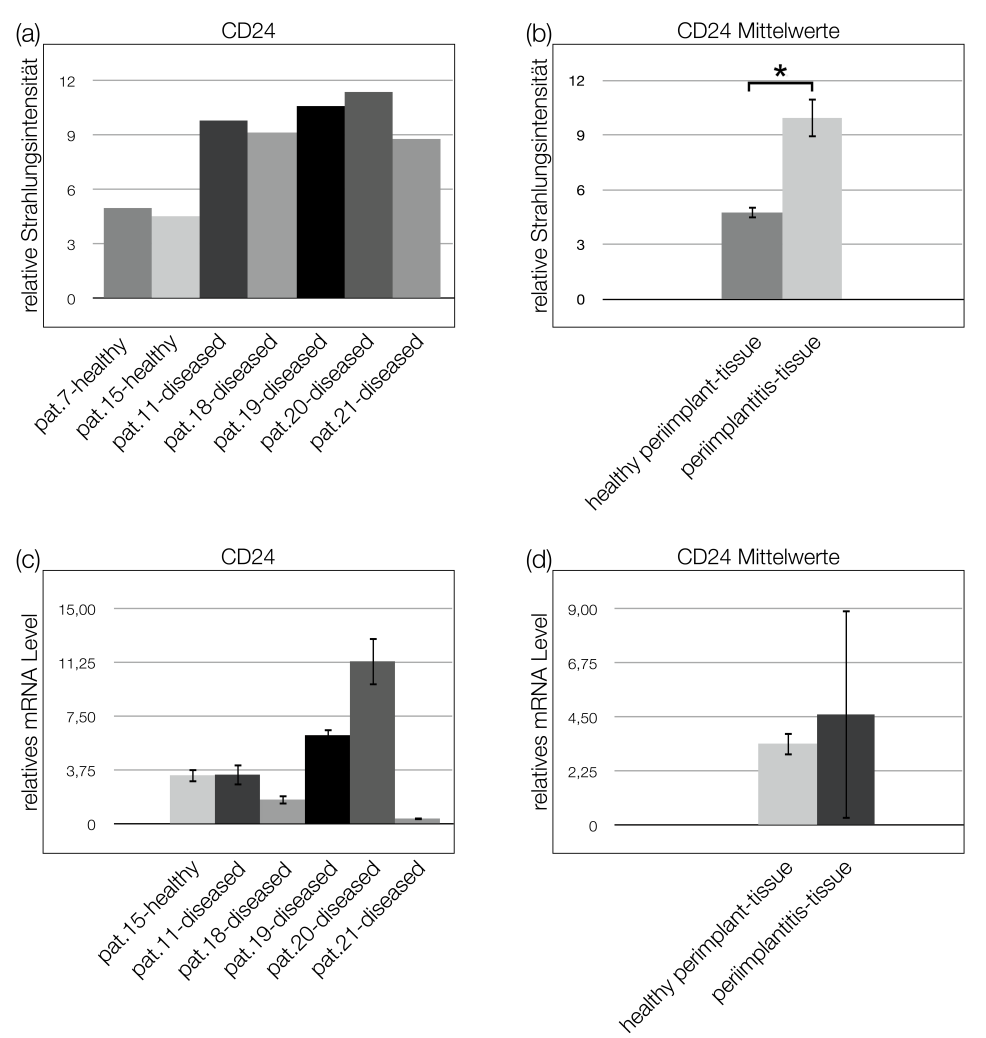

Abbildung 3.3: (a-d) Zu sehen ist die Genexpression von CD24 im Vergleich Gesund (healthy) mit Erkrankt (diseased) mit Microarray und qPCR-Technik. (a) Zu sehen sind die Ergebnisse des Microarray mit den Einzelwerten der Patienten und (b) die Darstellung der Mittelwerte. (c) Zu sehen sind die Ergebnisse der qPCR mit den Einzelwerten der Patienten und (d) die Darstellung der Mittelwerte. 


\subsection{Weitere CD-Moleküle}

Eine Auswahl von relevanten CD-Moleküle zeigt, dass neben CD24 die Moleküle CD9, 14, 97, 27, 79A und CD96 in ihrer Expression im entzündeten periimplantären Gewebe erhöht sind . CD5, 22, 8 und CD79B sind in ihrer Expression niedriger.

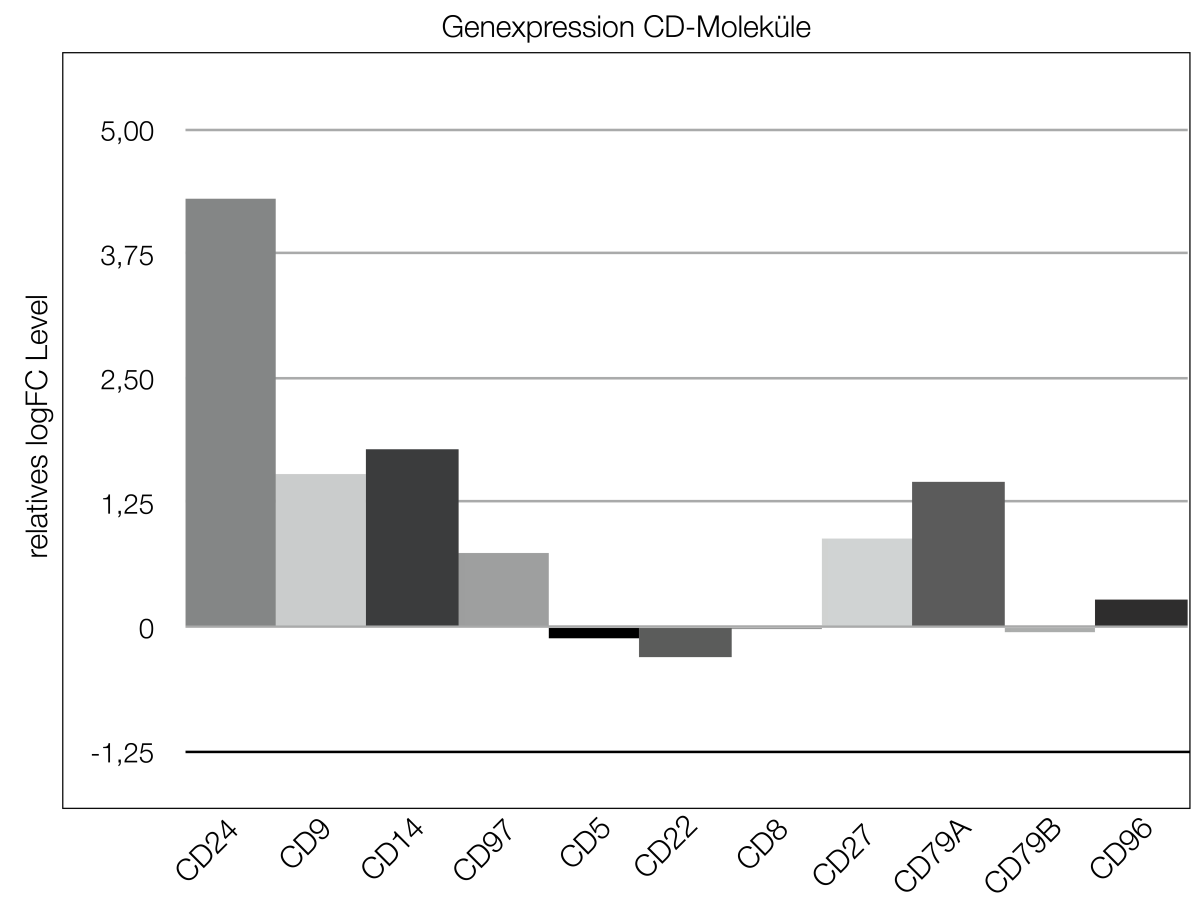

Abbildung 3.4: Zu sehen sind die Ergebnisse der Microarray-Untersuchung für CD24, CD9, CD14, CD97, CD5, CD22, CD8, CD27, CD79A, CD79B und CD96. Relatives logFC Level = relative Ratio von Erkrankt gegenüber Gesund. 


\subsection{MMP1}

Die Untersuchung der Genexpression von MMP1 in Gesund und Krank ergaben widersprüchliche Ergebnisse zwischen Microarray und PCR. Der Microarray zeigte im Mittelwert, dass im erkrankten Gewebe signifikant mehr MMP1 vorhanden ist als im gesunden. Auch die Einzelergebnisse der erkrankten Patienten zeigen alle erhöhte Expressionsraten. Pat. 18 und 21 weisen hierbei die höchsten Werte auf. Im Unterschied dazu, ergab die PCR entgegengesetzte Werte. Gemittelte als auch alle Einzelwerte des entzündeten Gewebe zeigen niedrigere Expressionsraten von MMP1 als das gesunde Gewebe auf. Die Ergebnisse der Patienten 18 und 20 haben dabei die niedrigsten und Pat. 19 hat die höchsten Werte.
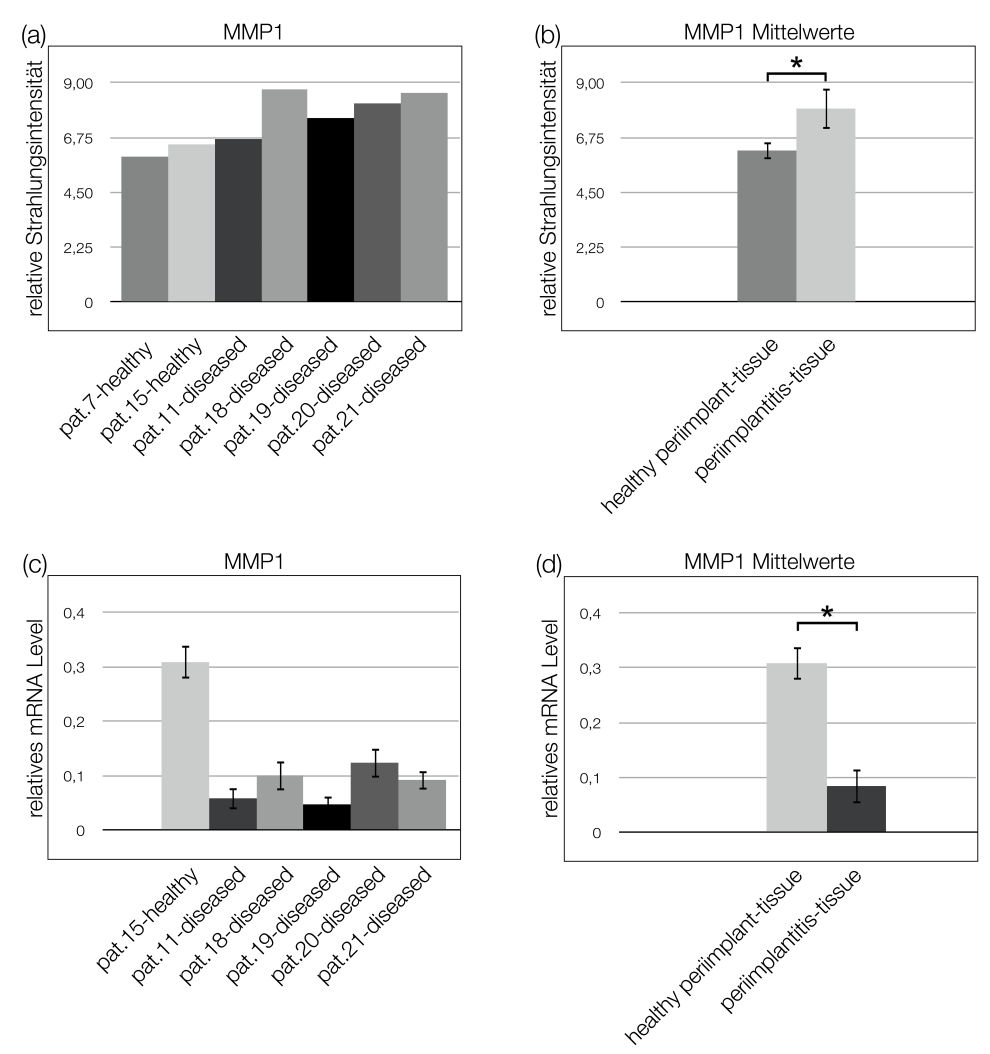

Abbildung 3.5: (a-d) Zu sehen ist die Genexpression von MMP1 im Vergleich Gesund (healthy) mit Erkrankt (diseased) mit Microarray und qPCR-Technik. (a) Zu sehen sind die Ergebnisse des Microarray mit den Einzelwerten der Patienten und (b) die Darstellung der Mittelwerte. (c) Zu sehen sind die Ergebnisse der qPCR mit den Einzelwerten der Patienten und (d) die Darstellung der Mittelwerte. 


\subsection{MMP13}

Ähnlich den Ergebnissen von MMP1 zeigen auch die Ergebnisse von MMP13 Widersprüche zwischen Microarray- und PCR-Daten. Wie MMP1 ist auch MMP13 nach den Microarray-Daten im entzündeten periimplantären Gewebe stärker exprimiert. Jedoch ist der Unterschied in der Expression im Mittel nicht signifikant. Dabei hat Pat. 19 den höchsten Wert. Die Resultate der PCR-Untersuchung zeigen ein gegensätzliches Bild. Sowohl der Mittelwert als auch alle Einzelwerte für die Genexpression von MMP13 im entzündeten Gewebe sind signifikant geringer als im Gesunden. Dabei sind die Werte von Pat. 19 unter den Erkrankten am höchsten.
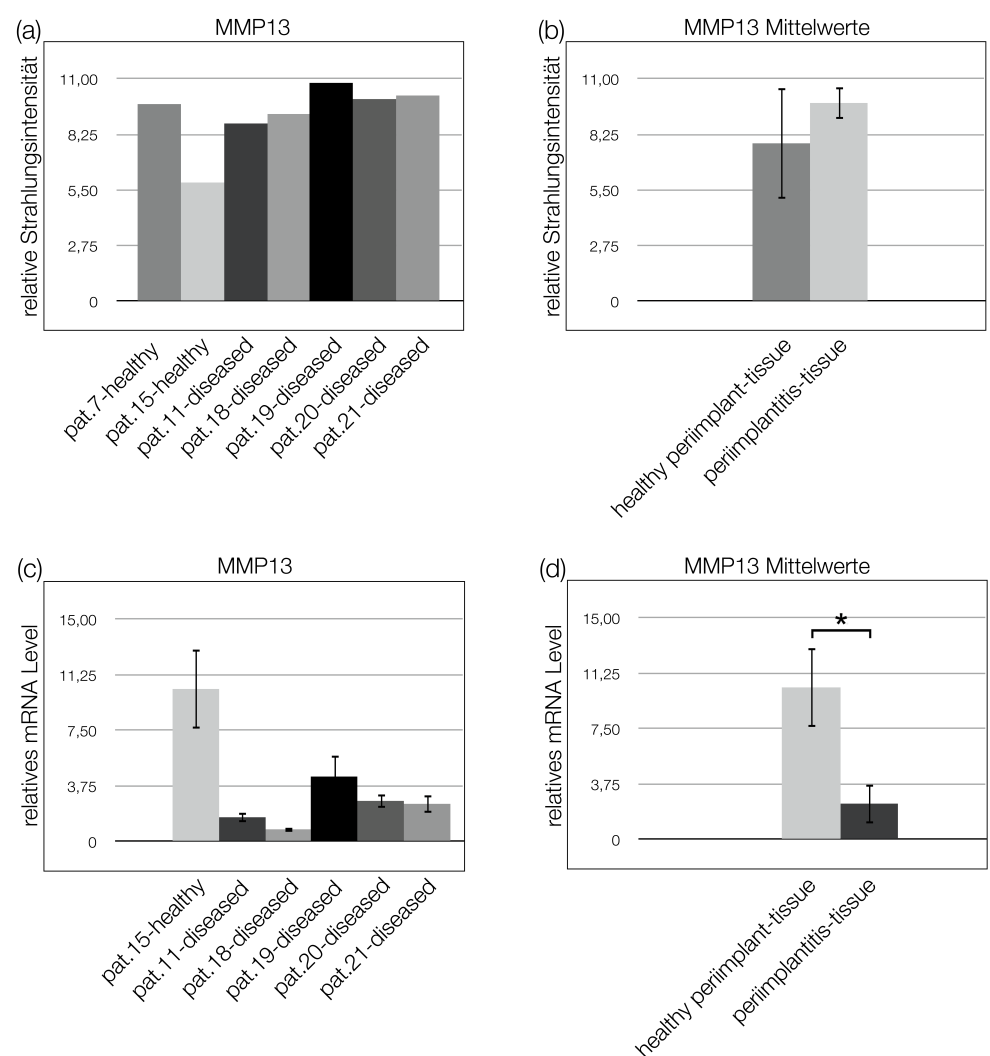

Abbildung 3.6: (a-d) Zu sehen ist die Genexpression von MMP13 im Vergleich Gesund (healthy) mit Erkrankt (diseased) mit Microarray und qPCR-Technik. (a) Zu sehen sind die Ergebnisse des Microarray mit den Einzelwerten der Patienten und (b) die Darstellung der Mittelwerte. (c) Zu sehen sind die Ergebnisse der qPCR mit den Einzelwerten der Patienten und (d) die Darstellung der Mittelwerte. 


\subsection{TIMP1}

Die Expression von TIMP1 ist, den Ergebnissen des Microarray nach, im erkrankten Gewebe stärker ausgeprägt. Der Mittelwert aus den erkrankten Proben ist signifikant größer als der aus den gesunden Proben. Auch alle Einzelwerte liegen in ihrer Expression über denen der gesunden Probe. Die Patienten 18 und 21 weisen die höchsten Werte auf. Im Gegensatz dazu zeigen die Ergebnisse der PCR-Versuche ein entgegengesetztes Verhältnis. Die Expression von TIMP1 ist im entzündeten periimplantären Gewebe signifikant geringer als im gesunden. Sowohl der Mittelwert als auch alle Einzelwerte der untersuchten Proben sind signifikant. Die Ergebnisse der Proben von Pat. 19 und 20 weisen dabei die niedrigsten Expressions-Werte auf.
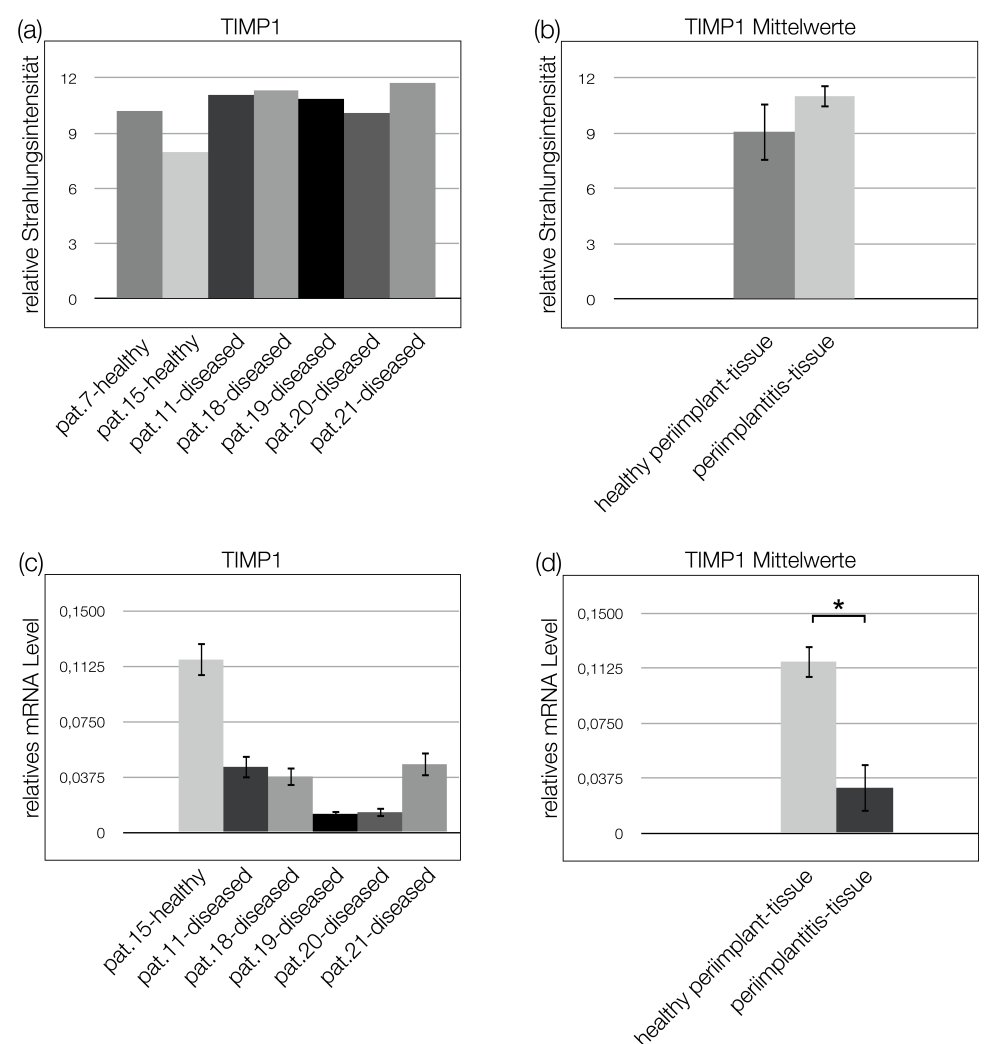

Abbildung 3.7: (a-d) Zu sehen ist die Genexpression von TIMP1 im Vergleich Gesund (healthy) mit Erkrankt (diseased) mit Microarray und qPCR-Technik. (a) Zu sehen sind die Ergebnisse des Microarray mit den Einzelwerten der Patienten und (b) die Darstellung der Mittelwerte. (c) Zu sehen sind die Ergebnisse der qPCR mit den Einzelwerten der Patienten und (d) die Darstellung der Mittelwerte. 


\subsection{TIMP3}

Die Ergebnisse des Microarray für TIMP3 zeigen, dass drei der Proben des entzündeten Gewebes (Pat. 11, 18 und 21) in ihren Expressionsraten über mindestens einer der gesunden Probe liegen. Die Werte der Periimplantitis-Proben von Pat. 19 und 20 liegen unter denen der gesunden Proben. Im Mittel ergibt sich eine leicht niedrigere Expression des entzündlichen Gewebes gegenüber dem gesunden. Jedoch ist dieses Ergebnis nicht signifikant. Das Resultat der PCR-Untersuchung zeigt eine ähnliche Tendenz auf. Alle Werte der Proben erkrankten Gewebes - bis auf die von Pat. 11 - sind in Ihrer Expression signifikant geringer als im gesunden Gewebe. Im Mittel ergibt sich jedoch keine signifikant geringere Expression von erkrankt im Vergleich zu gesund, lediglich eine Tendenz in diese Richtung.
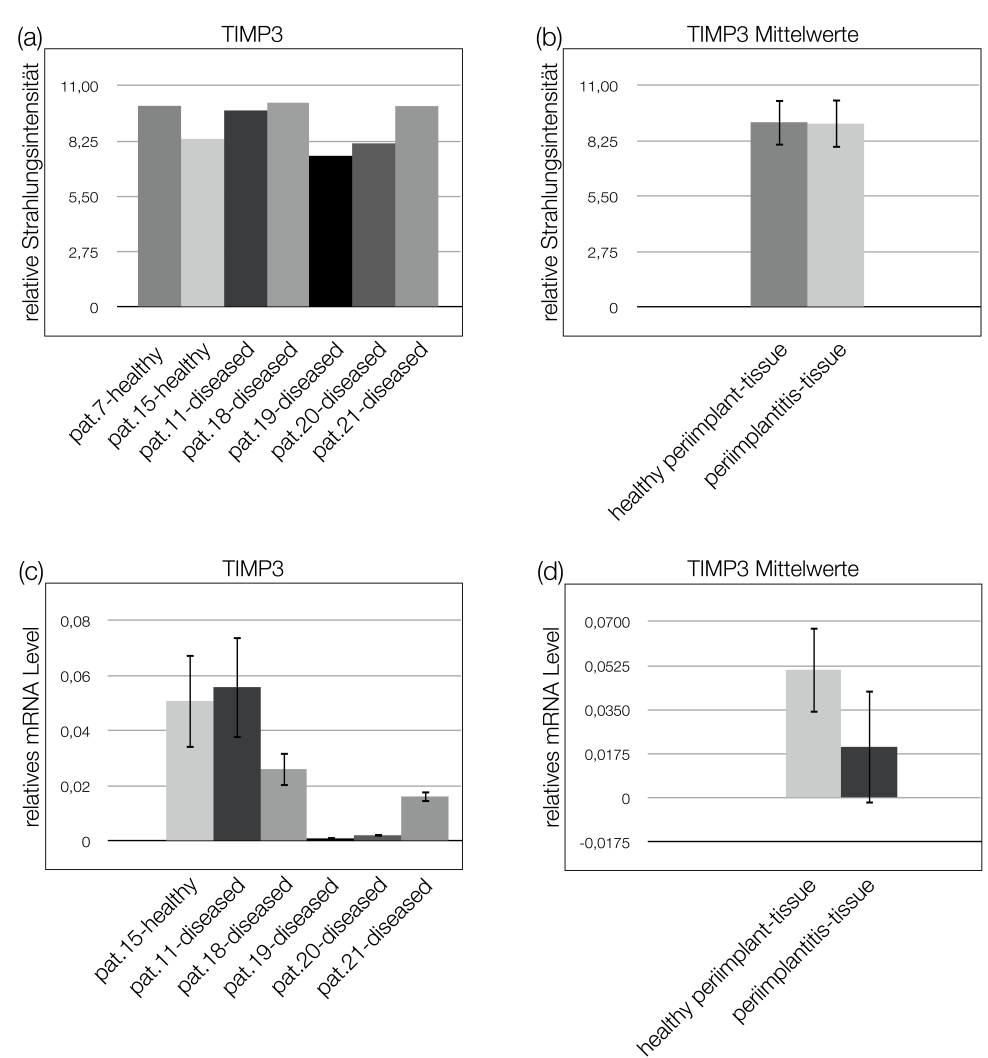

Abbildung 3.8: (a-d) Zu sehen ist die Genexpression von TIMP3 im Vergleich Gesund (healthy) mit Erkrankt (diseased) mit Microarray und qPCR-Technik. (a) Zu sehen sind die Ergebnisse des Microarray mit den Einzelwerten der Patienten und (b) die Darstellung der Mittelwerte. (c) Zu sehen sind die Ergebnisse der qPCR mit den Einzelwerten der Patienten und (d) die Darstellung der Mittelwerte. 


\subsection{COL9A1}

Die Ergebnisse des Microarray für Kollagen, Typ IX, Alpha 1 (COL9A1) sind leicht inhomogen. Die Expressionsraten der erkrankten Gewebe sind bis auf die von Pat. 20 alle geringer als im gesunden Gewebe. Die Gewebeprobe von Pat. 20 weist leicht höhere Werte im Vergleich zum gesunden Pat. 15 auf. Gemittelt ist die Genexpression von Collagen IX im erkrankten Gewebe geringer im Vergleich zum gesunden, das Ergebnis ist jedoch nicht signifikant. Die Werte der Proben von Pat. 11 und 20 haben unter den Erkrankten die höchsten Werte, Pat. 18 die niedrigsten. Die Ergebnisse der qPCR bestätigen diese Tendenz und sind signifikant. Sowohl gemittelt als auch alle jeweiligen Proben erkrankten Gewebes sind in ihrer Expression signifikant niedriger als im gesunden. Dabei haben unter den Proben des entzündeten Gewebes die von Pat. 20 und 21 die höchsten Werte und Pat. 18 hat den niedrigsten Wert.
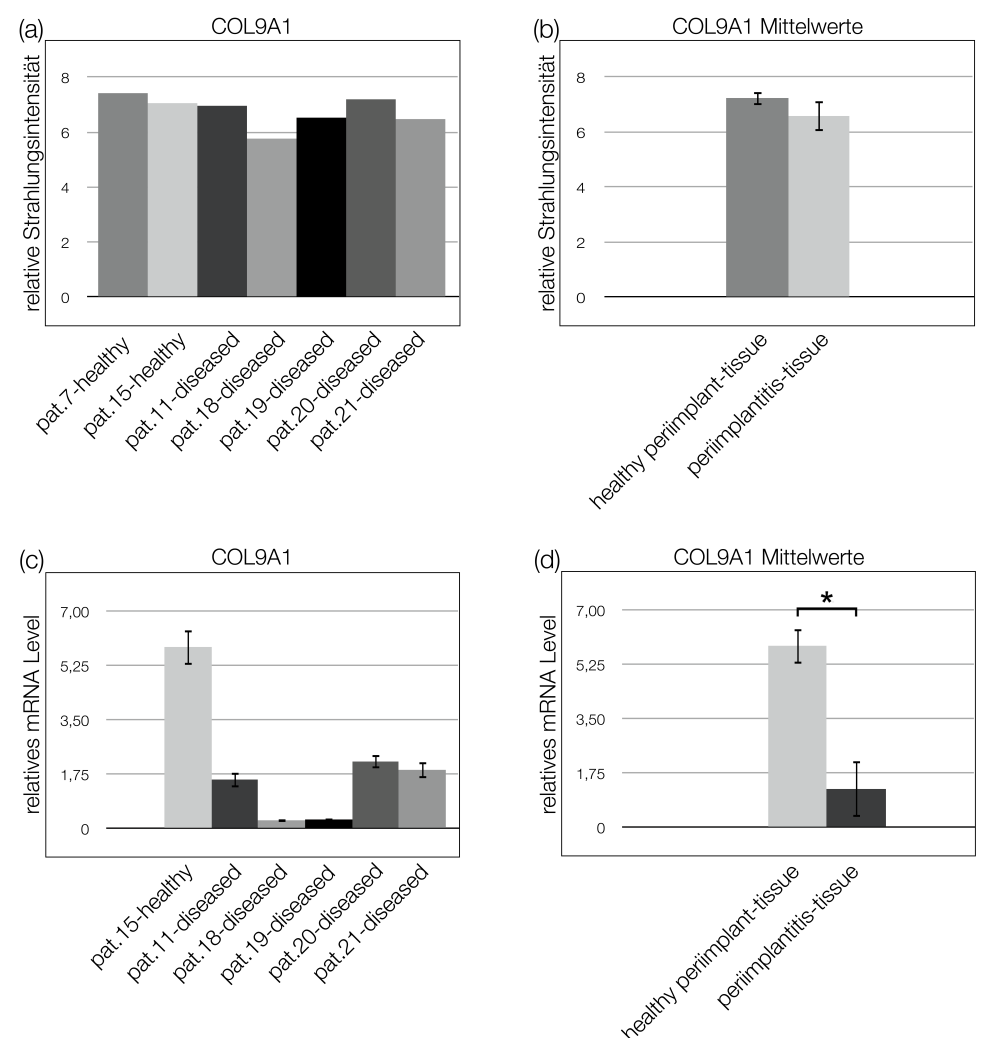

Abbildung 3.9: (a-d) Zu sehen ist die Genexpression von Kollagen, Typ IX, Alpha 1 (COL9A1) im Vergleich Gesund (healthy) mit Erkrankt (diseased) mit Microarray und qPCR-Technik. (a) Zu sehen sind die Ergebnisse des Microarray mit den Einzelwerten der Patienten und (b) die Darstellung der Mittelwerte. (c) Zu sehen sind die Ergebnisse der qPCR mit den Einzelwerten der Patienten und (d) die Darstellung der Mittelwerte. 


\subsection{COL1A1}

Die Ergebnisse des Microarray zeigen, dass Kollagen, Typ I, Alpha 1 (COL1A1) im entzündeten Gewebe tendenziell geringer exprimiert ist als im gesunden. Jedoch sind die Unterschiede nicht signifikant. Die Einzelwerte der gesunden Proben sind zueinander relativ homogen. Die Einzelwerte der erkrankten Proben sind inhomogener, wobei Pat. 19 die geringsten und Pat. 18 den höchsten Wert zeigt. Die Ergebnisse der qPCR zeigen ebenfalls eine tendenziell geringere Expression im entzündeten Gewebe. Jedoch sind die Unterschiede zwischen Gesund und Krank im Mittel nicht signifikant. Die Einzelwerte der untersuchten erkrankten Patienten sind sehr inhomogen. Pat. 19 zeigt dabei die geringste und Pat. 11 die höchste Expression von Kollagen, Typ I, Alpha 1. Die Werte der erkrankten Patienten 19, 20 und 21 sind signifikant niedriger im Vergleich zum gesunden Pat. 15. Pat. 11 zeigt eine signifikant höhere Expression im Vergleich zum Gesunden. Die Expressionswerte von Pat. 18 zeigen keinen signifikanten Wert.
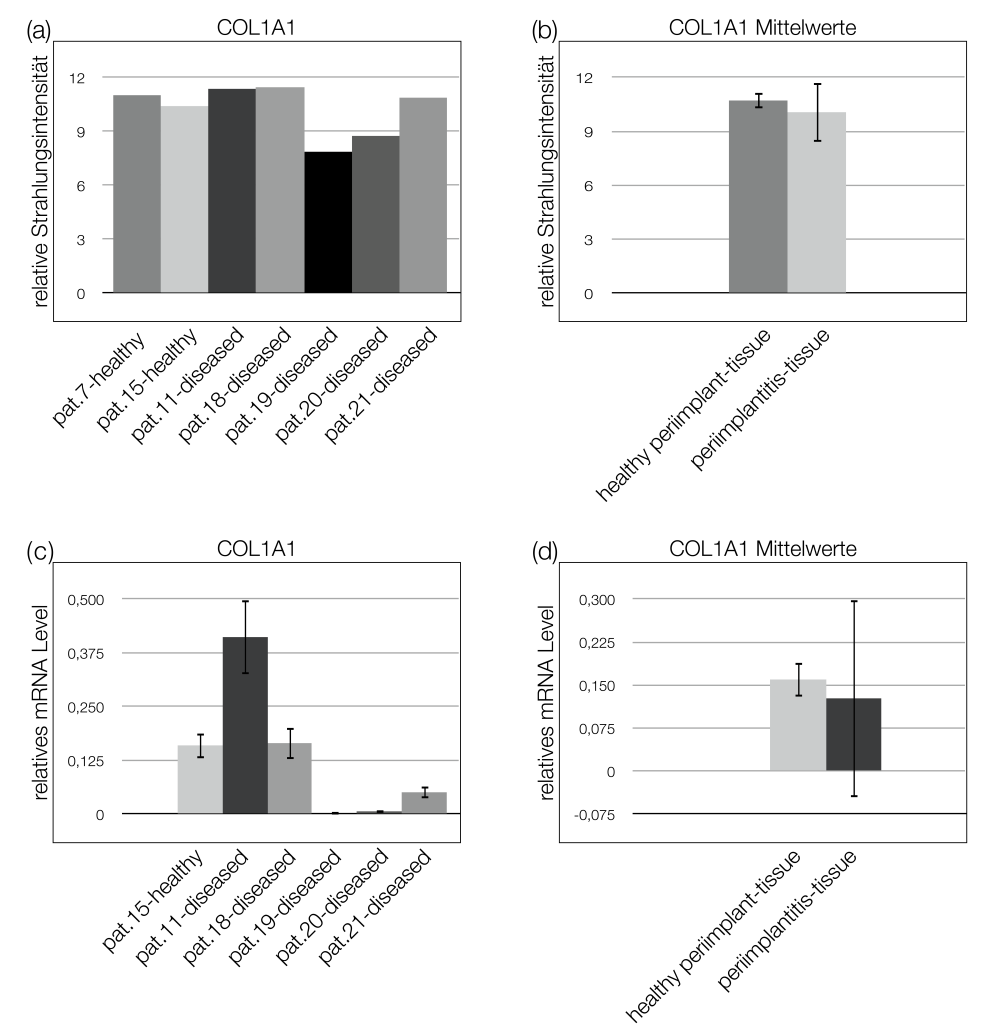

Abbildung 3.10: (a-d) Zu sehen ist die Genexpression von Kollagen, Typ I, Alpha 1 (COL1A1) im Vergleich Gesund (healthy) mit Erkrankt (diseased) mit Microarray und qPCR-Technik. (a) Zu sehen sind die Ergebnisse des Microarray mit den Einzelwerten der Patienten und (b) die Darstellung der Mittelwerte. (c) Zu sehen sind die Ergebnisse der qPCR mit den Einzelwerten der Patienten und (d) die Darstellung der Mittelwerte. 


\subsection{Weitere Kollagene}

In der Übersicht der Microarray Daten sieht man, dass unter den für diese Studie als relevant erachteten Kollagenen lediglich Kollagen 3 und die Alpha 1 Kette von Kollagen 4 im entzündeten periimplantären Gewebe eine erhöhte Expression aufweisen. Sowohl die Kollagene 1, 2, die Alpha Ketten 3 und 4 des Kollagens 4 als auch die Kollagene 7, 9, und 13 sind im erkrankten Gewebe in ihrer Expression niedriger im Vergleich zum gesunden.

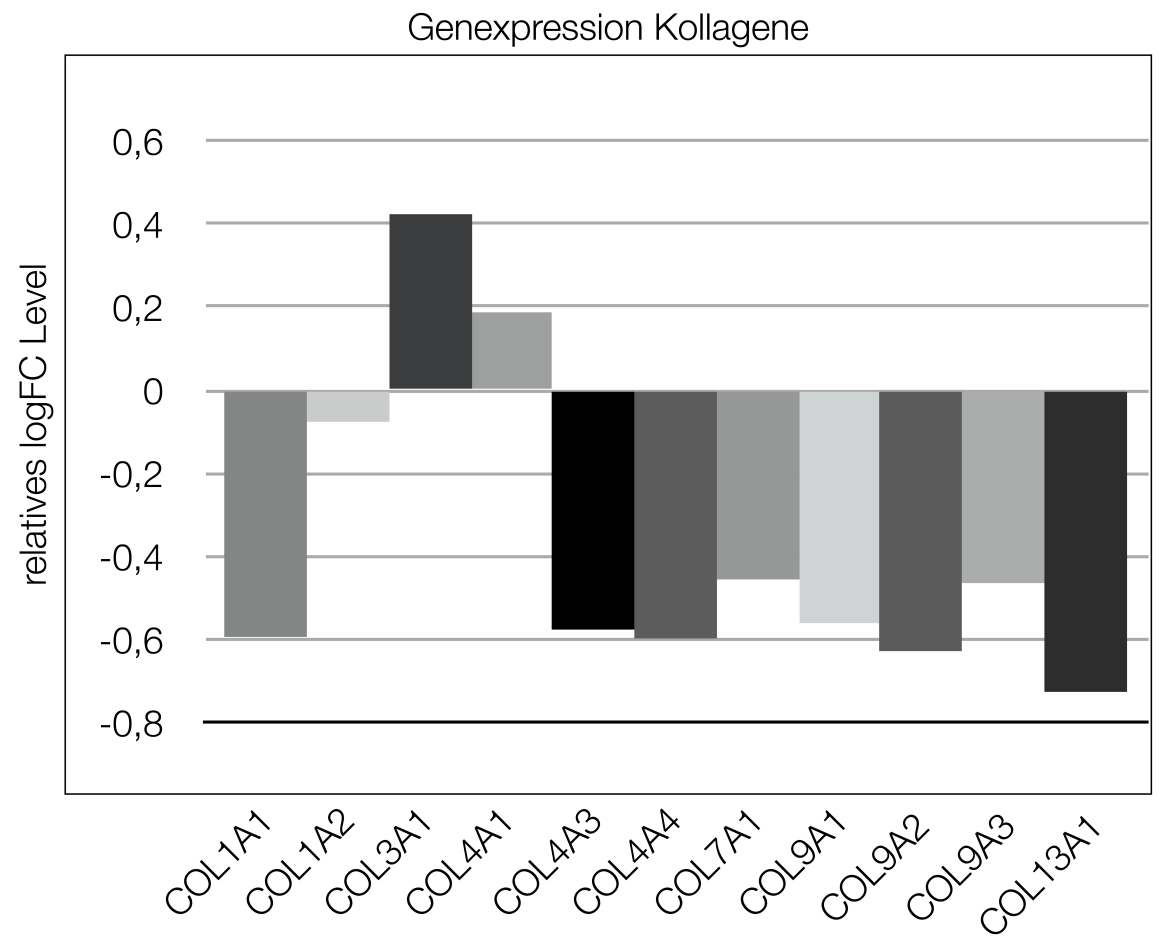

Abbildung 3.11: Zu sehen sind die Ergebnisse der Microarray-Untersuchung für die Kollagene COL1A1 (Kollagen, Typ I, Alpha 1), COL1A2 (Kollagen, Typ I, Alpha 2), COL3A1 (Kollagen, Typ III, Aplha 2), COL4A1 (Kollagen, Typ IV, Alpha 1), COL4A3 (Kollagen, Typ IV, Alpha 3), COL4A4 (Kollagen, Typ IV, Alpha 4), COL7A1 (Kollagen, Typ VII, Alpha 1), COL9A1 (Kollagen, Typ IX, Alpha 1), COL9A2 (Kollagen, Typ IX, Alpha 2), COL9A3 (Kollagen, Typ IX, Alpha 3) und COL13A1 (Kollagen, Typ XIII, Alpha 1). Relatives $\log F c$ Level = relative Ratio von Erkrankt gegenüber Gesund. 


\subsection{BGLAP}

Die Ergebnisse des Microarrays für bone gamma-carboxyglutamate (gla) protein (BGLAP), auch als Osteocalcin bekannt, zeigen, dass die Expression für dieses Gen im gesunden Gewebe signifikant höher exprimiert ist als im erkrankten. Die Werte jeder einzelnen Probe der erkrankten periimplantären Gewebe sind alle niedriger als in den gesunden Proben von Pat. 7 und 15. Dabei zeigen die Proben der erkrankten Pat. 11 und 21 die höchsten Expressionsraten, Pat. 20 die niedrigste. Die Ergebnisse der qPCR bestätigen diese Resultate. Im Mittel ist die Expression vom BGLAP im erkrankten Gewebe signifikant niedriger als im gesunden. Alle Einzelwerte der Periimplantitisproben bis auf Pat. 21 sind signifikant niedriger als bei Pat. 15, wobei die Werte von Pat. 19 und 20 am niedrigsten sind.
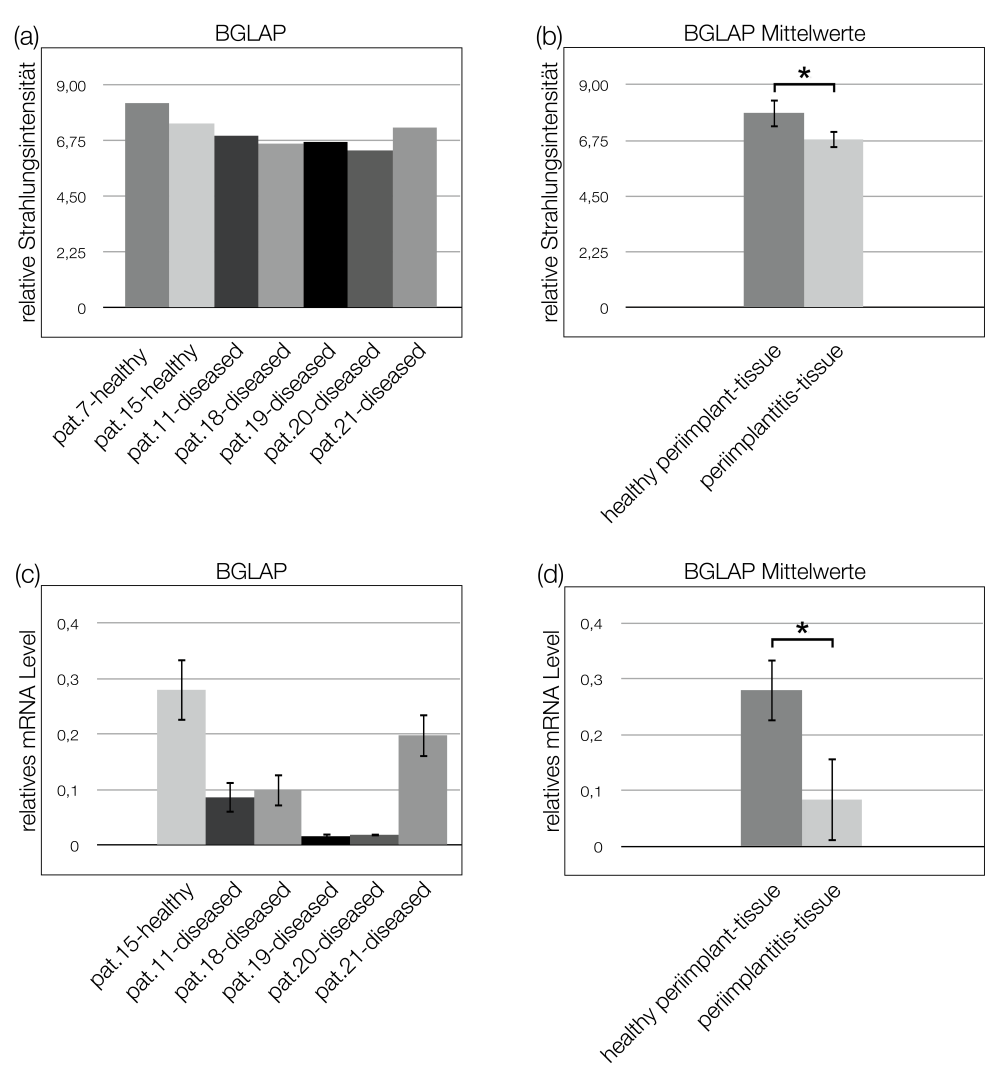

Abbildung 3.12: (a-d) Zu sehen ist die Genexpression von BGLAP im Vergleich Gesund (healthy) mit Erkrankt (diseased) mit Microarray und qPCR-Technik. (a) Zu sehen sind die Ergebnisse des Microarray mit den Einzelwerten der Patienten und (b) die Darstellung der Mittelwerte. (c) Zu sehen sind die Ergebnisse der qPCR mit den Einzelwerten der Patienten und (d) die Darstellung der Mittelwerte. 


\subsection{OPG (TNFRSF11B)}

Die Ergebnisse für OPG, auch als Tumornekrosefaktor-Rezeptor-Superfamilie 11B (TNFRSF11B) bekannt, sind inhomogen. Die Mittelwerte der Microarray-Untersuchung zeigen eine tendenziell niedrigere OPG-Expression im erkrankten Gewebe gegenüber dem gesunden. Der Unterschied ist jedoch nicht signifikant. Die Einzelwerte der erkrankten Patienten 21 und 20 zeigen die höchsten Expressionswerte unter den erkranken Patienten. Die Expressionsraten der qPCR-Ergebnisse zeigen ebenfalls relativ inhomogene Werte auf. Gemittelt ist OPG im Kranken niedriger exprimiert als im Gesunden, jedoch sind die Werte nicht signifikant. Die Ergebnisse für die Proben der Patienten 11, 18 und 20 sind geringer im Vergleich zum gesunden Pat. 15. Allein Pat. 18 zeigt signifikante Werte. Die Expressionswerte der Pat. 19 und 21 für OPG liegen über dem des gesunden Pat. 15, sind jedoch nicht signifikant.
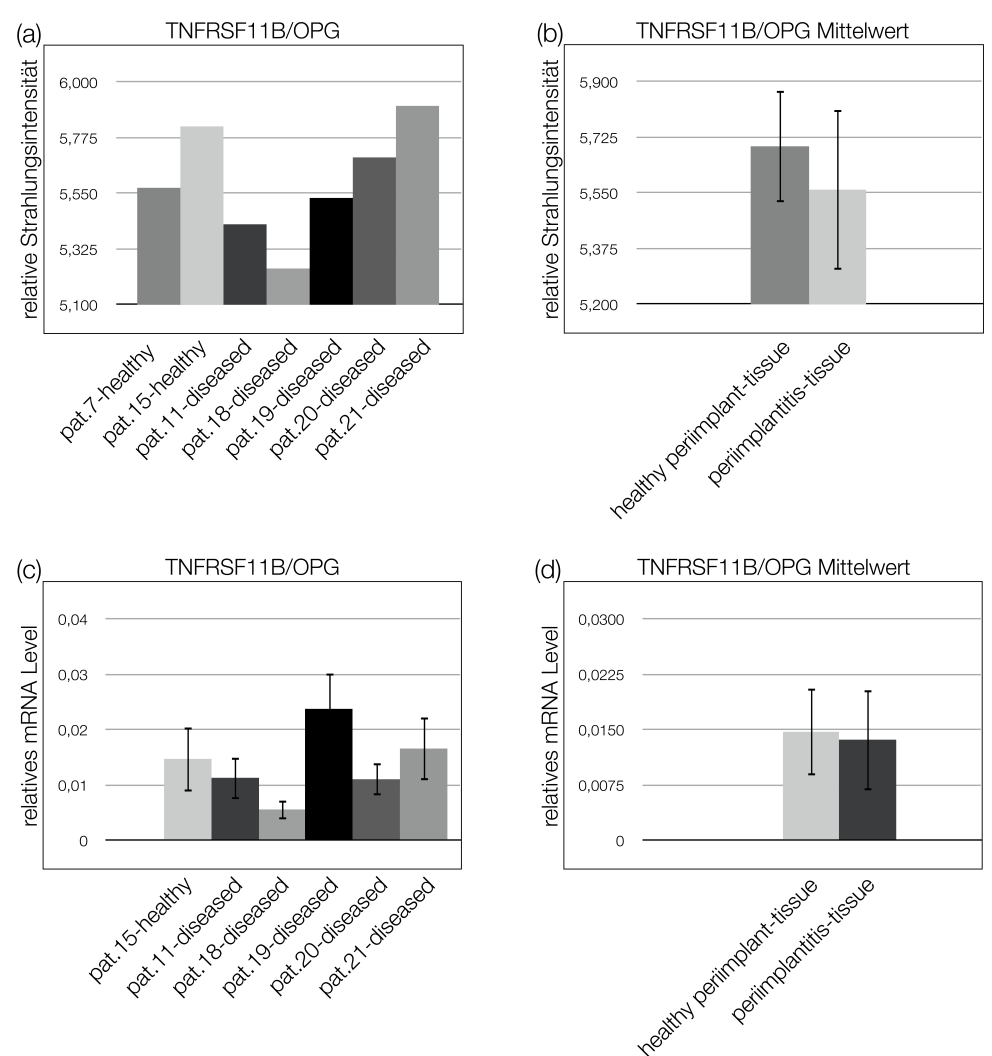

Abbildung 3.13: (a-d) Zu sehen ist die Genexpression von OPG (TNFRSF11B) im Vergleich Gesund (healthy) mit Erkrankt (diseased) mit Microarray und qPCR-Technik. (a) Zu sehen sind die Ergebnisse des Microarray mit den Einzelwerten der Patienten und (b) die Darstellung der Mittelwerte. (c) Zu sehen sind die Ergebnisse der qPCR mit den Einzelwerten der Patienten und (d) die Darstellung der Mittelwerte. 


\subsection{RUNX2}

Die Ergebnisse des Microarray zeigen, dass im von Periimplantitis betroffenen Gewebe RUNX2 im Vergleich zum gesunden tendenziell niedriger exprimiert ist. Unter den erkrankten Patienten weisen Pat. 19 und 21 die höchsten RUNX2-Expressionswerte auf. Gemittelt ergeben die Werte keine Signifikanz. Sie weisen jedoch eine Tendenz zu einer niedrigeren Expression von Krank gegenüber Gesund auf. Den qPCR-Versuchen nach lässt sich diese Tendenz bestätigen. Im erkrankten Gewebe ist RUNX2 signifikant niedriger exprimiert als im gesunden Gewebe. Sowohl der Mittelwert als auch alle einzelnen Patientenwerte sind signifikant niedriger gegenüber der gesunden Probe. Wie im Microarray sind die Expressionswerte der Proben der Pat. 19 und 21 unter den Erkrankten am höchsten.
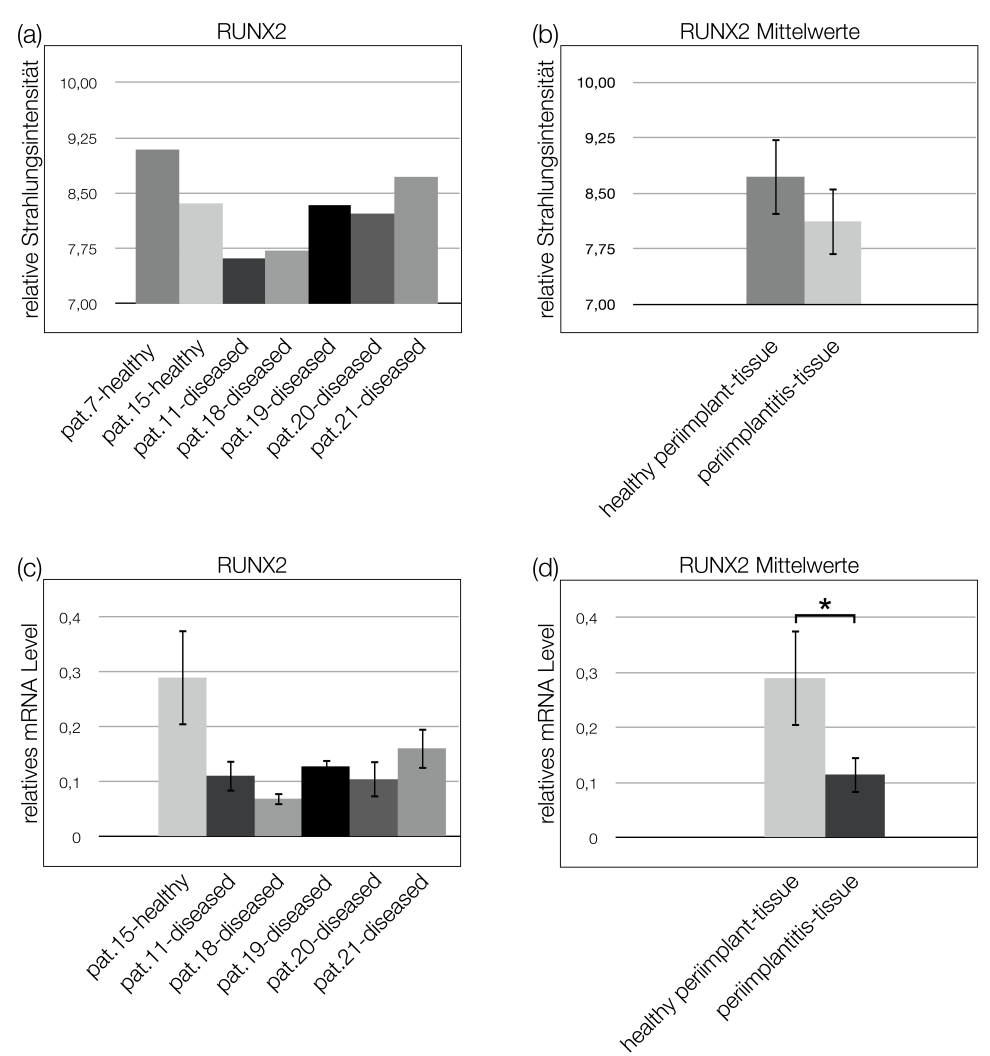

Abbildung 3.14: (a-d) Zu sehen ist die Genexpression von RUNX2 im Vergleich Gesund (healthy) mit Erkrankt (diseased) mit Microarray und qPCR-Technik. (a) Zu sehen sind die Ergebnisse des Microarray mit den Einzelwerten der Patienten und (b) die Darstellung der Mittelwerte. (c) Zu sehen sind die Ergebnisse der qPCR mit den Einzelwerten der Patienten und (d)die Darstellung der Mittelwerte. 


\section{$3.16 \mathrm{SOX} 2$}

Die Ergebnisse für SOX2 sind nur teilweise signifikant und zeigen eine Tendenz der niedrigeren Expression von SOX2 im entzündeten periimplantären Gewebe. Die Daten des Microarray zeigen eine homogene Verteilung innerhalb der erkrankten Proben. Alle erkankten Proben sind in ihrer Expressionsrate niedriger im Vergleich zu dem gesunden Pat. 15. Das Ergebnis für den gesunden Pat. 7 liegt dagegen gering unter dem der erkrankten. Im Mittel ergibt sich eine leichte Tendenz hin zu einer niedrigeren Expression von SOX2 im erkrankten Gewebe. Die Ergebnisse der qPCR bestätigen diese Tendenz. Es liegen alle Einzelwerte der erkrankten Patienten in ihrer Expression unter dem der gesunden Probe. Davon sind Pat. 11 und 20 in ihrer Expression signifikant niedriger im Vergleich zum Gesunden. Der Mittelwerte von Krank im Vergleich zu Gesund zeigt einen deutlich niedrigeren Wert, ist aber nicht signifikant.
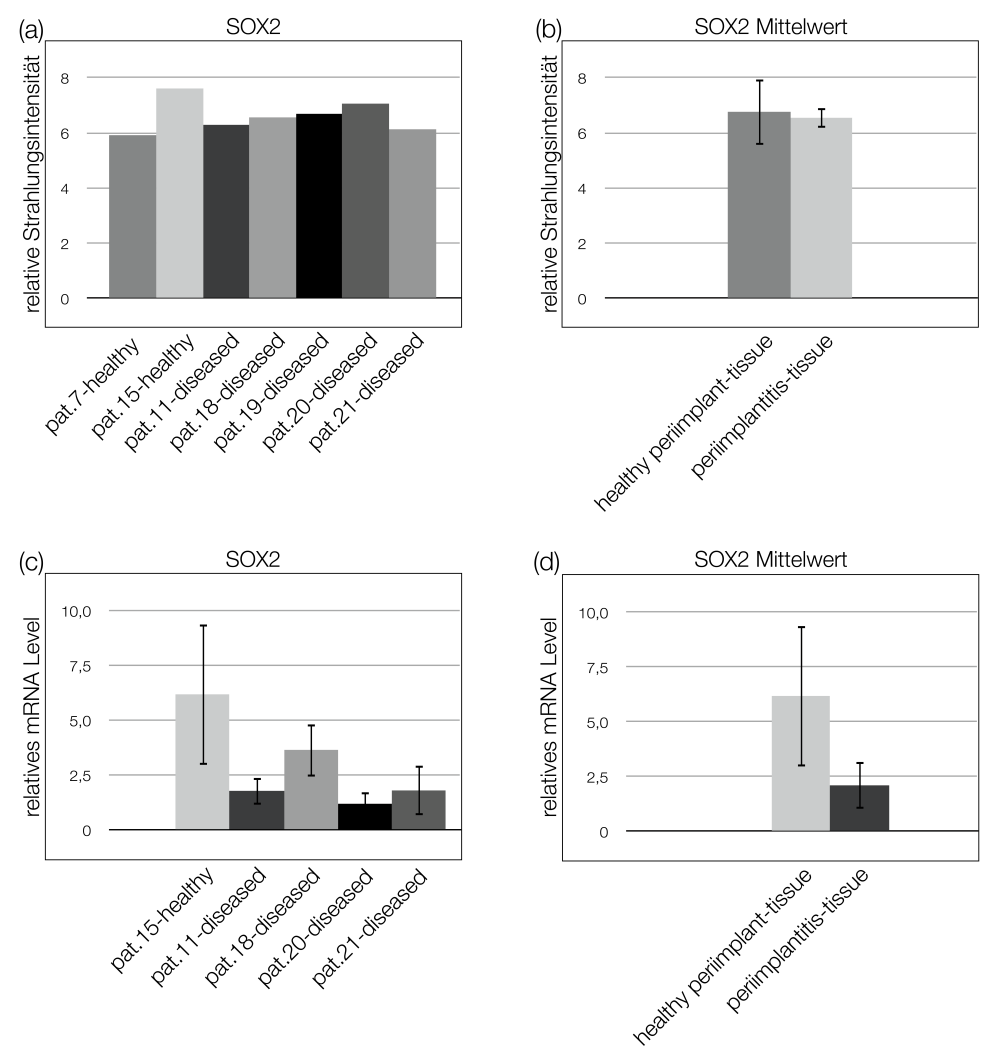

Abbildung 3.15: (a-d) Zu sehen ist die Genexpression von SOX2 im Vergleich Gesund (healthy) mit Erkrankt (diseased) mit Microarray und qPCR-Technik. (a) Zu sehen sind die Ergebnisse des Microarray mit den Einzelwerten der Patienten und (b) die Darstellung der Mittelwerte. (c) Zu sehen sind die Ergebnisse der qPCR mit den Einzelwerten der Patienten und (d) die Darstellung der Mittelwerte. 


\subsection{Weitere Transkriptionsfaktoren}

Die Microarray-Ergebnisse lassen erkennen, dass neben RUNX2 und SOX2 die Transkriptionsfaktoren SOX5, SOX6, SOX9, PPARA und TFEC im entzündeten periimplantären Gewebe ebenfalls in ihrer Expression erniedrigt sind. SOX5 und Sox6 zeigen dabei die niedrigsten Expressionswerte.

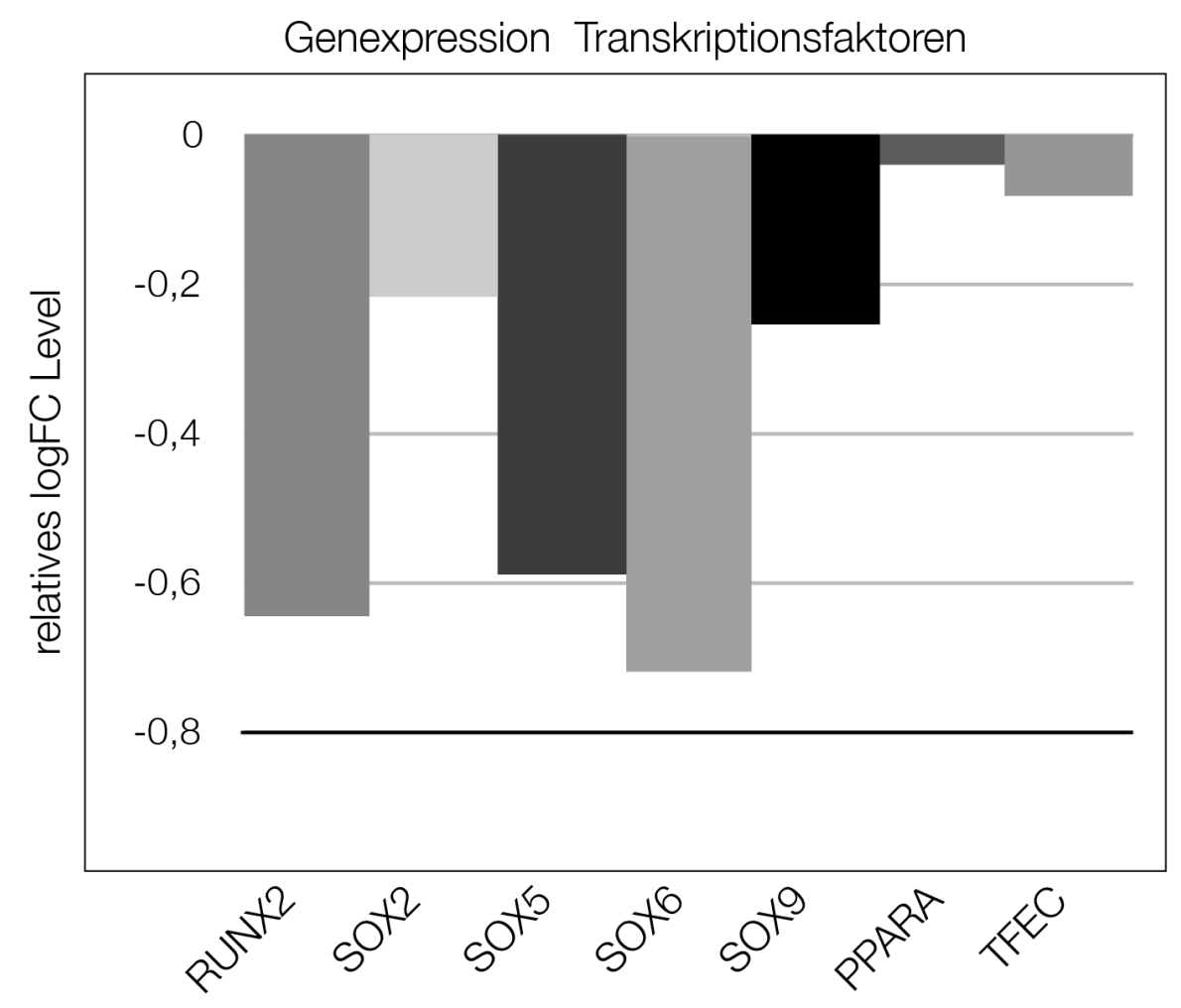

Abbildung 3.16: Zu sehen sind die Ergebnisse der Microarray-Untersuchung für die Transkriptionsfaktoren RUNX2 (runt-related transcription factor 2), SOX2 (SRY (sex determining region Y)-box 2), SOX5 (SRY (sex determining region Y)-box 5), SOX6 (SRY (sex determining region Y)-box 6), SOX9 (SRY (sex determining region Y)-box 9), PPARA (peroxisome proliferator-activated receptor alpha) und TFEC (transcription factor EC). Relatives logFc Level = relative Ratio von Erkrankt gegenüber Gesund. 


\subsection{FGF8}

Die Ergebnisse des Microarray zeigen für den Fibroblast Growth Faktor 8 (FGF8), dass die Expression aller erkrankten Proben bis auf Pat. 11 im Vergleich zu den gesunden niedriger ist. Die Werte der Proben der Patienten 11 und 20 haben unter den erkrankten die höchsten Werte, die von Pat. 18, 19 und 21 die niedrigsten. Der Mittelwert der erkrankten Proben liegt unter dem der gesunden Proben, ist aber nicht signifikant. Die mit der qPCR gewonnenen Ergebnisse zeigen im Mittelwert die gleiche Tendenz, jedoch nicht signifikant. Betrachtet man die einzelnen Ergebnisse der Patienten, so sind sie für Pat. 18 und 19 gegenüber der gesunden Probe signifikant geringer. Die Werte der Patienten 20 und 21 sind tendenziell ebenfalls niedriger als beim Gesunden, jedoch nicht signifikant. Die Genexpression von FGF8 von Pat. 11 ist tendenziell etwas höher als die der gesunden Probe von Pat. 15, aber nicht signifikant.
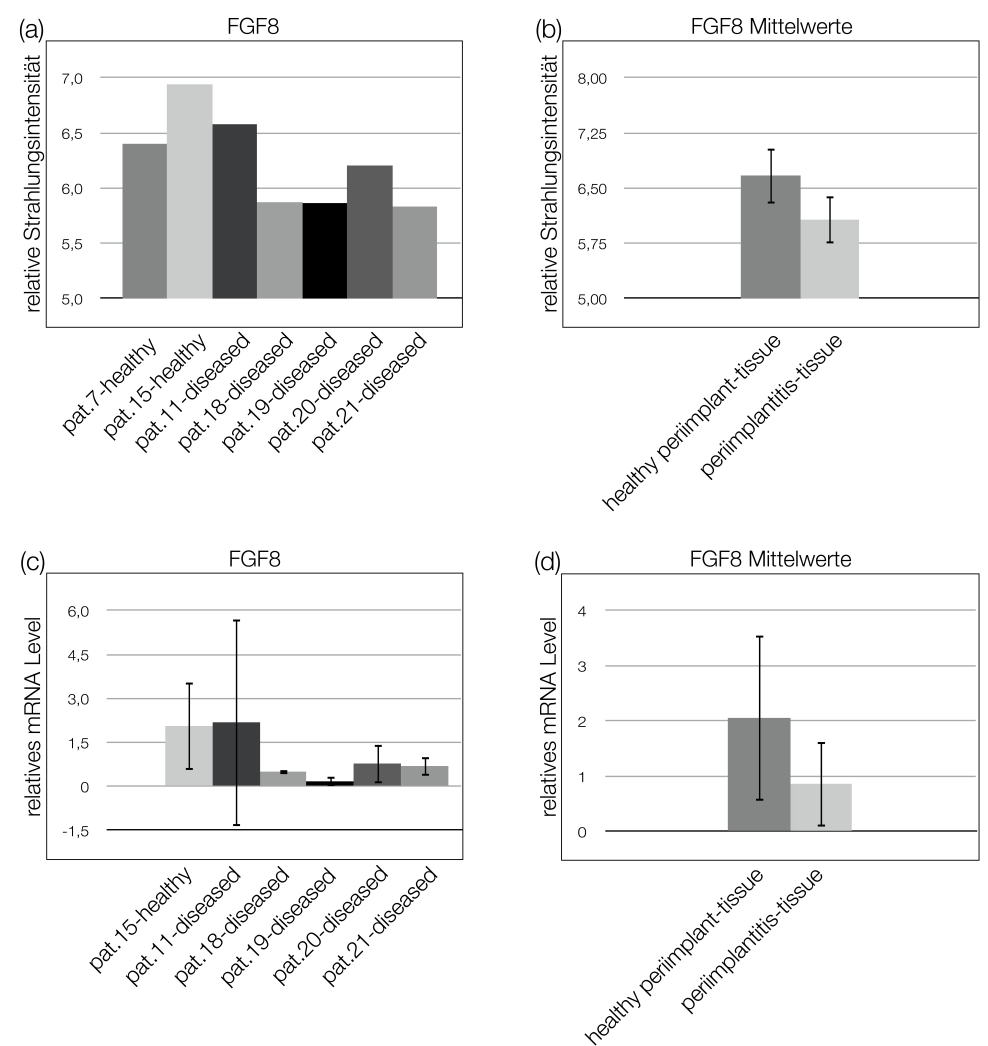

Abbildung 3.17: (a-d) Zu sehen ist die Genexpression von FGF8 im Vergleich Gesund (healthy) mit Erkrankt (diseased) mit Microarray und qPCR-Technik. (a) Zu sehen sind die Ergebnisse des Microarray mit den Einzelwerten der Patienten und (b) die Darstellung der Mittelwerte. (c) Zu sehen sind die Ergebnisse der qPCR mit den Einzelwerten der Patienten und (d) die Darstellung der Mittelwerte. 


\subsection{FGF18}

FGF18 ist den Ergebnissen des Microarray und der qPCR nach im erkrankten Gewebe geringer exprimiert als im gesunden. Den Ergebnissen des Microarray nach liegen alle Einzelwerte der erkrankten Proben in ihrer Genexpression unter denen der gesunden Proben. Gemittelt zeigen diese Ergebnisse eine signifikant niedrigere Expression von Erkankt gegenüber Gesund. Alle Ergebnisse der erkrankten Proben stellen sich als homogen dar. Die Ergebnisse der qPCR bestätigen die Ergebnisse des Microarrays. Sowohl der Mittelwert der qPCR-Daten als auch alle Einzelwerte der erkranken Patienten sind signifikant geringer im Vergleich zum Gesunden. Pat. 11 und 21 zeigen die höchsten Expressionen unter den kranken Proben und die größten Standardabweichungen.
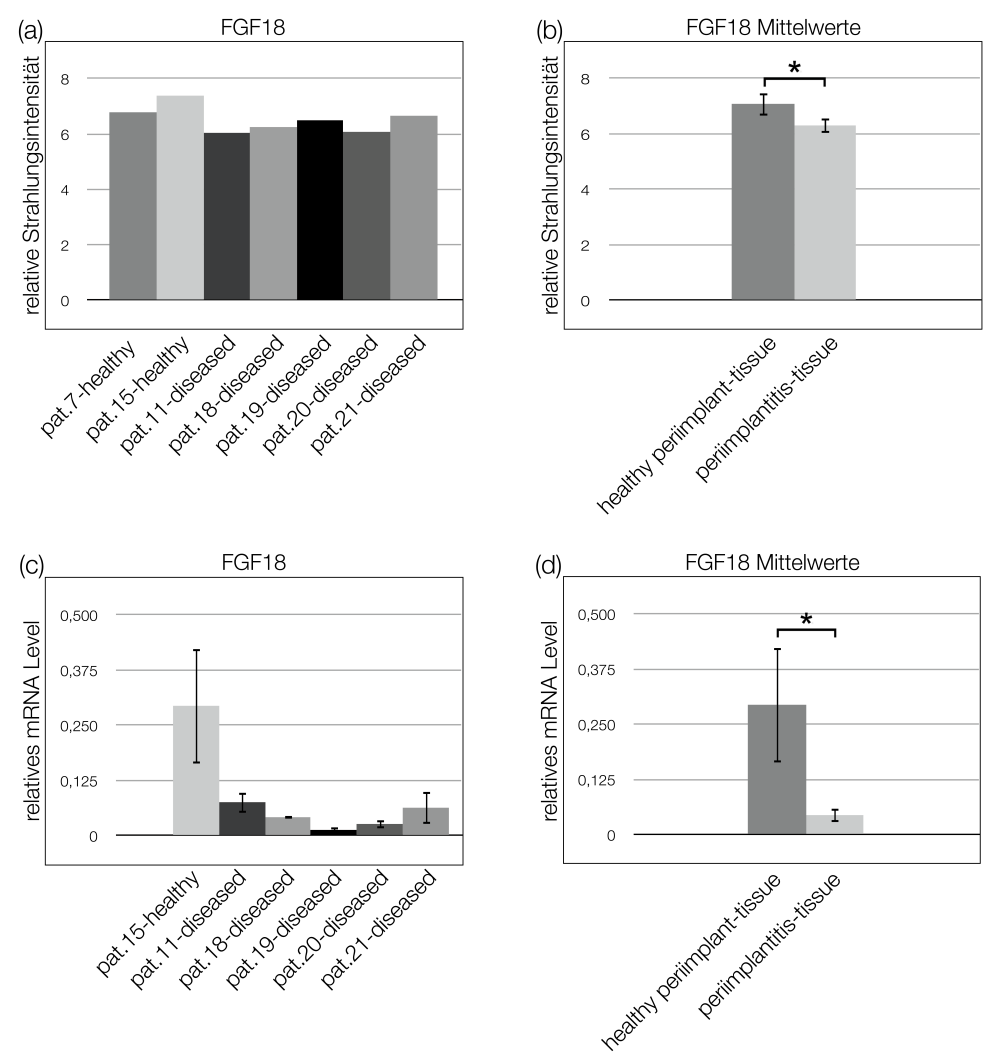

Abbildung 3.18: (a-d) Zu sehen ist die Genexpression von FGF18 im Vergleich Gesund (healthy) mit Erkrankt (diseased) mit Microarray und qPCR-Technik. (a) Zu sehen sind die Ergebnisse des Microarray mit den Einzelwerten der Patienten und (b) die Darstellung der Mittelwerte. (c) Zu sehen sind die Ergebnisse der qPCR mit den Einzelwerten der Patienten und (d) die Darstellung der Mittelwerte. 
KAPITEL 4

Diskussion

\subsection{Einleitung}

Aus der riesigen Menge an Ergebnissen der angefertigten Microarrays wurden bestimmte Gene, welche für das Verständnis und die Charakterisierung der Periimplantitis dienlich sein können, ausgewählt und in ihrer Expression untersucht und verglichen. Um diese Ergebnisse mit einem zweiten Verfahren zu prüfen, wurde für 22 dieser Gene jeweils eine RT-qPCR durchgeführt. Trotz sorgfältigster Arbeit sind die Ergebnisse des Microarray und der qPCR nicht für alle Gene identisch oder zumindest ähnlich. Ein Teil ist sogar widersprüchlich. In einer Arbeit von Peter B. Dallas et al. aus dem Jahr 2005 wird die Thematik aufgegriffen, inwieweit Microarray- und qPCR-Ergebnisse miteinander korrelieren. Das Ergebnis zeigt, dass die qPCR eine adäquate Technik ist, um die Ergebnisse eines Microarrays zu verifizieren. Jedoch haben Dallas et al. auch festgestellt, dass in $16 \%$ der Fälle nur eine geringe Korrelation zwischen den Ergebnissen beider Techniken zu beobachten war (Dallas et al. 2005). Einer der Gründe für die Abweichungen zwischen den Untersuchungsmethoden in der vorliegenden Arbeit mag sein, dass für die Überprüfung der Werte mit der qPCR-Technik leider nur eine der zwei Proben des 
gesunden periimplantären Gewebe für die Untersuchung mit der qPCR-Technik geeignet war.

\subsection{Diskussion der Methoden}

\subsubsection{Diskussion der Probengewinnung und des Studienaufbaus}

Das periimplantäre Gewebe von insgesamt acht explantierten dentalen Implantaten von jeweils unterschiedlichen Patienten wurde in dieser Studie untersucht. Da der Focus dieser Arbeit auf den zellulären Vorgängen des stützenden periimplantären Gewebes liegt, wurde erstrangig versucht, das noch anhaftende Knochengewebe für die Untersuchung zu gewinnen.

Die Menge der Probanden dieser Studie ist nicht dafür geeignet, eine epidemiologische Studie zu gestalten. Zwei Gesundproben für die Microarray Untersuchung und eine Gesundprobe für die qPCR-Untersuchung sind keine Datenmengen, die unanfechtbare Ergebnisse erzielen lassen. Jedoch ist es sehr schwer, humanes gesundes periimplantäres Gewebe zu gewinnen, da normalerweise eine Explantation von entzündungsfreien Implantaten nicht vorkommen sollte. Und falls es doch eintreffen sollte, ist es schwer, dieses Material zu akquirieren, da in der medizinischen Kultur, wie sie bisher in Deutschland existiert, Behandlungsfehler selten öffentlich werden und somit auch nicht der Forschung zugänglich sind.

Der Versuchsaufbau wurde so gestaltet, dass wenige unbekannte Faktoren einspielen können und während der Versuche die Qualität der Proben untersucht werden konnte. Ursachen, die zu Verzerrungen der Ergebnisse führen können, sind die Möglichkeit genetischer Varianzen unter den untersuchten Patienten oder Ungenauigkeiten bei der Gewebeakquirierung. Fehler bei den molekularbiologischen Verfahren sind nahezu auszuschließen, da sie alle lang erprobt und innerhalb des Labors nach standardisierten Protokollen durchgeführt wurden. Die Isolierung, Aufbereitung und Umschreibung der mRNA aus den Proben wurde mittels anerkannter und bekannter Verfahren etablierter Hersteller durchgeführt ${ }^{1}$.

\footnotetext{
${ }^{1}$ Peqlab, Quiagen, siehe Kapitel Material und Methoden S.19
} 


\subsubsection{Diskussion der Microarray-Technik}

Die Technik der Microarray-Gensondenhybridisierung ist eine mittlerweile viel erprobte und zuverlässige Methode. Dies ist durch viele Studien belegt und sie führt zu sehr gut reproduzierbaren Resultaten. Der Verwendete GeneChip ${ }^{\circledR}$ (Human Gene 1.0 Array) der Firma Affymetrix ist einer der aktuell modernsten Mittel für die breite Genexpressionsanalyse. Bei dieser Technik wird das gesuchte Gen durch bis zu 25 Gensonden, die sich über die ganze Sequenz des Genes verteilen, hybridisiert. Dadurch ist eine sehr spezifische Detektion der Gene mit ihren verschiedenen Transkript-Varianten möglich. Im Gegensatz dazu steht die veraltete Generation der sog. 3'-Expression-Microarrays, welche lediglich am 3' Ende der synthetisierten mRNA hybridisieren. Diese Art der Microarrays haben den Nachteil, dass sie voraussetzen, dass das 3' Ende klar definiert ist, immer ein intakter Poly-A-Schwanz vorhanden ist und das komplette Gen als eine zusammenhängende Einheit exprimiert ist. Es konnte jedoch gezeigt werden, dass über $60 \%$ der bekannten Gene alternativ gespleißt werden und somit tausende von Transkriptvarianten mit potenziell individuellen Funktionen entstehen können ( Lee und Roy 2004).

Obwohl die mRNA nicht das ultimative Produkt eines Genes ist, ist die Transkription der erste Schritt in der Genexpression. Das Wissen über die Transkriptionslevel der Gene ist ein erster Schritt zum Verständnis vom Netzwerk der Genregulation. Bisher ist die Messung von mRNA-Level günstiger, schneller und mit einem größeren Datendurchsatz möglich als im Vergleich zur direkten Messung von Proteinmengen. Die Mengen an mRNA und Proteinen korrelieren zwar nicht immer direkt miteinander, jedoch lässt eine geringe Menge oder gar das Nichtvorhandensein einer mRNA auf ein niedriges Level des entsprechenden Proteins schließen. Studien zum Zusammenhang zwischen mRNA-Level und Proteinlevel gibt es bisher nur wenige (Alvis Brazma 2000; Anderson und Seilhamer 1997; Celis et al. 2000; Gygi et al. 1999).

Aus einer Pionierstudie von Anderson und Seilhamer von 1997 geht hervor, dass 29 von 50 am höchsten exprimierten mRNA's in untersuchten menschlichen Leberzellen für sezernierte Proteine kodieren. Dem gegenüber stehen die 50 am höchsten exprimierten Proteine, von welchen kein einziges ein sezerniertes Protein darstellt. Die Untersuchungen ergaben einen Korrelationsfaktor zwischen mRNA- und Proteinexpression von 0,48 (Anderson und Seilhamer 1997). Dennoch lässt sich festhalten, dass so gut wie alle Veränderungen und Unterschiede von Zellen, wie zum Beispiel ihre Differenzierung, ihr Entwicklungsstatus oder eine Reaktion auf veränderte endogene oder exogene Einflüsse, 
sich in einer Veränderung der mRNA-Level vieler Gene widerspiegeln (Piatetsky-Shapiro und Tamayo 2003).

\subsubsection{Diskussion der PCR-Technik}

Die zweite Nachweismethode, die in dieser Arbeit zum Einsatz kam, ist die RT-qPCR. Die Technik der qPCR ist bereits seit Jahren erprobt und ein Standardverfahren vieler molekularbiologischer Labore. Sie wurde von unserer Forschungsgruppe bereits vielfach verwendet. Die Methode der qPCR zeichnet sich durch ihre hohe Sensitivität und Analysemöglichkeit kleinster Mengen an DNA aus. Sie ist ein Standardverfahren bei der Genexpressionsanalyse und nachweislich ein geeignetes Mittel, um die Ergebnisse von Microarray-Analysen zu validieren (Rajeevan et al. 2001). Es existieren mehrere Studien, in denen untersucht wurde, inwiefern die Ergebnisse von Microarray und qPCR miteinander korrelieren. Es wurden Korrelationen von 0,7 bis 0,8 festgestellt (Morey et al. 2006). Man kann also von einer guten Technik sprechen, um Microarray-Daten zu validieren. Bisher gibt es keine Standards für die Validierung von Microarray-Daten, jedoch ist die qPCR eine der gängigsten Methode dafür.

\section{Pfaffl-Normalisierung}

Die Ergebnisse der qPCR wurden mit der relativen Quantifizierung nach Michael W. Paffl aus dem Jahr 2001 normalisiert. Diese Methode ist mittlerweile weit verbreitet und vielfach zitiert worden. Es werden hierbei vier Datensätze miteinander in ein Verhältnis gesetzt. Bei dieser Normalisierung der Daten dient ein Housekeeping-Gen als ReferenzGen. Die Hauptcharakteristik des Referenz-Gens sollte sein, dass es keiner Regulation unterliegt und in allen untersuchten Zellen bzw. Geweben gleich stark exprimiert ist. Für diesen Zweck wurde hierfür das Beta-2-Mikroglobulin (B2M) verwendet. Dieses Protein ist mit dem Haupthistokompatibilitätskomplex assoziiert und kommt auf der Oberfläche von fast allen zellkernhaltigen Zellen vor. Die Genexpression der gesuchten Gene und des Referenz-Gens wurden neben dem untersuchten periimplantärem Gewebe auch für die in vitro gezogene Osteozyten untersucht. Daraus ergeben sich die vier Datensätze, welche für die Normalisierung verwendet wurden: das periimplantäre Gewebe, welches auf das zu untersuchende Gen und das Referenz-Gen untersucht wurde, und in diesem Fall die Osteozyten, welche ebenfalls auf das zu untersuchen Gen und das Referenz-Gen untersucht wurden (Pfaffl 2001). 


\subsection{Diskussion der Ergebnisse}

\subsubsection{Diskussion der Expression der Interleukine}

Interleukine sind bekannte Entzündungsmediatoren. Zur Verifizierung durch die qPCR wurde das Interleukin-8 gewählt, da es ein vor allem lokal sezerniertes Zytokin ist und neben Epithelzellen auch von Fibroblasten ausgeschüttet wird, welche sich im untersuchten Gewebe befinden (Sower et al. 1996). Interleukin-8 verursacht unter anderem die Chemotaxis von neutrophilen Granulozyten und deren Degranulation (Mukaida 2000; Taub et al. 1996). Es ist damit also Teil der unspezifischen Immunantwort.

Bisher gibt es keine Publikationen, die untersuchten, wie stark die Genexpression von Interleukin-8 in periimplantärem Gewebe ist. Nach den Ergebnissen des Microarray dieser Arbeit sind vor allem Interleukin-1 und -8 in ihrer Expression stark erhöht. Die Proteine beider Gene stehen in engem Zusammenhang mit entzündlichen Vorgängen. Interleukin-10, welches für die Inhibition von entzündlichen Vorgängen verantwortlich ist, ist in seiner Expression im entzündlichen Gewebe herunterreguliert. In bisherigen Publikationen wird die Frage von Polymorphismen im Interleukin-8 Gen in Zusammenhang mit der Parodontitis diskutiert (Andia et al. 2013). Interleukin-8 ist ein sehr potentes Zytokin und für die Chemotaxis von vielen Akut-Phase-Abwehrzellen verantwortlich. Es wird wie oben beschrieben von Zellen vor Ort synthetisiert und kann durch seine geringe Größe von 72 Aminosäuren schnell im Gewebe diffundieren. Das Protein an sich ist sehr stabil und kann aus diesem Grund auch in suboptimalen Bedingungen wie entzündlichem Infiltrat lange verweilen. Die Ausschüttung dieses Proteins wird neben von Bakterien sezernierten Lipopolysacchariden auch von Interleukin-1 (IL1) und Tumornekrosefaktor (TNF ) stimuliert (Remick 2005). Interleukin-1 ist, den Ergebnissen nach, im von Periimplantitis betroffenen Gewebe, ebenfalls stärker exprimiert, was mit der größeren Exprimierung von Interleukin-8 zusammenpasst. TNF dagegen ist nicht erhöht, jedoch die Rezeptoren über die es wirkt sind zum größten Teil höher exprimiert. Interleukin-8 ist besonders in der Akutphase von Entzündungen tätig (Mukaida 2000). Es kann schnell sezerniert werden von fast allen Zellen des Körpers, welche einen Zellkern besitzen. Die Abwehrzellen werden durch den Konzentrationsgradienten zum Einsatzort gelockt. Das heißt, die Zellen wandern in Richtung der größeren Interleukin-8 Konzentration. Für die Chemotaxis ist also nicht die absolute Menge an Interleukin-8 wichtig, sondern der Konzentrationsgradient. Aus bisherigen Studien lässt sich, wie bereits erwähnt, entnehmen, dass Interleukin- 8 neben seiner wichtigen Rolle bei der Akutphase von Entzündungen 
auch noch Tage bis Wochen im entzündeten Gewebe vorzufinden ist. Grund dafür ist die stabile Struktur des Proteins, welche es resistent gegen Hitze, Proteolyse und eine saure Umgebung macht (Baggiolini und Clark-Lewis 1992). Interleukin-8 kann also nicht als Marker für die Unterscheidung dienen, ob eine akute oder chronischen Entzündung vorliegt. Die gewonnenen Ergebnisse zeigen, dass Interleukin-8 im entzündlichen periimplantären Gewebe erhöht vorliegt. Es kann also der Schluss gezogen werden, dass Interleukin-8 ein wichtiger Faktor bei der Entstehung und dem Fortbestand der Periimplantitis ist. Ob unterschiedliche Haplotypen des Interleukin-8-Gens Einfluss auf den Verlauf der Krankheit haben, wurde bisher nur für die Parodontitis untersucht, und die Forschungsarbeiten liefern zum Teil gegensätzliche Ergebnisse (Andia et al. 2013; Andia et al. 2010; Corbi et al. 2014; Finoti et al. 2013).

Wenn man die übrigen Interleukine betrachtet, sieht man, dass auch Interleukin-6 eine erhöhte Expression im entzündeten periimplantärem Gewebe im Vergleich zum gesunden aufweist. Interleukin-6 ist ebenfalls ein potentes proinflammatorisches Zytokin. Es ist unter anderem für die Reifung von B-Zellen verantwortlich und wird sowohl in akut als auch chronisch entzündetem Gewebe produziert (Akira et al. 1990). Es gibt bereits Studien, die den Gehalt der Sulkusflüssigkeit von mit Periimplantitis betroffenen Implantaten mit denen gesunder Implantate auf ihren Gehalt von Zytokinen verglichen haben (Casado et al. 2013; Murata et al. 2002). Diesen Arbeiten zufolge ist Interleukin-1 stark erhöht, dies zeigen auch die Ergebnisse dieser Arbeit. Ebenfalls wurde der Zusammenhang von Interleukin-10 in gesundem und entzündetem periimplantärem Gewebe untersucht. Die gewonnenen Ergebnisse zeigen wie bisherige Publikationen, dass Interleukin-10 in entzündetem periimplantärem Gewebe weniger vorhanden ist als in gesundem. Interleukin-10 ist für seine entzündungshemmende Eigenschaft bekannt. Es kann besonderen Einfluss auf Monozyten, Makrophagen und dendritische Zellen nehmen. IL-10 kann die Produktion von IL-1 $\alpha$, IL-1 $\beta$, IL-6, IL-10 selbst, IL-12, IL-18, TNF und noch einigen mehr inhibieren. Es wirkt auf diese Weise indirekt. Besonders die Wirkung von IL-10 auf IL-1 und TNF ist für seine antiinflammatorische Wirkung entscheidend, da diese beiden Faktoren in entzündlichen Geschehen synergistisch arbeiten und ihre Wirkung verstärken, indem sie die Produktion weiterer Chemokine und Prostaglandine fördern (Moore et al. 2001). Es lässt sich also bisher zusammenfassen, dass die klassischen entzündungsverursachenden Interleukine-1, -6, und -8 im entzündeten periimplantären Gewebe in ihrer Expression erhöht sind. Das entzündungshemmende IL-10 ist dagegen in seiner Expression erniedrigt. Andere Interleukine wie IL-2, -4, -5 und -7 sind ebenfalls in ihrer Expression erniedrigt. IL-2, -4 und -7 teilen sich in ihrer Molekularstruktur die gleiche Gammakette. Neben anderen Faktoren wäre das eine 
Erklärung, warum sie gemeinsam herunterreguliert sind.

Um eine Idee zu bekommen welche Entzündungszellen sich hauptsächlich im entzündeten periimplantären Gewebe befinden, kann anhand der höher exprimierten Gene ein Muster erstellt werden. IL- $1 \alpha$ und $-\beta$ werden hauptsächlich von Makrophagen und Monozyten produziert. Die Interleukine welche herunterreguliert sind, stehen in engerem Zusammenhang mit dem erworbenen Immunsystem. Das heißt, sie werden zum einen von B- und T-Lymphozyten sezerniert und zum anderen können sie die selbigen in ihrer Funktion und Proliferation beeinflussen. Weiter lässt sich feststellen, dass Interferon Gamma (IFNG) in seiner Expression im erkrankten Gewebe im Vergleich zum gesunden erniedrigt ist. Interferon Gamma ist unter anderem für die Stimulierung der IL-10 Produktion verantwortlich. Da beide herunterreguliert sind, ergibt sich daraus ein schlüssiges Bild. Interferon Gamma ist außerdem ein potenter Aktivator für Makrophagen. Da Interferon Gamma im erkrankten Gewebe aber eher gering exprimiert ist, kommt es in diesem Fall nicht als solcher in Frage.

\subsubsection{Diskussion der Expression von CD24}

CD24 ist ein Oberflächenprotein. Es kann auf hämatopoetischen und nicht-hämatopoetischen Zellen nachgewiesen werden. Dazu zählen B-Zellen (Allman et al. 1993; Kay et al. 1991; Pirruccello und LeBien 1986), T-Zellen (Li et al. 2004; Williams et al. 1996), neutrophile und eosinophile Granulozyten (Elghetany und Patel 2002; Williams et al. 1996) sowie dendritische Zellen (Martinez del Hoyo et al. 2002) und Makrophagen (De Bruijn et al. 1996). Außerdem sind neuronale Zellen (Rougon et al. 1991; Shewan et al. 1996), epitheliale Zellen (Ye et al. 2005), Keratinozyten (Magnaldo und Barrandon 1996), Muskelzellen (Drosch et al. 2014; Figarella-Branger et al. 1993)), epitheliale Stammzellen (Lawson et al. 2007; Shackleton et al. 2006), viele Krebszellen (Kristiansen et al. 2004) und einige andere mehr als CD24 positiv befunden worden. Das Protein ist durch einen Glycosylphosphatidylinositol-Anker (GPI-Anker) mit der Zelloberfläche verbunden. CD24 besteht aus einer Kette von 27-30 Aminosäuren. Das Oberflächenprotein wurde bereits in vielen Forschungsarbeiten behandelt und in verschiedensten Geweben nachgewiesen. Es wurde zuerst 1978 von Springer nachgewiesen (Springer et al. 1978). CD24 ist auf dem Chromosom 6q21 lokalisiert (Hough et al. 1994).

CD24 ist nach den Microarray-Ergebnissen der vorliegenden Arbeit im entzündeten periimplantären Gewebe höher als im gesunden exprimiert. Die Ergebnisse der qPCR weisen eine Tendenz in die gleiche Richtung auf. Daraus lässt sich ableiten, dass die oben 
genannten Zellen im entzündeten periimplantären Gewebe vermehrt auftreten. Vor allem ist es wahrscheinlich, dass Zellen des Immunsystems das Gros dieser Zellen ausmachen. $\mathrm{Zu}$ diesen Zellen zählen für CD24 demnach B- und T-Zellen, Monozyten, Makrophagen und Granulozyten, also das ganze Spektrum an spezifischen und unspezifischen Abwehrzellen. Um hier eine genauere Charakterisierung der Periimplantitis zu erlangen, müssen noch weitere Cluster of Differentiation (CD) herangezogen werden. CD9, CD14 und CD97 sind spezifisch für Makrophagen und Monozyten. Alle diese sind den Ergebnissen dieser Arbeit zufolge im entzündeten Gewebe heraufreguliert. CD5, CD22, und CD8 sind Marker für T- und B-Zellen und in ihrer Expression herunterreguliert. CD27, CD79a und CD96 gehören ebenfalls zu dieser Gruppe (Bernard und Boumsell 1984; Kozlov und Yemelyanov 1998). Sie sind im Vergleich in ihrer Expression leicht herauf reguliert. Jedoch ist CD79b in seiner Expression im Kranken erniedrigt. CD79 kann jedoch nur mit Beteiligung beider Untereinheiten regelrecht funktionieren. Es lässt sich mit diesen Ergebnissen die Vermutung anstellen, dass der Großteil der Abwehrzellen, die sich im entzündeten periimplantären Gewebe befinden, zu den unspezifische Abwehrzellen, den Granulozyten, Monozyten und Makrophagen gehören.

\subsubsection{Diskussion der Expression der Matrix-Metalloproteinasen (MMPs) und der Inhibitoren der Matrix-Metalloproteinasen (TIMPs)}

Neben dem Aufbau von Gewebe ist auch der Abbau von Gewebe ein wichtiger Teil in der Entwicklung, Instandhaltung und Reparatur von Bindegewebe. Beide Vorgänge kommen exakt reguliert unter physiologischen Bedingungen in allen Geweben des menschlichen Körpers vor. Unter krankhaften bzw. unphysiologischen Bedingungen kann sich das Gleichgewicht von Auf- und Abbau des Bindegewebes in Richtung Abbau verschieben. Dies kann direkt durch von Bakterien sezernierten proteolytischen Enzymen und Zellgiften geschehen oder auch indirekt durch die Reaktion des Wirtes auf externe Noxen (Birkedal-Hansen et al. 1993).

MMP-1 und -13 sind zwei der drei Kollagenasen. Sie sind mitverantwortlich für den Umbau der extrazellulären Matrix und besonders aktiv in Geweben, in denen entzündliche Prozesse vonstatten gehen (Sorsa et al. 2004). In den Ergebnissen der vorliegenden Arbeit zeigen sich Widersprüche zwischen den Werten des Microarray und der qPCR. Dem Microarray nach, sind im entzündeten periimplantären Gewebe die MMPs-1 und -13 (interstitielle Kollagenase und Kollagenase-3) höher exprimiert als im gesunden. Die 
Werte der qPCR zeigen ein umgekehrtes Verhältnis. Interessanterweise konnte dieser Widerspruch zwischen Microarray und qPCR-Ergebnissen auch bei den Inhibitoren der Matrix-Metalloproteinasen (TIMPs) festgestellt werden. Warum die Ergebnisse sich widersprechen ist schwierig zu sagen. Die Einzelmessungen der qPCR waren sehr homogen und lassen daher nicht den Schluss auf Fehler in den Messungen zu. Zudem ist die qPCR wie oben bereits erwähnt eine sehr sensitive Methode. Es kann auf die bereits erwähnte Fehlerquote der Korrelation von Microarray und qPCR von 15 bis 20\% verwiesen werden, deren Ursache bisher noch nicht eindeutig geklärt werden konnte (siehe Kap. 4.2.3) .

Viele Zellen wie Fibroblasten, Epithelzellen, Endothelzellen, Monozyten/Makrophagen und Plasmazellen können dazu angeregt werden, MMPs zu produzieren, unter anderem MMP-8, welches mit als Hauptverursacher der Gewebedestruktion bei der Parodontitis angesehen wird (Golub et al. 1997; Sorsa et al. 2004; Xu et al. 2008). Nach dem klinischen Erscheinungsbild der Periimplantitis, welches neben anderen die Zerstörung von periimplantärem Gewebe zeigt, ist davon auszugehen, dass MMPs mit ihrer gewebedestruierenden Kompetenz eine Rolle im Geschehen der Periimplantitis spielen. Es gibt bisher jedoch wenige Studien, welche die Präsenz von MMPs und TIMPs im entzündeten Implantatbett untersuchen. Bisher gibt es nur Studien, in denen Biopsien von periimplantärer marginaler Gingiva (Degidi et al. 2013) oder die Sulkusflüssigkeit (Kivelä-Rajamäki et al. 2003; Nomura et al. 2000; Xu et al. 2008) von entzündeten Implantaten untersucht wurden. Bei den Untersuchungen zu MMP-Level in der Sulkusflüssigkeit entzündeter dentaler Implantate wurde MMP-8 als dominantes MMP festgestellt (Kivelä-Rajamäki et al. 2003; Xu et al. 2008). Jedoch wurden in diesen Studien nur MMP-7 und -8 oder nur MMP-8 untersucht, was die Aussagekraft dieser Studien einschränkt.

Den Microarray-Ergebnissen dieser Arbeit nach sind MMP-1, -12 und -13 am stärksten im entzündeten periimplantären Gewebe exprimiert. Zu MMP-12 ist in diesem Zusammenhang noch keine Forschungsarbeit zu finden. MMP-12 ist die makrophagenspezifische Elastase (Banda und Werb 1981; Belaaouaj et al. 1995; Werb und Gordon 1975). Wie bereits genannt, ist davon auszugehen, dass Makrophagen maßgeblich am Gewebeab- und -umbau periimplantärer Läsionen beteiligt sind. Die Tatsache, dass nach den Ergebnissen dieser Arbeit MMP-12 unter den MMPs am höchsten im entzündeten periimplantären Gewebe exprimiert ist, stützt diese Vermutung.

Kollagen-1 ist das Kollagen des Knochens. Es stellt die größte organische Masse des Knochengewebes dar und ist maßgeblich für die Stabilität und Elastizität des Knochens 
verantwortlich. Außerdem ist es für das Knochenwachstum und Remodeling wichtig, da sich die knochenbildenden Zellen an den Kollagenfibrillen orientieren. Kollagen-1 wird hauptsachlich von den drei Kollagenasen abgebaut: der interstitiellen Kollagenase (MMP-1), der neutrophilen Kollagenase (MMP-8) und der Kollagenase-3 (MMP-13). Alle diese Kollagenasen sind den Microarray-Ergebnissen zufolge in ihrer Expression erhöht. Das lässt darauf schließen, dass eine Hauptverantwortung für den Abbau des Kollagens des Knochens um entzündete Implantate von MMPs ausgeht.

Es gibt Untersuchungen, in denen gezeigt werden konnte, dass subantimikrobielle Dosen von Doxyzyklin die Aktivität von MMPs bei der Parodontitis mindern können und so die Gewebedestruktion durch MMPs verringert werden kann bzw. der Gewebeaufbau erleichtert wird (Choi et al. 2004; Golub et al. 1997). Dies wäre auch ein möglicher Therapieansatz, den man bei der Pariimlantitis verfolgen könnte, wozu bisher jedoch Studien fehlen.

\subsubsection{Diskussion der Expression der Kollagene}

Kollagene sind wichtige Bestandteile der menschlichen extrazellulären Matrix. Im gesunden periimplantären Gewebe, welches hauptsächlich aus Knochengewebe besteht, ist Kollagen-1 daher der Hauptvertreter. Durch den Verlust an Knochenmasse bei der Periimplantitis geht somit auch Kollagen-1 verloren. Es stellt sich die Frage, wie die Zellen, im besonderen Fibroblasten und Osteozyten des entzündeten Gewebes, auf diese Veränderung reagieren; ob mit einer Überexpression, um den Verlust an extrazellulärem Kollagen auszugleichen, oder ob sie dahin beeinflusst werden, die Kollagenproduktion zu reduzieren. Es gibt Untersuchungen, in denen im entzündeten periimplantären Gewebe der Umbau des knöchernen Implantatbetts hin zu einer bindegewebigen Struktur beschrieben wird (Berglundh et al. 2004). Das würde bedeuten, dass es zu einer gesteigerten Produktion von Kollagen im Zuge der Entzündung kommt.

Die Ergebnisse des Microarray zeigen, dass Kollagen-1 im entzündeten periimplantären Gewebe leicht geringer exprimiert ist als im gesunden, jedoch nicht signifikant. Auch die Kontrolle dieser Daten mit der qPCR konnte keine signifikante Veränderung feststellen, nur ebenfalls eine gleiche Tendenz wie die Microarray-Analyse. Die Untersuchungen zu Kollagen-9 ergaben ähnliche Ergebnisse. Nach der Microarray-Analyse ist Kollagen-9 im erkrankten leicht geringer exprimiert als im gesunden Gewebe, jedoch nicht signifikant. Die Kontrolle dieser Ergebnisse mit der qPCR-Technik ergab eine signifikant geringere Expression von Kollagen-9 im entzündeten Gewebe. Diese Resultate spre- 
chen eher gegen die Theorie, dass das knöcherne Implantatbett bei der Periimplantitis einen bindegewebigen Umbau erfährt. Nur Kollagen-3 ist dem Microarray nach in seiner Expression erhöht. Von Kollagen-4 ist lediglich die Alpha 1 Kette in Ihrer Expression erhöht. Es gibt jedoch 6 Untereinheiten von Kollagen-4, von denen sich immer drei zu einer Trippelhelix-Struktur zusammenlagern können. Die übrigen 5 Untereinheiten sind in ihrer Expression im entzündeten periimplantären Gewebe erniedrigt. Daher ist die erhöhte Expression von Kollagen-4 im entzündeten Gewebe zu vernachlässigen. Kollagen-3 kommt neben der Haut und Skelettmuskulatur in der Wand von Blutgefäßen vor. Da in entzündlichem Gewebe eine erhöhte Durchblutung vorherrscht und es auch zu einer Angiogenese kommen kann (Schlingemann et al. 1991), wäre das eine Erklärung dafür, dass Kollagen-3 in seiner Expression erhöht ist. Gabbiani et al. stellten 1975 fest, dass in induziertem granulomatösem Gewebe bei Ratten ein hoher Gehalt an Kollegen-3 vorhanden ist. Außerdem stellten sie eine Veränderung der Fibroblasten hinzu Myofibroblasten fest. Myofibroblasten enthalten in ihrem Inneren eine große Menge Kollagen-3 (Gabbiani et al. 1976).

Es stellt sich die Frage, wie das entzündete periimplantäre Gewebe zu charakterisieren ist. Es wäre möglich, dass der bindegewebige Anschein durch viele neugebildete Blutgefäße entsteht, welche eventuell auch in Zusammenhang mit gebildetem Granulationsgewebe stehen könnten. Granulationsgewebe ist ein neugebildetes blutgefäßreiches Gewebe, das sowohl bei der Wundheilung als auch bei chronischen Entzündungen produziert wird. Es enthält neben vielen neu gebildeten Kapillaren viele Fibroblasten und extrazelluläre Matrix, welche zum Großteil aus Kollagenen und Proteoglykanen besteht (Walter 1976).

Die Periimplantitis kann als chronische Entzündung klassifiziert werden, da sie über einen Zeitraum von mehreren Wochen bis Monaten oder auch über Jahre hin bestehen kann. Daher wäre es möglich, dass sich im entzündeten periimplantären Bereich Granulationsgewebe bildet. Fibroblasten, welche in großer Zahl in Granulationsgewebe vorkommen, werden durch die Einwanderung von Makrophagen zur Zellteilung angeregt und können sich zu Myofibroblasten differenzieren. Myofibroblasten haben eine hohe endogene Kollagensynthese. Sie sind eine Zwischenstufe von Fibroblasten und glatten Muskelzellen. Myofibroblasten produzieren das fibrilläre Kollagen-3. Die Tatsache, dass Kollagen-3 eine hohe Expression zeigt, unterstützt diese Hypothese.

Toriseva et al. zeigten in ihrer Arbeit, dass MMP-13 maßgeblich am Wachstum und der Entwicklung von Granulationsgewebe beteiligt ist. Außerdem zeigten sie, dass MMP-13 für die Aktivität von Myofibroblasten, die Steuerung und Aufrechterhaltung der Entzün- 
dung und für die Angiogenese mitverantwortlich ist (Toriseva et al. 2012). Wie weiter oben bereits aufgeführt, zeigen die Ergebnisse der vorliegenden Arbeit, dass MMP-13 im entzündeten periimplantären Gewebe am stärksten von allen MMPs in seiner Genexpression erhöht ist. Diese Tatsache unterstützt die Vermutung, dass das entzündete periimplantäre Gewebe als Granulationsgewebe charakterisiert werden kann.

\subsubsection{Diskussion der Expression von Osteocalcin (BGLAP) und Osteoprotegerin (TNFRSF11B)}

Das bone gamma-carboxyglutamate (gla) protein (BGLAP), auch als Osteocalcin bekannt, ist ein Faktor für die Osteoblastenaktivität und den Knochenauf- und -abbau. BGLAP ist ein Peptidhormon und kommt im Körper der meisten Wirbeltiere vor. Es stellt ein bis zwei Prozent der extrazellulären organischen nicht-kollagenen Knochenmatrix dar. Sezerniert wird es im Zahn von Odontoblasten und im Knochen von Osteoblasten. Es hat eine hohe Affinität zu Hydroxylapatit und Calcium (Raymond et al. 1999). Den Ergebnissen des Microarray und der qPCR zufolge ist BGLAP im entzündeten periimplantären Gewebe in seiner Expression signifikant niedriger als im gesunden Implantatbett. In einer vorangegangenen Studie (Murata et al. 2002) wurden die BGLAP- und Interleukin-1 $\beta$-Werte der Sulkusflüssigkeit von periimplantärer Mukositis, Periimplantitis und gesunden Implantaten verglichen. Das Ergebnis zeigte, dass die BGLAP-Werte bei der periimplantären Mukositis signifikant höher waren im Vergleich zum gesunden Implantat. Es gab jedoch keinen signifikanten Unterschied zwischen den Ergebnissen der Periimplantitis-Sulkusflüssigkeit und den beiden anderen Werten. Die erhöhten Werte von BGLAP werden als Indiz für einen erhöhten Knochen-Umsatz bei der periimplantären Mukositis gesehen. Murata et al. stellten außerdem fest, dass die Menge an Interleukin$1 \beta$ in der Sulkusflüssigkeit von Implantaten mit einer Periimplantitis signifikant erhöht waren im Vergleich zur periimplantären Mukositis oder zu gesunden Implantaten. Die Ergebnisse der Microarray-Untersuchung dieser Arbeit bestätigen das. Sie zeigen eine erhöhte Genexpression von Interleukin- $1 \beta$ im entzündeten periimplantären Gewebe. Interleukin- $1 \beta$ kann also als Marker für eine periimplantäre Entzündung angesehen werden. BGLAP ist den Ergebnissen des Microarray und der qPCR nach im entzündeten periimplantären Gewebe niedriger exprimiert als im gesunden periimplantären Gewebe. Das spricht dafür, dass eine verminderte Aktivität an Osteoblasten vorliegt und ein geringerer Knochenumbau bzw. Knochenaufbau stattfindet. Im Zusammenhang mit den genannten beschleunigenden Faktoren für den Gewebe- bzw. Knochenabbau lässt 
sich damit, neben anderen, der schnelle Knochenabbau bei der Periimlantitis erklären. Das ebenfalls von Osteoblasten sezernierte Osteoprotegerin (OPG, TNFRSF11B, tumor necrosis factor receptor superfamily, member $11 \mathrm{~b}$ ) gehört zu der Tumornekrosefaktor (TNF)-Rezeptor-Familie und ist ein Zytokin-Rezeptor. Es ist ein sog. Lockvogel-Rezeptor für RANK-Liganden (RANK-L). RANK selbst wiederum findet sich auf der Oberfläche monozytärer Osteoklasten-Vorläuferzellen und ist mit seiner Aktivierung durch RANKL für die Differenzierung dieser zu maturen Osteoklasten zuständig. Somit trägt eine erhöhte Expression von OPG zu einer Hemmung des Knochenabbaus bei. Die Ergebnisse der Microarray-Untersuchung und der qPCR zeigen keine signifikanten Werte. Jedoch zeigen beide die Tendenz zu einer geringeren Expression von OPG im entzündlichen periimplantären Gewebe. Diese Tatsache lässt eine geringere Aktivität von Osteoblasten im entzündlichen periimplantären Gewebe vermuten und lässt auf eine verringerte Hemmung des RANK-Liganden und somit auf eine erhöhte Aktivierung von Osteoklasten schließen.

\subsubsection{Diskussion der Expression von RUNX2, SOX2 und weiterer Transkriptionsfaktoren}

RUNX2 ist ein Transkriptionsfaktor und gehört zu der großen Familie der RUNXTranskriptionsfaktoren. RUNX2 ist einer der wichtigsten Faktoren für die Differenzierung und Funktion von Osteoblasten und damit auch der Osteogenese (KS Lee et al. 2000). Das regulatorische Protein ist auch unter dem Namen Core-binding factor-alpha (CBFA1) oder Osteoblast-specific factor 2 (OSF2) bekannt. Die Bindung an die DNA erfolgt über eine Runt-DNA-Bindungsdomäne, welche aus einer glutamin-alaninreichen Domäne an dessen N-Terminal besteht (Komori 2002). RUNX2 ist in Osteoblasten, hypertrophen Chondrozyten und Odonto- und Ameloblasten zu finden (Liu und EH Lee 2013). RUNX2 ist laut den Ergebnissen des Microarrays der vorliegenden Arbeit im entzündeten periimplantären Gewebe tendenziell geringer exprimiert als im gesunden periimplantären Gewebe. Die Ergebnisse der qPCR unterstützen dieses Resultat und zeigen signifikant geringere Expressionsraten von RUNX2 im entzündeten periimplantären Gewebe. Wie schon weiter oben genannt, ist zu vermuten, dass dadurch eine verringerte Aktivität von Osteoblasten und damit ein verringerter Knochenaufbau vorliegt. Lacey et al. zeigten, dass die Expression von Interleukin- $1 \beta$ und TNF- $\alpha$ die Expression von RUNX2 in Osteoblasten erniedrigt (Lacey et al. 2009). Interleukin-1 $\beta$ ist den Untersuchungen der vorliegenden Arbeit nach im entzündeten periimplantären Gewebe stark 
erhöht und könnte so mitverantwortlich für die verringerte Expression von RUNX2 sein. SOX2 ist ein Transkriptionsfaktor, der für die Aufrechterhaltung der Pluripotenz von Stammzellen wichtig ist. Er wird heute oft bei der Transformation von differenzierten Zellen zu Stammzellen in vitro verwendet. Ronay et al. publizierten im Jahr 2013 eine Arbeit, in welcher zum erstem Mal der Gehalt von SOX2 in entzündlichem parodontalem Granulationsgewebe untersucht wurde (Ronay et al. 2013). Ziel war es zu evaluieren, ob durch die Entfernung granulomatösem Gewebes dem Parodontium eventuell das Potenzial zur Regeneration genommen oder zumindest verringert wird und damit eine neue Bewertung der Behandlungsmaßnahmen nötig würde. Es zeigte sich in dieser Studie, dass SOX2 nur eine gering erhöhte Expression aufweist. Andere Stammzellmarker waren im Vergleich dazu höher exprimiert. Die vorliegende Arbeit ergab eine Tendenz zu einer verringerten Expression von SOX2 im entzündeten periimplantären Gewebe. Jedoch sind die Ergebnisse nicht signifikant. Sie lassen aber die Vermutung zu, dass das entzündete periimplantäre Gewebe ein komprimitiertes Regenerationsvermögen besitzt und damit eine Entfernung dessen zu unterstützen ist. Man kann daraus den Schluss ziehen, dass im Vergleich zur Parodontitis die Geweberegeneration bei der Periimplantitis geringer ist. Wie in der Übersicht Abb. 3.16 zu sehen ist, sind auch weitere Transkriptionsfaktoren bzw. Stammzellmarker wie SOX5, -6, -9, PPARA und TFEC in ihrer Expression erniedrigt, was darauf hindeutet, dass ein verminderter Zellumsatz und ein geringeres Regenerationspotenzial vorliegen.

\subsubsection{Diskussion der Expression von FGF8 und FGF18}

Die Familie der Fibroblasten-Wachstumsfaktoren umfasst eine Größe von 22 Mitgliedern, welche an der embryonalen Entwicklung, der Gewebshomöostase und der Antwort auf Verletzungen beteiligt sind (Ornitz und Itoh 2001). Die Ergebnisse der vorliegenden Arbeit zeigen, dass FGF8 und FGF18 eine verringerte Expression im entzündeten periimplantären Gewebe haben. FGF18 ist nach Microarray- und qPCR-Untersuchung signifikant niedriger exprimiert, FGF8 zeigt eine Tendenz zu einer niedrigeren Expression im entzündlichen Gewebe, die Werte sind jedoch nicht signifikant. Behr et al. zeigten 2011 in einem Mausmodell, dass FGF18 ein ausschlaggebender Faktor in der Knochenregeneration ist. Ein Mangel an FGF18 konnte durch ein Überangebot an FGF-Liganden und BMP2 nicht kompensiert werden. Interessanterweise konnte bei einem Mangel an FGF18 keine verminderte Angiogenese beobachtet werden (Behr et al. 2011). Ein Mangel an FGF18, wie er bei der Periimplantitis zu beobachten ist, wird ein weiterer Grund 
für den sehr raschen Knochenverlust sein und außerdem dafür, dass eine Knochenheilung ohne eine Behandlung sehr unwahrscheinlich ist. Die Tatsache, dass laut Behr et al. der Mangel an FGF18 die Angiogenese nicht einschränkt, ist eine Bestätigung für das Auffinden einiger oben genannter Marker, die für eine größere Menge an Blutgefäßen und das Vorhandensein von stark durchblutetem Granulationsgewebe sprechen.

Inwieweit FGF8 eine Rolle bei der Periimplantitis spielt, ist schwer zu sagen. Bisher gibt es keine Untersuchungen zu FGF8 in Zusammenhang mit entzündlichen Prozessen im Mund-, Kiefer- und Gesichtsbereich. Laut den Ergebnissen dieser Arbeit zeigt FGF8 eine Tendenz zu einer geringeren Expression im entzündeten periimplantären Gewebe. Eventuell besteht hier also ein Zusammenhang mit der verringerten Expression von FGF18 und der Gewebedegeneration. 


\section{KAPITEL 5}

\section{Zusammenfassung}

Mit den Ergebnissen dieser Arbeit lässt sich ein erstes Bild der Genexpression der Zellen des entzündeten periimplantären Gewebes machen. Aus den gewonnenen Erkenntnissen können wiederum Schlüsse auf die Eigenschaften der Zellen und damit auch auf die des Gewebes gezogen werden.

Neben der Frage, welche Entzündungsmediatoren eine wichtige Rolle bei der Periimplantits spielen, stellt sich die Frage, welche Eigenschaften das entzündliche periimplantäre Gewebe aufweist. Eine umfassende histologische Untersuchung von periimplantärem Gewebe ist aufgrund der metallenen Implantate und der schwierigen Beschaffung von Probenmaterial bisher nicht möglich. Die Ergebnisse dieser Arbeit ließen anhand der festgestellten Expressionsmuster wie etwa der erhöhten Exprimierung von Kollagen-3, CD24, CD9 und CD14 die Vermutung zu, dass das entzündete periimplantäre Gewebe als Granulationsgewebe charakterisiert werden kann. An den entzündlichen Vorgängen sind die Interleukine-1, -6 und -8 wesentlich beteiligt. Interleukin-10 als Hemmer entzündlicher Reaktionen ist in seiner Expression erniedrigt. Außerdem ist eine Beteiligung der MatrixMetalloproteinasen-1 und -13 sehr wahrscheinlich. Stammzell- und Transkriptionsfaktoren wie RUNX2 und SOX2 sind in ihrer Expression erniedrigt, was auf ein vermindertes Regenerationsvermögen des entzündeten periimplantären Gewebe schließen lässt. Eine Entfernung des entzündlichen Gewebes ist also anzustreben. 
Knochenprotektive Faktoren wie Osteocalcin (BGLAP) und Osteoprotegerin (TNFRSF11B) sind in ihrer Expression erniedrigt. Dadurch verringert sich unter anderem die Aktivierung von Osteoblasten, und eine Reifung von Osteoklasten wird begünstigt. Auch FGF18 aus der Gruppe der Wachstumsfaktoren ist in seiner Expression erniedrigt, was einen weiteren Faktor für den raschen Verlust an Knochengewebe darstellt und gleichzeitig der Angiogenese nicht hinderlich ist.

Zusammenfassend lässt sich sagen, dass bei der Periimplantitis die klassischen Entzündungsmarker beteiligt sind und es sich vorrangig um eine Reaktion der unspezifischen Immunabwehr handelt. Die Gewebshomöostase ist stark gestört und in Richtung der Gewebedestruktion verschoben. Es findet ein Umbau von gesundem knöchernem Implantatbett zu einem wahrscheinlich granulationsgewebe-ähnlichen Gewebe mit den dafür bekannten Eigenschaften statt. Aufbauend auf die vorliegende Arbeit könnte eine weitere Verifizierung der hier dargestellten Ergebnisse durch größere Probandengruppen folgen und Versuche gestartet werden, die verschiedene Einflussmöglichkeiten auf das Gen-Expressionsmuster des periimplantären Gewebes untersuchen. 
KAPITEL 6

Anhang 
Abbildungsverzeichnis

1.1 Aufbau eines Implantats $\ldots \ldots \ldots$

1.2 Verankerung von Zahn und Implantat . . . . . . . . . . . . 5

2.1 Varianten des Microarray . . . . . . . . . . . . . . . . . 24

2.2 Biotinylierung . . . . . . . . . . . . . . . . 25

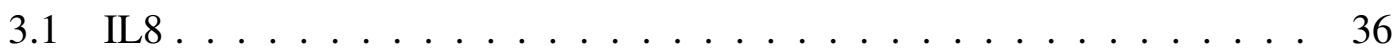

3.2 Interleukine . . . . . . . . . . . . . . 37

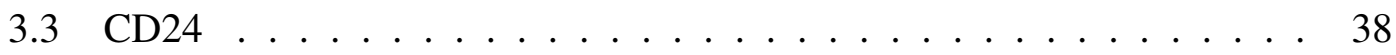

3.4 CD-Moleküle Übersicht . . . . . . . . . . . . . . . . . . . . . . . . 39

$3.5 \mathrm{MMP1} \ldots \ldots \ldots \ldots \ldots$. . . . . . . . . . . . . . 40

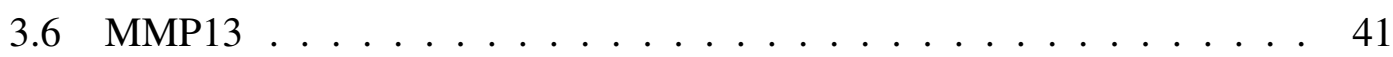

3.7 TIMP1 .......................... 42

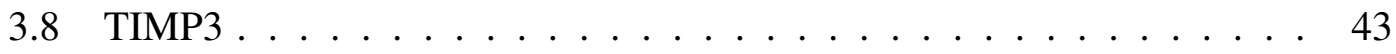

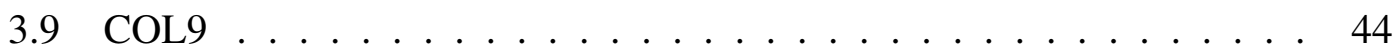

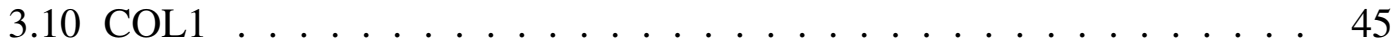

3.11 Kollagene . . . . . . . . . . . . . . . . 46

3.12 BGLAP . . . . . . . . . . . . . . . . . . 47

3.13 OPG $($ TNFRSF11B) $\ldots \ldots \ldots \ldots \ldots$

3.14 RUNX2 . . . . . . . . . . . . . . . . . . . . . 49

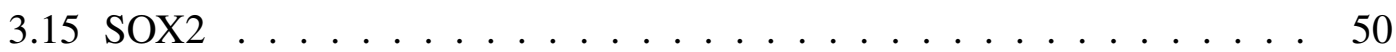


Abbildungsverzeichnis

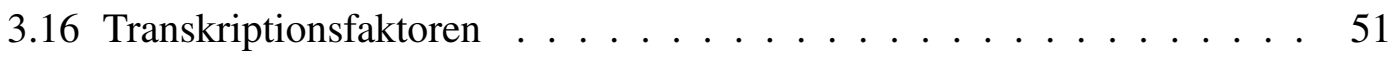

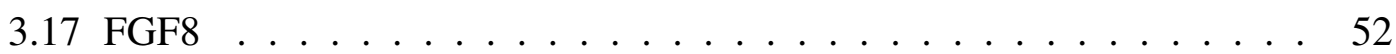

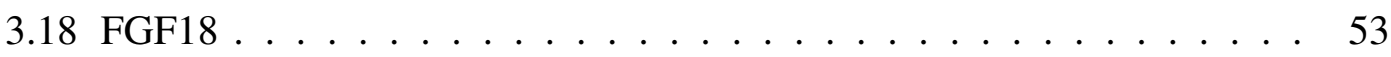




\section{Tabellenverzeichnis}

2.1 Pipettieransatz der qPCR pro Well: Master-Mix + cDNA . . . . . . . 28

2.2 Protokoll der qPCR . . . . . . . . . . . . . . . . . . . . . . . 28

2.3 Oligonukleotidprimer für die qPCR . . . . . . . . . . . . 31

2.4 Pipettieransatz der Gradienten-PCR pro Well . . . . . . . . . . . . . . . . . . . 32

2.5 Protokoll der Gradienten-PCR . . . . . . . . . . . . . . . 33 


\section{Literaturverzeichnis}

Abusleme L, Dupuy AK, Dutzan N, Silva N, Burleson JA, Strausbaugh LD, Gamonal

J, Diaz PI (2013): The subgingival microbiome in health and periodontitis and its relationship with community biomass and inflammation. ISME J $\underline{7}, 1016-1025$

Akira S, Hirano T, Taga T, Kishimoto T (1990): Biology of multifunctional cytokines:

IL 6 and related molecules (IL 1 and TNF). FASEB J 4, 2860-2867

Albandar JM (2014): Aggressive and acute periodontal diseases. Periodontol 2000 $\underline{65}, 7-12$

Albrektsson T, Dahlin C, Jemt T, Sennerby L, Turri A, Wennerberg A (2014): Is marginal bone loss around oral implants the result of a provoked foreign body reaction? Clin Implant Dent Relat Res 16, 155-165

Algraffee H, Borumandi F, Cascarini L (2012): Peri-implantitis. Br J Oral Maxillofac Surg 50, 689-94

Allman D, Ferguson S, Lentz V, Cancro M (1993): Peripheral B cell maturation. II. Heat-stable antigen (hi) splenic B cells are an immature developmental intermediate in the production of long-lived marrow-derived B cells. The Journal of Immunology 151, 4431-4444

Alvis Brazma JV (2000): Gene expression data analysis. FEBS, Functional Genomics

Anderson L, Seilhamer J (1997): A comparison of selected mRNA and protein abundances in human liver. Electrophoresis $\underline{18}, 533-7$ 
Andia DC, Oliveira d NF de, Casarin RC, Casati MZ, Line SR, Souza d AP de (2010): DNA methylation status of the IL8 gene promoter in aggressive periodontitis. J Periodontol 81, 1336-41

Andia DC, Letra A, Casarin RCV, Casati MZ, Line SRP, de Souza AP (2013): Genetic analysis of the IL8 gene polymorphism (rs4073) in generalized aggressive periodontitis. Arch Oral Biol 58, 211-217

Armas J, Culshaw S, Savarrio L (2013): Treatment of peri-implant diseases: a review of the literature and protocol proposal. Dent Update 40, 472-4, 476-8, 480

Baggiolini M, Clark-Lewis I (1992): Interleukin-8, a chemotactic and inflammatory cytokine. FEBS Lett 307, 97-101

Banda MJ, Werb Z (1981): Mouse macrophage elastase. Purification and characterization as a metalloproteinase. Biochem J 193, 589-605

Becker ST, Beck-Broichsitter BE, Graetz C, Dörfer CE, Wiltfang J, Häsler R (2014): Peri-implantitis versus periodontitis: functional differences indicated by transcriptome profiling. Clin Implant Dent Relat Res 16, 401-411

Behr B, Sorkin M, Manu A, Lehnhardt M, Longaker MT, Quarto N (2011): Fgf-18 is required for osteogenesis but not angiogenesis during long bone repair. Tissue Eng Part A 17, 2061-9

Belaaouaj A, Shipley JM, Kobayashi DK, Zimonjic DB, Popescu N, Silverman GA, Shapiro SD (1995): Human macrophage metalloelastase. Genomic organization, chromosomal location, gene linkage, and tissue-specific expression. J Biol Chem 270, 1456814575

Berglundh T, Lindhe J (1996): Dimension of the periimplant mucosa. Biological width revisited. J Clin Periodontol 23, 971-3

Berglundh T, Lindhe J, Ericsson I, Marinello CP, Liljenberg B, Thomsen P (1991): The soft tissue barrier at implants and teeth. Clin Oral Implants Res 2, 81-90

Berglundh T, Lindhe J, Jonsson K, Ericsson I (1994): The topography of the vascular systems in the periodontal and peri-implant tissues in the dog. J Clin Periodontol 21, 189-193

Berglundh T, Gislason O, Lekholm U, Sennerby L, Lindhe J (2004): Histopathological observations of human periimplantitis lesions. J Clin Periodontol 31, 341-347

Bernard A, Boumsell L (1984): The clusters of differentiation (CD) defined by the First International Workshop on Human Leucocyte Differentiation Antigens. Hum Immunol $\underline{11,1-10}$ 
Birkedal-Hansen H, Moore WG, Bodden MK, Windsor LJ, Birkedal-Hansen B, DeCarlo A, Engler JA (1993): Matrix metalloproteinases: a review. Crit Rev Oral Biol Med 4, 197-250

Brånemark PI (1983): Osseointegration and its experimental background. J Prosthet Dent 50, 399-410

Bustin SA, Benes V, Garson JA, Hellemans J, Huggett J, Kubista M, Mueller R, Nolan T, Pfaffl MW, Shipley GL, Vandesompele J, Wittwer CT (2009): The MIQE guidelines: minimum information for publication of quantitative real-time PCR experiments. Clin Chem 55, 611-622

Casado PL, Canullo L, Almeida Filardy d A de, Granjeiro JM, Barboza EP, Leite Duarte ME (2013): Interleukins 1 beta and 10 expressions in the periimplant crevicular fluid from patients with untreated periimplant disease. Implant Dent 22, 143-50

Cavaillon J (1994): [Cytokines in inflammation]. Comptes Rendus des Seances de la Societe de Biologie et de ses Filiales 189, 531-544

Celis JE, Kruhøffer M, Gromova I, Frederiksen C, Ostergaard M, Thykjaer T, Gromov P, Yu J, Pálsdóttir H, Magnusson N, Orntoft TF (2000): Gene expression profiling: monitoring transcription and translation products using DNA microarrays and proteomics. FEBS Lett 480, 2-16

Chen J, Zhu Y, Jiang Y, Yu H, Sun K, Song W, Luan L, Lou K, Li Y, Jiang P, Pang Q, Hui R (2012): A functional variant of the collagen type III alphal gene modify risk of sporadic intracranial aneurysms. Hum Genet 131, 1137-1143

Chiu IM, Heesters BA, Ghasemlou N, Von Hehn CA, Zhao F, Tran J, Wainger B, Strominger A, Muralidharan S, Horswill AR, Bubeck Wardenburg J, Hwang SW, Carroll MC, Woolf CJ (2013): Bacteria activate sensory neurons that modulate pain and inflammation. Nature 501, 52-57

Choi DH, Moon IS, Choi BK, Paik JW, Kim YS, Choi SH, Kim CK (2004): Effects of sub-antimicrobial dose doxycycline therapy on crevicular fluid MMP-8, and gingival tissue MMP-9, TIMP-1 and IL-6 levels in chronic periodontitis. J Periodontal Res 39, 20-26

Corbi SCT, Finoti LS, Anovazzi G, Tanaka MH, Kim YJ, Secolin R, Marcaccini AM, Gerlach RF, Orrico SRP, Cirelli JA, Scarel-Caminaga RM (2014): Clinical outcomes of periodontal therapy are not influenced by the ATC/TTC haplotype in the IL8 gene. J Periodontal Res 49, 489-498 
Costa C, Incio J, Soares R (2007): Angiogenesis and chronic inflammation: cause or consequence? Angiogenesis 10, 149-166

Cromie WJ (2002): Discovering who lives in your mouth: Bacteria give clues to cancer and gum disease. Harvard Gazette Archives [news.harvard.edu/gazette/2002/08.22/01oralcancer.html, Zugriff am 23.06.14]

Dallas PB, Gottardo NG, Firth MJ, Beesley AH, Hoffmann K, Terry PA, Freitas JR, Boag JM, Cummings AJ, Kees UR (2005): Gene expression levels assessed by oligonucleotide microarray analysis and quantitative real-time RT-PCR - how well do they correlate? BMC Genomics $\underline{6}, 59$

Dalle Carbonare L, Innamorati G, Valenti MT (2012): Transcription factor Runx2 and its application to bone tissue engineering. Stem Cell Rev $\underline{8}, 891-7$

De Bruijn ML, Peterson PA, Jackson MR (1996): Induction of heat-stable antigen expression by phagocytosis is involved in in vitro activation of unprimed CTL by macrophages. J Immunol 156, 2686-2692

Degidi M, Artese L, Franceschini N, Sulpizio S, Piattelli A, Piccirilli M, Perrotti V, Iezzi G (2013): Matrix metalloproteinases 2, 3, 8, 9, and 13 in the peri-implant soft tissues around titanium and zirconium oxide healing caps. Int $\mathbf{J}$ Oral Maxillofac Implants $28,1546-51$

Drosch M, Schmidt N, Markowski DN, Zollner TM, Koch M, Bullerdiek J (2014): The CD24hi smooth muscle subpopulation is the predominant fraction in uterine fibroids. Mol Hum Reprod 20, 664-676

du Preez LA, Bütow KW, Swart TJP (2007): Implant failure due to titanium hypersensitivity/ allergy?-Report of a case. SADJ 62, 22, 24-25

Duarte PM, de Mendonça AC, Máximo MBB, Santos VR, Bastos MF, Nociti Júnior FH (2009): Differential cytokine expressions affect the severity of peri-implant disease. Clin Oral Implants Res 20, 514-520

Elghetany MT, Patel J (2002): Assessment of CD24 expression on bone marrow neutrophilic granulocytes: CD24 is a marker for the myelocytic stage of development. Am J Hematol 71, 348-349

Evans JP (2010): The Human Genome Project at 10 years: a teachable moment. Genet Med 12, 477

Figarella-Branger D, Moreau H, Pellissier JF, Bianco N, Rougon G (1993): CD24, a signal-transducing molecule expressed on human B lymphocytes, is a marker for human regenerating muscle. Acta Neuropathol 86, 275-284 
Finoti LS, Corbi SC, Anovazzi G, Teixeira SR, Steffens JP, Secolin R, Kim YJ, Orrico SR, Cirelli JA, Mayer MP, Scarel-Caminaga RM (2013): Association between IL8 haplotypes and pathogen levels in chronic periodontitis. Eur J Clin Microbiol Infect Dis $\underline{32}, 1333-40$

Fodor SP, Read JL, Pirrung MC, Stryer L, Lu AT, Solas D (1991): Light-directed, spatially addressable parallel chemical synthesis. Science 251, 767-73

Gabbiani G, Le Lous M, Bailey AJ, Bazin S, Delaunay A (1976): Collagen and myofibroblasts of granulation tissue. A chemical, ultrastructural and immunologic study. Virchows Arch B Cell Pathol 21, 133-145

Gardemann A, Meyer F, Braun-Dullaeus R (2013): [What the surgeon needs to know about basic new concepts of inflammation and their therapeutic consequences: sanitation of inflammation is not a passive but rather an active process regulated by lipid mediators]. Zentralbl Chir 138, 322-330

Garlanda C, Dinarello CA, Mantovani A (2013): The interleukin-1 family: back to the future. Immunity 39, 1003-1018

Gatti C, Gatti F, Chiapasco M, Esposito M (2008): Outcome of dental implants in partially edentulous patients with and without a history of periodontitis: a 5-year interim analysis of a cohort study. Eur J Oral Implantol 1, 45-51

Gaviria L, Salcido JP, Guda T, Ong JL (2014): Current trends in dental implants. J Korean Assoc Oral Maxillofac Surg 40, 50-60

Goldbach-Mansky R (2012): Immunology in clinic review series; focus on autoinflammatory diseases: update on monogenic autoinflammatory diseases: the role of interleukin (IL)-1 and an emerging role for cytokines beyond IL-1. Clin Exp Immunol 167, 391-404

Golub LM, Lee HM, Greenwald RA, Ryan ME, Sorsa T, Salo T, Giannobile WV (1997): A matrix metalloproteinase inhibitor reduces bone-type collagen degradation fragments and specific collagenases in gingival crevicular fluid during adult periodontitis. Inflamm Res $\underline{46}, 310-319$

Gygi SP, Rochon Y, Franza BR, Aebersold R (1999): Correlation between protein and mRNA abundance in yeast. Mol Cell Biol 19, 1720-30

Haque T, Nakada S, Hamdy RC (2007a): A review of FGF18: Its expression, signaling pathways and possible functions during embryogenesis and post-natal development. Histol Histopathol 22, 97-105 
Haque T, Amako M, Nakada S, Lauzier D, Hamdy RC (2007b): An immunohistochemical analysis of the temporal and spatial expression of growth factors FGF 1, 2 and 18, IGF 1 and 2, and TGFbeta1 during distraction osteogenesis. Histol Histopathol $22,119-128$

Hardt CR, Grondahl K, Lekholm U, Wennstrom JL (2002): Outcome of implant therapy in relation to experienced loss of periodontal bone support: a retrospective 5- year study. Clin. Oral Implants Res. 13, 488-94

Harrington CA, Rosenow C, Retief J (2000): Monitoring gene expression using DNA microarrays. Curr Opin Microbiol 3, 285-91

He J, Li Y, Cao Y, Xue J, Zhou X (2015): The oral microbiome diversity and its relation to human diseases. Folia Microbiol (Praha) 60, 69-80

Heitz-Mayfield LJ (2008): Diagnosis and management of peri-implant diseases. Aust Dent J 53 Suppl 1, S43-8

Heitz-Mayfield LJ, Lang NP (2010): Comparative biology of chronic and aggressive periodontitis vs. peri-implantitis. Periodontol 2000 53, 167-81

Hough MR, Rosten PM, Sexton TL, Kay R, Humphries RK (1994): Mapping of CD24 and homologous sequences to multiple chromosomal loci. Genomics 22, 154-161

Hultin M, Gustafsson A, Hallström H, Johansson LA, Ekfeldt A, Klinge B (2002): Microbiological findings and host response in patients with peri-implantitis. Clin Oral Implants Res 13, 349-358

Hume DA (2006): The mononuclear phagocyte system. Curr Opin Immunol 18, 49-53

Janeway CA, Travers P, Walport M, Shlomchik MJ et al.: Immunobiology: the immune system in health and disease; Churchill Livingstone, London 2001

Javed F, Al-Hezaimi K, Salameh Z, Almas K, Romanos GE (2011): Proinflammatory cytokines in the crevicular fluid of patients with peri-implantitis. Cytokine 53, 8-12

Javed F, Alghamdi AST, Ahmed A, Mikami T, Ahmed HB, Tenenbaum HC (2013a): Clinical efficacy of antibiotics in the treatment of peri-implantitis. Int Dent J 63, 169176

Javed F, Hussain HA, Romanos GE (2013b): Re-stability of dental implants following treatment of peri-implantitis. Interv Med Appl Sci 5, 116-121

Jones SJ, Boyde A, Pawley JB (1975): Osteoblasts and collagen orientation. Cell Tissue Res $\underline{159}, 73-80$

Karoussis IK, Salvi GE, Heitz-Mayfield LJ, Bragger U, Hammerle CH, Lang NP (2003): Long-term implant prognosis in patients with and without a history of chronic 
periodontitis: a 10-year prospective cohort study of the ITI Dental Implant System. Clin Oral Implants Res 14, 329-39

Kay R, Rosten PM, Humphries RK (1991): CD24, a signal transducer modulating B cell activation responses, is a very short peptide with a glycosyl phosphatidylinositol membrane anchor. J Immunol 147, 1412-1416

Kent J, Block M, Finger I, Guerra L, Larsen H, Misiek D (1990): Biointegrated hydroxylapatite-coated dental implants: 5-year clinical observations. The Journal of the American Dental Association 121, 138-144

Kerschnitzki M, Wagermaier W, Roschger P, Seto J, Shahar R, Duda GN, Mundlos S, Fratzl P (2011): The organization of the osteocyte network mirrors the extracellular matrix orientation in bone. J Struct Biol 173, 303-311

Khammissa RAG, Feller L, Meyerov R, Lemmer J (2012): Peri-implant mucositis and peri-implantitis: clinical and histopathological characteristics and treatment. SADJ $\underline{67}, 122,124-122,126$

Kivelä-Rajamäki M, Maisi P, Srinivas R, Tervahartiala T, Teronen O, Husa V, Salo T, Sorsa T (2003): Levels and molecular forms of MMP-7 (matrilysin-1) and MMP8 (collagenase-2) in diseased human peri-implant sulcular fluid. J Periodontal Res 38, 583-590

Kleppe K, Ohtsuka E, Kleppe R, Molineux I, Khorana HG (1971): Studies on polynucleotides. XCVI. Repair replications of short synthetic DNA's as catalyzed by DNA polymerases. J Mol Biol 56, 341-361

Klinge B, Meyle J (2012): Peri-implant tissue destruction. The Third EAO Consensus Conference 2012. Clin Oral Implants Res 23 Suppl 6, 108-10

Komori T (2002): Runx2, a multifunctional transcription factor in skeletal development. J Cell Biochem 87, 1-8

Kozlov IG, Yemelyanov AY (1998): CD Antigens: Review of Data Obtained by April' 98. Russ J Immunol 3, 107-132

Kristiansen G, Sammar M, Altevogt P (2004): Tumour biological aspects of CD24, a mucin-like adhesion molecule. J Mol Histol 35, 255-262

Lacey DC, Simmons PJ, Graves SE, Hamilton JA (2009): Proinflammatory cytokines inhibit osteogenic differentiation from stem cells: implications for bone repair during inflammation. Osteoarthritis Cartilage 17, 735-742

Lawson DA, Xin L, Lukacs RU, Cheng D, Witte ON (2007): Isolation and functional characterization of murine prostate stem cells. Proc Natl Acad Sci U S A 104, 181-186 
Lazarus GS, Daniels JR, Lian J, Burleigh MC (1972): Role of granulocyte collagenase in collagen degradation. Am J Pathol 68, 565-578

Lee C, Roy M (2004): Analysis of alternative splicing with microarrays: successes and challenges. Genome Biol 5, 231

Lee KS, Kim HJ, Li QL, Chi XZ, Ueta C, Komori T, Wozney JM, Kim EG, Choi JY, Ryoo HM, Bae SC (2000): Runx2 is a common target of transforming growth factor beta1 and bone morphogenetic protein 2, and cooperation between Runx2 and Smad5 induces osteoblast-specific gene expression in the pluripotent mesenchymal precursor cell line C2C12. Mol Cell Biol 20, 8783-8792

Li O, Zheng P, Liu Y (2004): CD24 expression on T cells is required for optimal T cell proliferation in lymphopenic host. The Journal of experimental medicine 200, 1083 1089

Lindhe J, Meyle J (2008): Peri-implant diseases: Consensus Report of the Sixth European Workshop on Periodontology. J Clin Periodontol 35, 282-5

Liu TM, Lee EH (2013): Transcriptional regulatory cascades in Runx2-dependent bone development. Tissue Eng Part B Rev 19, 254-263

Magnaldo T, Barrandon Y (1996): CD24 (heat stable antigen, nectadrin), a novel keratinocyte differentiation marker, is preferentially expressed in areas of the hair follicle containing the colony-forming cells. J Cell Sci 109 ( Pt 13), 3035-3045

Martinez del Hoyo G, Martín P, Arias CF, Marín AR, Ardavín C (2002): CD8alpha+ dendritic cells originate from the CD8alpha- dendritic cell subset by a maturation process involving CD8alpha, DEC-205, and CD24 up-regulation. Blood 99, 999-1004

Matsugaki A, Isobe Y, Saku T, Nakano T (2015): Quantitative regulation of bonemimetic, oriented collagen/apatite matrix structure depends on the degree of osteoblast alignment on oriented collagen substrates. J Biomed Mater Res A 103, 489-499

Medzhitov R, Janeway CJr (1997): Innate immunity: the virtues of a nonclonal system of recognition. Cell 91, 295-298

Mengel R, Flores-de-Jacoby L (2005): Implants in patients treated for generalized aggressive and chronic periodontitis: a 3-year prospective longitudinal study. J Periodontol 76, 534-43

Mengel R, Behle M, Flores-de-Jacoby L (2007): Osseointegrated implants in subjects treated for generalized aggressive periodontitis: 10-year results of a prospective, longterm cohort study. J Periodontol 78, 2229-37 
Mombelli A, Decaillet F (2011): The characteristics of biofilms in peri-implant disease. J Clin Periodontol 38 Suppl 11, 203-13

Mombelli A, Muller N, Cionca N (2012): The epidemiology of peri-implantitis. Clin Oral Implants Res 23 Suppl 6, 67-76

Moore KW, Waal Malefyt d R de, Coffman RL, O'Garra A (2001): Interleukin-10 and the interleukin-10 receptor. Annu Rev Immunol 19, 683-765

Morey JS, Ryan JC, Van Dolah FM (2006): Microarray validation: factors influencing correlation between oligonucleotide microarrays and real-time PCR. Biol Proced Online $\underline{8}, 175-193$

M'Rabet L, Vos AP, Boehm G, Garssen J (2008): Breast-feeding and its role in early development of the immune system in infants: consequences for health later in life. $\mathrm{J}$ Nutr 138, 1782S-1790S

Mukaida N (2000): Interleukin-8: an expanding universe beyond neutrophil chemotaxis and activation. Int $\mathrm{J}$ Hematol $\underline{72}$, 391-398

Murata M, Tatsumi JI, Kato Y, Suda S, Nunokawa Y, Kobayashi Y, Takeda H, Araki H, Shin K, Okuda K, Miyata T, Yoshie H (2002): Osteocalcin, deoxypyridinoline and interleukin-1beta in peri-implant crevicular fluid of patients with peri-implantitis. Clin Oral Implants Res 13, 637-643

Naert I, Duyck J, Vandamme K (2012): Occlusal overload and bone/implant loss. Clin Oral Implants Res 23 Suppl 6, 95-107

Nanci A, Bosshardt DD (2006): Structure of periodontal tissues in health and disease. Periodontol 2000 40, 11-28

Nicholl DS: An introduction to genetic engineering; Cambridge University Press, New York 2008

Nomura T, Ishii A, Shimizu H, Taguchi N, Yoshie H, Kusakari H, Hara K (2000): Tissue inhibitor of metalloproteinases-1, matrix metalloproteinases-1 and -8, and collagenase activity levels in peri-implant crevicular fluid after implantation. Clin Oral Implants Res 11, 430-40

Ohshima H, Tatemichi M, Sawa T (2003): Chemical basis of inflammation-induced carcinogenesis. Arch Biochem Biophys 417, 3-11

Olmedo D, Fernández MM, Guglielmotti MB, Cabrini RL (2003): Macrophages related to dental implant failure. Implant Dent $\underline{12}, 75-80$

Olmedo D, Tasat DR, Duffó G, Guglielmotti MB, Cabrini RL (2009): The issue of corrosion in dental implants: a review. Acta Odontol Latinoam 22, 3-9 
Ornitz DM, Itoh N (2001): Fibroblast growth factors. Genome Biol 2, REVIEWS3005

Osmond DG (1985): The ontogeny and organization of the lymphoid system. J Invest Dermatol 85, 2s-9s

Persson GR, Renvert S (2014): Cluster of bacteria associated with peri-implantitis. Clin Implant Dent Relat Res 16, 783-793

Pfaffl MW (2001): A new mathematical model for relative quantification in real-time RT-PCR. Nucleic Acids Res 29, e45

Piatetsky-Shapiro G, Tamayo P (2003): Microarray data mining: facing the challenges. ACM SIGKDD Explorations Newsletter 5, 1-5

Pirruccello SJ, LeBien TW (1986): The human B cell-associated antigen CD24 is a single chain sialoglycoprotein. J Immunol 136, 3779-3784

Porter J, von Fraunhofer J (2004): Success or failure of dental implants? A literature review with treatment considerations. General dentistry 53, 423-32

Quabius ES, Ossenkop L, Harder S, Kern M (2012): Dental implants stimulate expression of Interleukin-8 and its receptor in human blood-an in vitro approach. J Biomed Mater Res B Appl Biomater 100, 1283-8

Rabinow P: Making PCR: A story of biotechnology; University of Chicago Press, Chicago 1996

Rajeevan MS, Vernon SD, Taysavang N, Unger ER (2001): Validation of array-based gene expression profiles by real-time (kinetic) RT-PCR. J Mol Diagn 3, 26-31

Raymond MH, Schutte BC, Torner JC, Burns TL, Willing MC (1999): Osteocalcin: genetic and physical mapping of the human gene BGLAP and its potential role in postmenopausal osteoporosis. Genomics $\underline{60}, 210-217$

Remick DG (2005): Interleukin-8. Crit Care Med 33, S466-S467

Renvert S, Polyzois I, Claffey N (2012): Surgical therapy for the control of periimplantitis. Clin Oral Implants Res 23 Suppl 6, 84-94

Ricklin D, Hajishengallis G, Yang K, Lambris JD (2010): Complement: a key system for immune surveillance and homeostasis. Nat Immunol 11, 785-797

Rigante D, Vitale A, Lucherini OM, Cantarini L (2014): The hereditary autoinflammatory disorders uncovered. Autoimmun Rev 13, 892-900

Ring ME (1995a): A thousand years of dental implants: a definitive history-part 1. Compend Contin Educ Dent 16, 1060, 1062, 1064 passim 
Ring ME (1995b): A thousand years of dental implants: a definitive history-part 2. Compend Contin Educ Dent 16, 1132, 1134, 1136 passim

Roediger M, Miró X, Geffers R, Irmer M, Huels A, Miosge N, Gersdorff N (2009): Profiling of Differentially Expressed Genes in Peri-implantitis and Periodontitis in vivo by Microarray Analysis. Journal of Oral Biosciences 51, 31-45

Ronay V, Belibasakis GN, Schmidlin PR, Bostanci N (2013): Infected periodontal granulation tissue contains cells expressing embryonic stem cell markers. A pilot study. Schweiz Monatsschr Zahnmed 123, 12-16

Rougon G, Alterman LA, Dennis K, Guo XJ, Kinnon C (1991): The murine heat-stable antigen: a differentiation antigen expressed in both the hematolymphoid and neural cell lineages. Eur J Immunol 21, 1397-1402

Rudy RJ, Levi PA, Bonacci FJ, Weisgold AS, Engler-Hamm D (2008): Intraosseous anchorage of dental prostheses: an early 20th century contribution. Compend Contin Educ Dent 29, 220-2, 224, 226-8 passim

Sanger F, Coulson AR (1975): A rapid method for determining sequences in DNA by primed synthesis with DNA polymerase. J Mol Biol 94, 441-448

Schall TJ, Bacon K, Toy KJ, Goeddel DV (1990): Selective attraction of monocytes and T lymphocytes of the memory phenotype by cytokine RANTES. Nature $\underline{347,669-671}$

Schlingemann RO, Rietveld FJ, Kwaspen F, van de Kerkhof PC, de Waal RM, Ruiter DJ (1991): Differential expression of markers for endothelial cells, pericytes, and basal lamina in the microvasculature of tumors and granulation tissue. Am J Pathol $\underline{138}, 1335-1347$

Schroeder HE, Listgarten MA (1997): The gingival tissues: the architecture of periodontal protection. Periodontol 2000 13, 91-120

Schupbach P, Glauser R (2007): The defense architecture of the human periimplant mucosa: a histological study. J Prosthet Dent 97, S15-25

Schwarz F, Bieling K, Bonsmann M, Latz T, Becker J (2006): Nonsurgical treatment of moderate and advanced periimplantitis lesions: a controlled clinical study. Clin Oral Investig $\underline{10,}$ 279-288

Severino VO, Napimoga MH, de Lima Pereira SA (2011): Expression of IL-6, IL-10, IL-17 and IL-8 in the peri-implant crevicular fluid of patients with peri-implantitis. Arch Oral Biol 56, 823-828 
Shackleton M, Vaillant F, Simpson KJ, Stingl J, Smyth GK, Asselin-Labat ML, Wu L, Lindeman GJ, Visvader JE (2006): Generation of a functional mammary gland from a single stem cell. Nature 439, 84-88

Shalhub S, Black JH3rd, Cecchi AC, Xu Z, Griswold BF, Safi HJ, Milewicz DM, McDonnell NB (2014): Molecular diagnosis in vascular Ehlers-Danlos syndrome predicts pattern of arterial involvement and outcomes. J Vasc Surg 60, 160-169

Shen H, Kreisel D, Goldstein DR (2013): Processes of sterile inflammation. J Immunol 191, 2857-2863

Shewan D, Calaora V, Nielsen P, Cohen J, Rougon G, Moreau H (1996): mCD24, a glycoprotein transiently expressed by neurons, is an inhibitor of neurite outgrowth. $\mathrm{J}$ Neurosci 16, 2624-2634

Sorsa T, Tjäderhane L, Salo T (2004): Matrix metalloproteinases (MMPs) in oral diseases. Oral Dis $\underline{10}, 311-318$

Sower LE, Klimpel GR, Hanna W, Froelich CJ (1996): Extracellular activities of human granzymes. I. Granzyme A induces IL6 and IL8 production in fibroblast and epithelial cell lines. Cell Immunol 171, 159-63

Springer T, Galfrè G, Secher DS, Milstein C (1978): Monoclonal xenogeneic antibodies to murine cell surface antigens: identification of novel leukocyte differentiation antigens. Eur J Immunol 8, 539-551

Staal FJT, van der Burg M, Wessels LFA, Barendregt BH, Baert MRM, van den Burg CMM, van Huffel C, Langerak AW, van der Velden VHJ, Reinders MJT, van Dongen JJM (2003): DNA microarrays for comparison of gene expression profiles between diagnosis and relapse in precursor-B acute lymphoblastic leukemia: choice of technique and purification influence the identification of potential diagnostic markers. Leukemia 17, 1324-1332

Sykaras N, Iacopino AM, Marker VA, Triplett RG, Woody RD (2000): Implant materials, designs, and surface topographies: their effect on osseointegration. A literature review. Int J Oral Maxillofac Implants 15, 675-90

Taub DD, Anver M, Oppenheim JJ, Longo DL, Murphy WJ (1996): T lymphocyte recruitment by interleukin-8 (IL-8). IL-8-induced degranulation of neutrophils releases potent chemoattractants for human $\mathrm{T}$ lymphocytes both in vitro and in vivo. J Clin Invest 97, 1931-1941

Toriseva M, Laato M, Carpén O, Ruohonen ST, Savontaus E, Inada M, Krane SM, Kähäri VM (2012): MMP-13 regulates growth of wound granulation tissue and modulates 
gene expression signatures involved in inflammation, proteolysis, and cell viability. PLoS One 7, e42596

Uchida M, Shima M, Shimoaka T, Fujieda A, Obara K, Suzuki H, Nagai Y, Ikeda T, Yamato H, Kawaguchi H (2000): Regulation of matrix metalloproteinases (MMPs) and tissue inhibitors of metalloproteinases (TIMPs) by bone resorptive factors in osteoblastic cells. J Cell Physiol 185, 207-14

Visse R, Nagase H (2003): Matrix metalloproteinases and tissue inhibitors of metalloproteinases: structure, function, and biochemistry. Circ Res 92, 827-39

Walter JB (1976): Wound healing. J Otolaryngol 5, 171-176

Warrington JA, Nair A, Mahadevappa M, Tsyganskaya M (2000): Comparison of human adult and fetal expression and identification of 535 housekeeping/maintenance genes. Physiol Genomics 2, 143-147

Weiss CM (1986): Tissue integration of dental endosseous implants: description and comparative analysis of the fibro-osseous integration and osseous integration systems. J Oral Implantol 12, 169-214

Werb Z, Gordon S (1975): Elastase secretion by stimulated macrophages. Characterization and regulation. J Exp Med 142, 361-377

Williams LA, Hock BD, Hart DN (1996): Human T lymphocytes and hematopoietic cell lines express CD24-associated carbohydrate epitopes in the absence of CD24 mRNA or protein. Blood 88, 3048-3055

Wilson V (2013): An insight into peri-implantitis: a systematic literature review. Prim Dent J 2, 69-73

Winkelhoff v AJ van (2010): [Consensus on peri-implant infections]. Ned Tijdschr Tandheelkd 117, 519-23

Xu L, Yu Z, Lee HM, Wolff MS, Golub LM, Sorsa T, Kuula H (2008): Characteristics of collagenase-2 from gingival crevicular fluid and peri-implant sulcular fluid in periodontitis and peri-implantitis patients: pilot study. Acta Odontol Scand 66, 219 224

Ye P, Simonian M, Nadkarni MA, Decarlo AA, Chapple CC, Hunter N (2005): Identification of epithelial auto-antigens associated with periodontal disease. Clin Exp Immunol 139, 328-337 
Danksagung

Ich danke an dieser Stelle Prof. Nicolai Miosge und Dr. Boris Schminke für die gute Betreuung meiner Arbeit. Ich danke Christa Bode und allen anderen Labormitarbeitern, die mich unterstützt haben. 
Lebenslauf

Ich, Simon Schmitt, wurde am 16. April 1988 in Erfurt, Thüringen als Kind von Mechthild (geb. Schmidt) und Matthias Schmitt geboren. Ich habe einen zweieinhalb Jahre älteren Bruder Jakob. Von 1994 bis 1998 besuchte ich die Puschkin-Schule (Grundschule 29) in Erfurt. Von 1998 bis 2006 besuchte ich die Edith-Stein-Schule Erfurt. Die ersten zwei Jahre davon ging ich auf den Regelschulzweig dieser Schule. Ab der siebten Klasse besuchte ich den Gymnasialzweig. Im Jahr 2006 erlangte ich meine Allgemeine Hochschulreife. Von September 2006 bis April 2007 arbeitete ich 8 Monate in Südafrika als Volunteer in drei verschiedenen nichtstaatlichen gemeinnützigen Einrichtungen. Im April 2008 begann ich mein Studium der Zahnmedizin an der Universitätsmedizin Göttingen. Am 07. Juni 2013 legte ich erfolgreich die Zahnärtzliche Prüfung an der Universitätsmedizin Göttingen ab. Von September 2013 bis September 2014 arbeitete ich mit Unterbrechungen in der Arbeitsgemeinschaft Orale Biologie und Geweberegeneration an der Universitätsmedizin Göttingen unter Leitung von Prof. N. Miosge an meiner Dissertation. Im Februar und März 2014 arbeitete ich sechs Wochen für die Organisation Dentists for Africa in Kenia als Zahnarzt. Seit Oktober 2014 arbeite ich als angestellter Zahnarzt in einer Praxis bei Dresden. 